\title{
USE OF A SEMICONDUCTOR LASER IN INFRARED SPECTROSCOPY
}

\author{
Rex Neil Morris
}

Ph. D. Thesis Submitted to Iowa State University

Ames Laboratory, DOE Iowa State University Ames, Iowa 50011

Date Transmitted: December 1977

$$
\begin{aligned}
& \text { This report was prepared as an account of work } \\
& \text { sponsored by the United States Government. Neither the } \\
& \text { United States nor the United States Department of } \\
& \text { Energy, nor any of their emplnyees, nor any of their } \\
& \text { contractors, subcontractors, or their employees, makes } \\
& \text { any warranty, express or implied, or assumes any legal } \\
& \text { liability or responsibility for the accuracy, completeness } \\
& \text { or usefulness of any infnrmation, apparatus, ppoduct it } \\
& \text { process disclosed, or represents that its use would not } \\
& \text { infringe privately owned rights. }
\end{aligned}
$$

PREPARED FOR THE U.S. DEPARTMENT OF ENERGY

UNDER CONTRACT NO. W-7405-eng-82 


\section{DISCLAIMER}

This report was prepared as an account of work sponsored by an agency of the United States Government. Neither the United States Government nor any agency Thereof, nor any of their employees, makes any warranty, express or implied, or assumes any legal liability or responsibility for the accuracy, completeness, or usefulness of any information, apparatus, product, or process disclosed, or represents that its use would not infringe privately owned rights. Reference herein to any specific commercial product, process, or service by trade name, trademark, manufacturer, or otherwise does not necessarily constitute or imply its endorsement, recommendation, or favoring by the United States Government or any agency thereof. The views and opinions of authors expressed herein do not necessarily state or reflect those of the United States Government or any agency thereof. 


\section{DISCLAIMER}

Portions of this document may be illegible in electronic image products. Images are produced from the best available original document. 




\section{WERE INTENTIONALLY \\ LEFT BLANK}




\section{Use of a semiconductor laser in infrared spectroscopy}

by

Rex Neil Morris

A Dissertation Submitted to the

Graduate Faculty in Partial Fulfirlment of

The Requirements for the Degree of

DOCTOR OF PHILOSOPHY

Department: Chemistry

Major: Analytical Chemistry

Approved:

$\frac{\text { S.S. Newng }}{\text { In charge of Major Wojk }}$

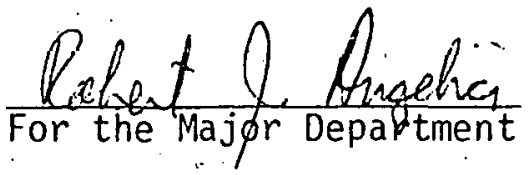

ror the Graduatc College

Iowa State University

Ames, Iowa

1977 
TABLE OF CONTENTS

I. INTRODUCTION 1

A. Environmental Effects 1

B. Environmental Measurements 2

II. REVIEW $\quad \cdot 8$

A. Semiconductor Laser Characteristics 8

B. Semiconductor Laser Outpul Reyiuns and Gas Absorption Bands

C. Spectroscopy with Semiconductor Lasers 23

III. EXPERIMENTAL

A. Growing Semiconductor Crystals for Possible Use as Laser Crystals

1. Glassware preparation 32

2. Making the starting samples of $\mathrm{PbTe}$ or $\mathrm{Pb}_{1-x} \mathrm{Sn}_{x} \mathrm{Te} \quad 32$

3. Vapor transport $\quad 33$

4. Solid state recrystallization 36

5. Annealing studies $\quad 37$

B. Spectroscopic Setups and Transfer System 37

1. Spectroscopic setup with the magnetic field $\begin{array}{ll}\text { cryostat } & 37\end{array}$

2. Spectroscopic setup with the Andonian cryostat 40

3. Spectroscopic setup with the low temperature gas 43 cell

4. Vacuun and gas transfer system 46

C. Components of the Laser System 49

1. Semiconductor laser package 49

2. Magnetic field cryostat 52

3. Andonian cryostat 58

4. Detector system 61

5. Laser power supply 65

6. A/D conversion and paper tape punch circuit 69 
IV. RESULTS $\cdot 74$

A. Attempts at Making Semiconductor Lasers 74

B. Preliminary Investigation of Semiconductor Laser Characteristics

C. Investigation of Gases Suitable for Spectroscopic Analysis Using the Semiconductor Laser $\quad 77$

D. Digitization and Computer Analys is of Experimental Data 88

E. $\mathrm{N}_{2} \mathrm{O}$ Analysis 92

F. $\mathrm{SO}_{2}$ Analysis 104

$\begin{array}{lll}\text { V. SUMMARY } & 128\end{array}$

VI. COMMENTS 130

$\begin{array}{lll}\text { VII. BIBLIOGRAPHY } & 134\end{array}$

$\begin{array}{ll}\text { VIII. ACKNOWLEDGMENTS } & 137\end{array}$

IX. APPENDIX A: PROGRAM FOR READING NUMBERS OFF PAPER TAPE 138

X. APPENDIX B: THE ANALYTICAL PARAMETER DETERMINING PROGRAM .141

XI. APPENDIX C: OPERATIONAL PROCEDURES FOR EXPERIMENTAL APPARATUS 


\section{ABSTRACT}

A semiconductor laser has certain properties which makes its use desirable as a continuous monitor of atmospheric pollutants. Its energy output is concentrated in widely separated energy modes of very narrow bandwidths (less than $10^{-5} \mathrm{~cm}^{-1}$ ) which can be centered on one infrared absorption 1 ine of one gas. This makes the jaser quite selective. The energy in each mode is typically greater than $200 \mu$ watts, and, because of the laser's small size, its light energy can be collimated over large distances with minimal ontical losses and bc casily detected.

One can rapidly measure the decrease in transmission of the light due to the absorption of the light by the gas being monitored, and, using certain analytical parameters, which are different for each absorption line, one can determine the concentration of the gas in question immediately.

In addition to the 1 ine center $\left(v_{0}\right)$; these analytical parameters are the intensity $(S)$ and the half width at half maximum $(\gamma)$. The intensity $(S)$ is dependent only on temperature when expressed in a per concentration basis and $\gamma$ is dependent on pressure. The Lorentzian lineshape equation $K(\nu)=S / \pi \gamma\left[\left\{\left(\nu-\nu_{0}\right) / \gamma\right\}^{2}+1\right]^{-1}$ is the equation which describes the absorption profile of a gas at ambient atmospheric pressure. Having determined $K(v)$ and knowing atmospheric pressure and path length of the laser light, one can obtain the concentration of the gas in question. 
This thesis examines the ease with which a semiconductor. laser can be incorporated and used in an experimental setup. Reproducibility and maintenance problems are examined and the continuous monitoring capabilities of a semiconductor laser are discussed.

Infrared absorption lines of $\mathrm{N}_{2} \mathrm{O}, \mathrm{SO}_{2}$, and $\mathrm{H}_{2} \mathrm{~S}$ are observed from low pressure $(\simeq 0.1$ torr $)$ to a total pressure of one atmosphere when mixed with room air. The analytical parameters $S$ and $\gamma$ are determined for some lines of $\mathrm{N}_{2} \mathrm{O}$, and $\nu_{0}, \mathrm{~S}$, and $\gamma$ are determined for several absorption lines of $\mathrm{SO}_{2}$. Also values of $\nu_{0}$ are obtained for several $\mathrm{H}_{2} \mathrm{~S}$ absorption lines. These parameters should lead to more reliable measurements in atmospheric pollution monitoring. 


\section{INTRODUCTION}

\section{A. Environmental Effects}

The effects of pollution on the environment are tremendous, and many texts have been written which discuss the chemistry of pollution and these detrimental effects $(1,2,3)$. In the field of atmospheric pollution, vegetation which is downwind of pollution sources shows definite deterioration. More recently the effects of specific pollutants, such as $0_{3}$, on crops are being carefully studied $(4,5)$.

In addition to vegetation, atmospheric pollution has a definite effect upon humans. Eye irritation and respiratory distress are obvious and certain pollutants are believed to be contributors to many diseases such as cancer. Many hydrocarbons which are originally placed in the atmosphere, although they themselves may not be harmful, undergo complex chemical reactions with air and other pollutants to produce compounds which are harmfut (1).

Many compounds emitted into the air undergo oxidation to form highly corrosive chemicals. For example, $\mathrm{SO}_{2}$ is oxidized to $\mathrm{SO}_{3}$ and then combines with moisture in the air to form $\mathrm{H}_{2} \mathrm{SO}_{4}$ mist.

Another problem of air pollution is its possible long range effects upon the climate. Enough evidence has been accumulated concerning the propellents of chlorofluoromethanes and their effect on the depletion of the ozone layer, which protects humans from too much ultra-violet light, that they are being removed from the market $(6,7)$. There is concern about the increasing concentration of $\mathrm{CO}_{2}$ in the air and its "greenhouse effect" 
(8). This is an increase in the average temperature due to the $\mathrm{CO}_{2}$ reabsorbing radiation from the earth which would normally go back into space.

All of these problems need to be carefully studied, and this requires the best possible, accurate information concerning ambient concentrations of all air pollutants.

\section{B. Environmental Measurements}

Many texts have been written which explain the methods most commonly used in determining the concentration of air pollutants $(9,10)$. Most of these methods involve adsorption techniques and subsequent colorimetric analyses and/or titrations, with a different type of analys is for each pol lutant.

For example, $\mathrm{SO}_{2}$ is most often analyzed by the West-Graeke method. Air is pumped through a filter to remove solid particles and bubbled through a solution of sodium tetrachloromercurate II. An airflow rate of about 1 iter $/ \mathrm{min}^{\circ}$ is used for a period of 30 minutes. The chemical reaction is

$$
\mathrm{SO}_{2}+\left[\mathrm{HgCl}_{4}\right]^{-}+\mathrm{H}_{2} \mathrm{O} \rightarrow\left[\mathrm{HgCl}_{2} \mathrm{SO}_{4}\right]^{-}+2 \mathrm{H}^{+}+2 \mathrm{Cl}^{-}
$$

The dichlorosulfitomercurate II complex solution is allowed to set for 20 minutes to allow for decomposition of any ozone present. Afterwards, solutions of pararosaniline and formaldehyde are added to the complex, and the solution left for 30 minutes as the colored pararosaniline methylsulfonic acid is produced. The absorbance of the solution is measured at $560 \mathrm{~nm}$. 
Gas chromatography has been used for monitoring hydrocarbons in the atmosphere. Ambient concentrations of a few $\mu \mathrm{g} / \mathrm{m}^{3}$ are typical for many hydrocarbons, but gas chromatographs cannot usually handle such small concentrations. Therefore, air is pumped through a column filled with adsorptive material cooled to $-30^{\circ} \mathrm{C}$ for 5 to 60 minutes. This concentrates the hydrocarbons, and then the column is backflushed with carrier gas into a gas chromatograph and heated at the same time. Ethylene, propylene, benzene, and toluene have been determined by such a method with a detection limit of $.005 \mathrm{mg} / \mathrm{m}^{3}$ for each component (11). Because these methods take 5 to 30 minutes and can only be used to analyze a small atmospheric volume, these methods are more useful in monitoring equilibrium conditions than dynamic changes. Semiconductor devices, which adsorb specific pollutants and have their electrical properties altered directly with concentration of the pollutant, have been developed. 'They are faster but also sample only a small volume and are not very selective (12).

Almost all atmospheric pollutants have absorption bands of many vibrational-rotational lines in the infrared region, and thus infrared spectroscopy is also used to measure air pollutants. Carbon monoxide is continuously monitored in the atmosphere by infrared spectrometry (10). Light from an infrared light source is split into two parallel beams with only one passing through the sample compartment. Each beam then passes into the detector, which consists of two matched cells filled with $\mathrm{CO}$ and separated by a diaphragm. The two cells absorb the radiation equally and the diaphragm is in its equilibrium position. When $\mathrm{CO}$ is pumped into the sample compartment, less energy strikes only one of the detector cells, 
reducing temperature and pressure in that cell. This results in a deflection of the diaphragm which is measured electronically. The detection limit for commercial instruments operating by this method is about .6 $\mathrm{mg} / \mathrm{m}^{3}$ or $.3 \mathrm{ppm}$. Any gas in the atmosphere which has absorption lines overlapping CO absorption lines will interfere.

0ther similar infrared spectroscopic devices have seen some use (13). Cross correlation spectrometers have been used in infrared spectroscopic studies of atmospheric pollutants $(13,14,15)$. Broad band light such as sunlight, after passing through the atmosphere, is detected after alternately passing through two gas cells containing the gas whose detection is desired at two different pressures. Because the light has passed through the atmosphere, better average atmospheric concentrations are determined. Other gases interfere as with the c0 detector mentioned above and solar noise is sometimes too great to obtain useful information. Infrared spectrometers with moderate resolution have been used for continuous monitoring of air pollutants near industrial stacks. These results are satisfactory as long as the concentration of the pollutant is large enough such that interfering gas absorption bands are insignificant. The ideal infrared spectroscopic system would use a light source with single frequency output tunable over a wide region and capable of being detected after shining through a large distance $(>50 \mathrm{~m})$. By tuning the source completely over an absorption line and determining the area under the absorption line, one obtains a very good value for the concentration of the gas. Taking the measurement over a large distance insures that a representative value for the average concentration of the gas is obtained. 
However, conventional infrared spectrometers are not adequate for this purpose. The bandpass of high resolution spectrometers in the infrared is approximately 0.1 to $0.3 \mathrm{~cm}^{-1}$ and gases are pressure broadened at one atmosphere to a full width at half maximum of $.15 \mathrm{~cm}^{-1}$ on the average. Some high resolution spectrometers have better resolutions than $0.1 \mathrm{~cm}^{-1}$ but all these instruments can only provide this kind of resolution under ideal laboratory conditions. The limits of resolution in these instruments are due to the use of incandescent light sources. These light sources have a very broad band of light output extending from the visible or ultraviolet regions through the far infrared region. As the entrance and exit slits are narrowed to reduce the band of light passing through the spectrometer, the intensity of light is reduced. A point is reached when the intensity is so small that it can io longer be detected. Extending the path length to $50 \mathrm{~m}$ would reduce the amount of light available for detection due to optical losses. $\mathrm{H}_{2} \mathrm{O}$ and $\mathrm{CO}_{2}$ have large concentrations in the atmosphere relative to atmospheric pollutants under most conditions, and $\mathrm{H}_{2} \mathrm{O}$ and $\mathrm{CO}_{2}$ have intense absorption bands in the infrared region. These bands are so broad that most long path measurments of pollutants must be in the infrared region beyond $8 \mu$. However, the output of incandescent sources becomes weaker in intensity at longer wavelengths. The net result is that the bandwidth of the source can be a few $\mathrm{cm}^{-1}$ while an absorption line's width is about $0.1 \mathrm{~cm}^{-1}$. Thus, one is possibly looking at several absorption lines and possibly lines of more than one gas. This causes inaccurate analytical results to be obtained. 
Recentiy infrared lasers and, in particular, infrared semiconductor lasers have been developed which can be used:to eliminate the previously described problems of spectrometers. Such lasers have at least moderately high light intensity with bandwidths of $10^{-5} \mathrm{~cm}^{-1}$ and less. The semiconductor lasers also have moderate tuning regions $\left(20 \mathrm{~cm}^{-1}\right)$ based on physical adjustment of parameters such as temperature, current, magnetic field, and pressure, and gross adjustment of tuning region based on actual composition.

A semiconductor laser has been used successfully in monitoring atmospheric carbon monoxide in a long path system (16). A Pb $\mathrm{S}_{0.82} \mathrm{Se}_{0.18}$ semiconductor diode was tuned into coincidence with an absorption line of $\mathrm{CO}$ in its fundamental band around $4.7 \mu \mathrm{m}$. The path length was $0.61 \mathrm{~km}$ and the detection limit was 5 parts per billior. Continuous monitoring was performed and increases in the ambient $\mathrm{CO}$ level due to commuter traffic were observed. But, semiconductor lasers are not easy to manufacture and are expensive. Hundreds would be required to cover the entire infrared region. To reduce the number required, one could judiciously choose those locations which have the greatest number of absorption lines for different gases which are suitable for analysis and do not overlap. A computer program has been written that, when given the parameters of absorption coefficients, line centers, half widths, and concentrations of the gases desired, generates a theoretical spectrum and analyzes that spectrum for gases of interest (17). It chooses those locations with the strongest absorption lines for a specific gas with the least background for the other gases. Although many gases are well-characterized, such as $\mathrm{CO}_{2}$, 
$\mathrm{CH}_{4}, \mathrm{NH}_{3}, \mathrm{H}_{2} \mathrm{O}$, etc., there is some question as to the reliability of their absorption coefficients, and many gases still do not have accurate values for their experimental parameters (18). Without such information, long path absorption cannot be used to monitor these gases.

This thesis examines the use of a semiconductor laser to obtain improved values for the linecenters of $\mathrm{H}_{2} \mathrm{~S}$ and $\mathrm{SO}_{2}$ gas absorption 1 ines. Also, pressure broadening studies on $\mathrm{N}_{2} \mathrm{O}$ by air and by $\mathrm{SF}_{6}$ and pressure broadening studies on $\mathrm{SO}_{2}$ by air are conducted. These values are necessary prerequisites to using a semiconductor laser to do atmospheric pollution analysis. 
II. REVIEW

\section{A. Semiconductor Laser Characteristics}

Most basic texts on laser operation have a chapter devoted to semiconductor lasers and there are many review articles that explain the operation and characteristics of semiconductor lasers $(19,20,21)$. Most of the original studies were done using a GaAs laser, but there are now many different semiconductor materials which have been made to undergo laser action. The methods of exciting semiconductor lasers to produce laser action are (1) electrical injection of carriers in $p-n$ junctions; (2) electrical injection of carriers in the vicinity of metal-semiconductor contacts; (3) optical pumping using another laser source; and (4) electron beam pumping. For the lasers which output in the infrared region of interest for atmospheric pollution monitoring, the highest performance is obtained using injection of carriers in $p-n$ junctions. Therefore, the following brief description will be concerned with the properties of the p-n junction lasers.

A p- $n$ junction is formed by diffusing an impurity into a semiconductor crystal to produce first either excess holes (p-type material) or excess electrons ( $n$-type material) and then diffusing a second impurity which produces material of the opposite type, such that the material has a junction between the two types. The energy level diagram of a $p-n$ junction is shown in Figure 1. Under the condition when there is no current flow, the crystal is at equilibrium and the electron energy levels in both the $n$ portion and the $p$ portion of the semiconductor are equal (Figure 1a). When the $p-n$ junction is under forward applied bias, i.e., the 
Figure 1a. $p-n$ junction at zero-applied bias.

Figure 1b. P-n junction at forward applied bias. 


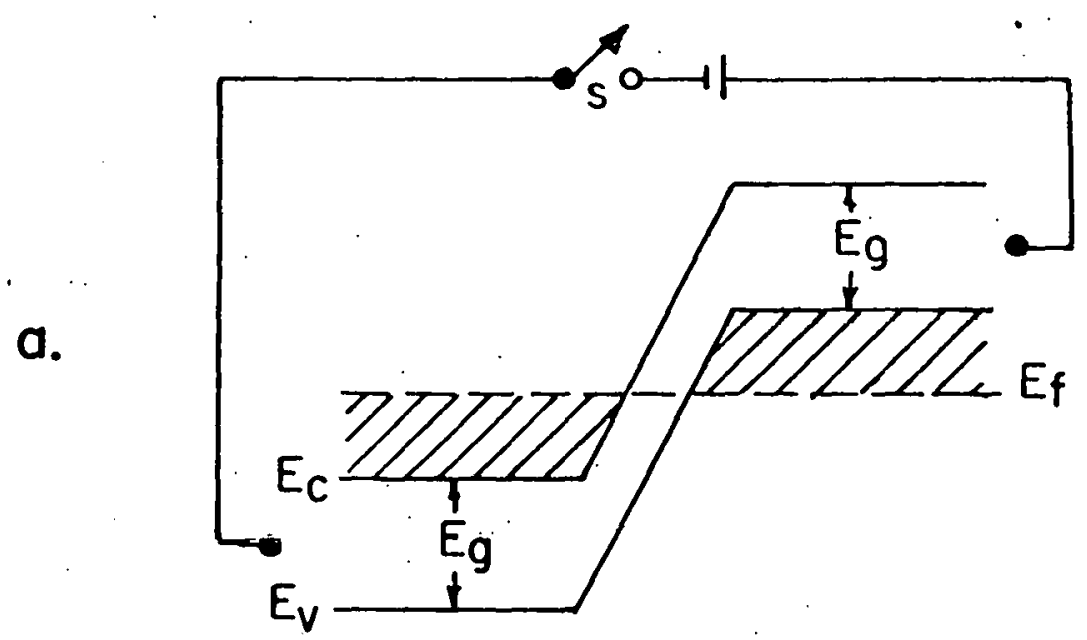

$\begin{gathered}\text { Degenerate } \\ N \text {-type }\end{gathered} \mid \begin{gathered}\text { Depletion } \\ \text { Region }\end{gathered} \quad \begin{gathered}\text { Degenerate } \\ \text { P-type }\end{gathered}$

b.

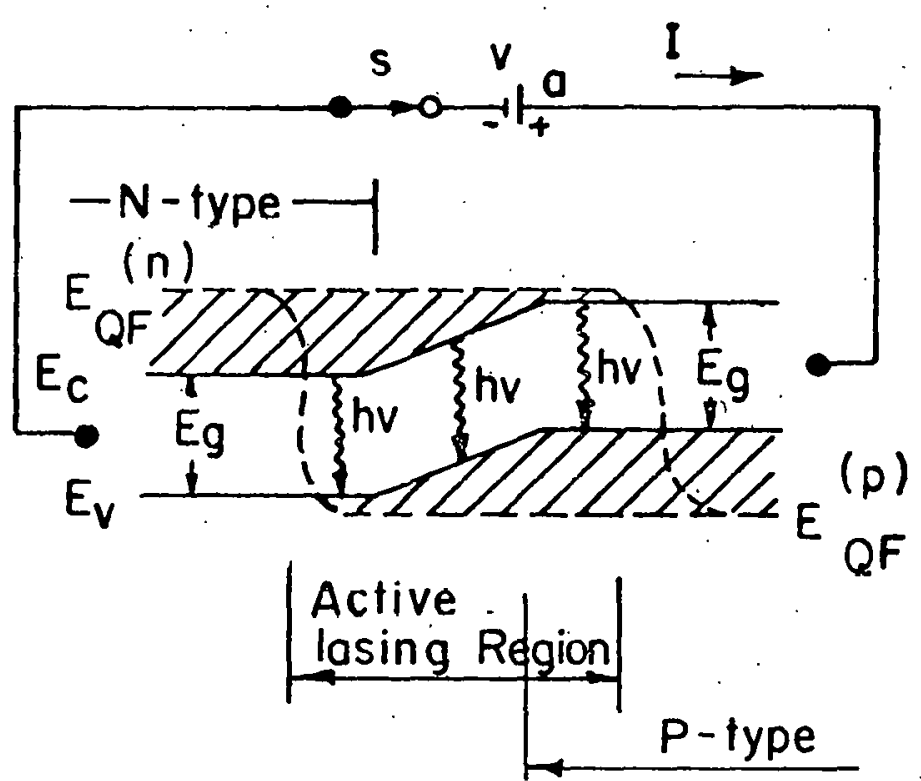


negative side of the current supply is attached to the $n$-type portion of the crystal and the positive side of the current supply to the p-type portion of the crystal, the crystal is in a nonequilibrium condition. The energy difference between the electrons in the n-type material and the holes in the p-type material is approximately the bandgap energy for that semiconductor (Figure lb): Current is carried by the electrons in the $n$ material and by the holes in the p material, and at the junction the electrons and holes combine. This combination may produce a photon of energy equal to the energy difference of the electron and hole that recombined. The structure of the semiconductor crystal: is similar to that shown in Figure $2 a$ with the $p-n$ junction located where the dotted line is located. The two faces at each end of the long portion of the crystal are parallel and polished while the other two faces are unpolished. Because of the large difference in the index of refraction between the crystal and air, the reflectivity of light generated in the crystal is quite high when the light arrives at the surface of the crystal. Thus, the two polished faces form an optical cavity where much of the light is continuously reflected back and forth, stimulating the emission of more photons. When the current flow is adequate to maintain the population inversion of electrons, lasing occurs.

Another effect occurring is the destructive interference of wavelengths of light which are not half-integral multiples of the length of the cavity and the constructive interference of those wavelengths which are half-integral multiples of the cavity length according to the equation for Figure $2 b . \lambda$ is the wavelength of light, $n$ is the index of refraction 
Figure 2a. Crystal shape with location of $p-n$ junction.

Figure 2b. Laser crystal as a Fabry-Perot cavity.

Figure 2c. Relative widths and positions of spontaneous and stimulated emission. 

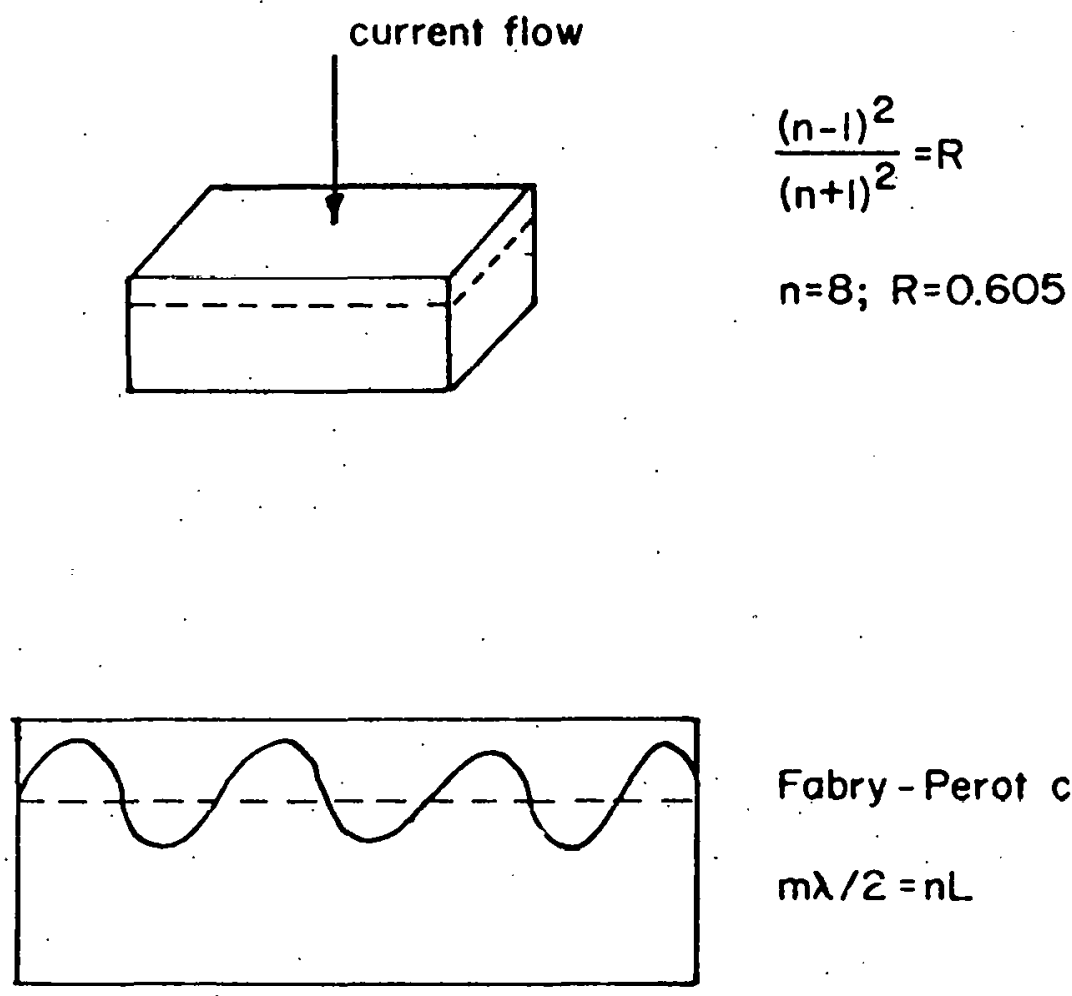

Fabry-Perot cavity

$m \lambda / \hat{c}=n L$

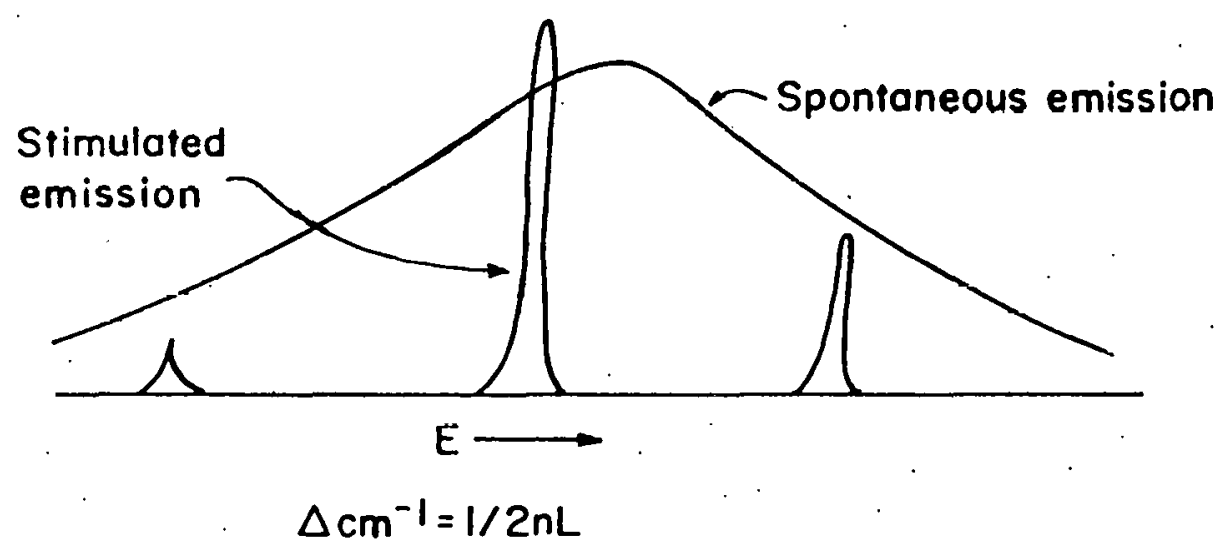


for the semiconductor, $L$ is the cavity's physical length and $m$ is an integer. The net effect is that, al though the spontaneous output (the light output before lasing) may be quite broad in bandwidth, at the onset of lasing the bandwidth of the light becomes quite narrow. Because it is possible that two or more wavelengths which satisfy the equation for Figure $2 \mathrm{~b}$ lie within the band for spontaneous emission, lasing may occur at all those wavelengths. This possibility increases as the current increases, expanding the bandwidth of the spontaneous output.

Temperature has an effect upon the amount of current required to initiate lasing (Figure 3 ). This effect is due to the tendency of the junction to reach equilibrium more rapidly as the temperature increases, requiring greater current densities to maintain the necessary population inversion for lasing. Energy released by electron-hole recombination will appear either as photons or as heat. Therefore, a temperature may be reached where the heat generated is greater than can be dissipated. This raises the temperature still higher causing more heat generation and lasing ceases. Although some of the semiconductor lasers with light output in the very near infrared are efficient enough to lase continuously at. room temperature, most semiconductor lasers require cooling to near liquid nitrogen or near liquid helium temperatures before continuous laser action is possible.

Current, temperature, pressure, and magnetic field variations are the methods which are used to tune the semiconductor laser. Figure 4 shows representative graphs of how the rate of change of wavelength proceeds with change in current, temperature, and magnetic field. Current tuning 
Figure 3. Temperature dependence of the threshold current for two striped Tasers (20). 


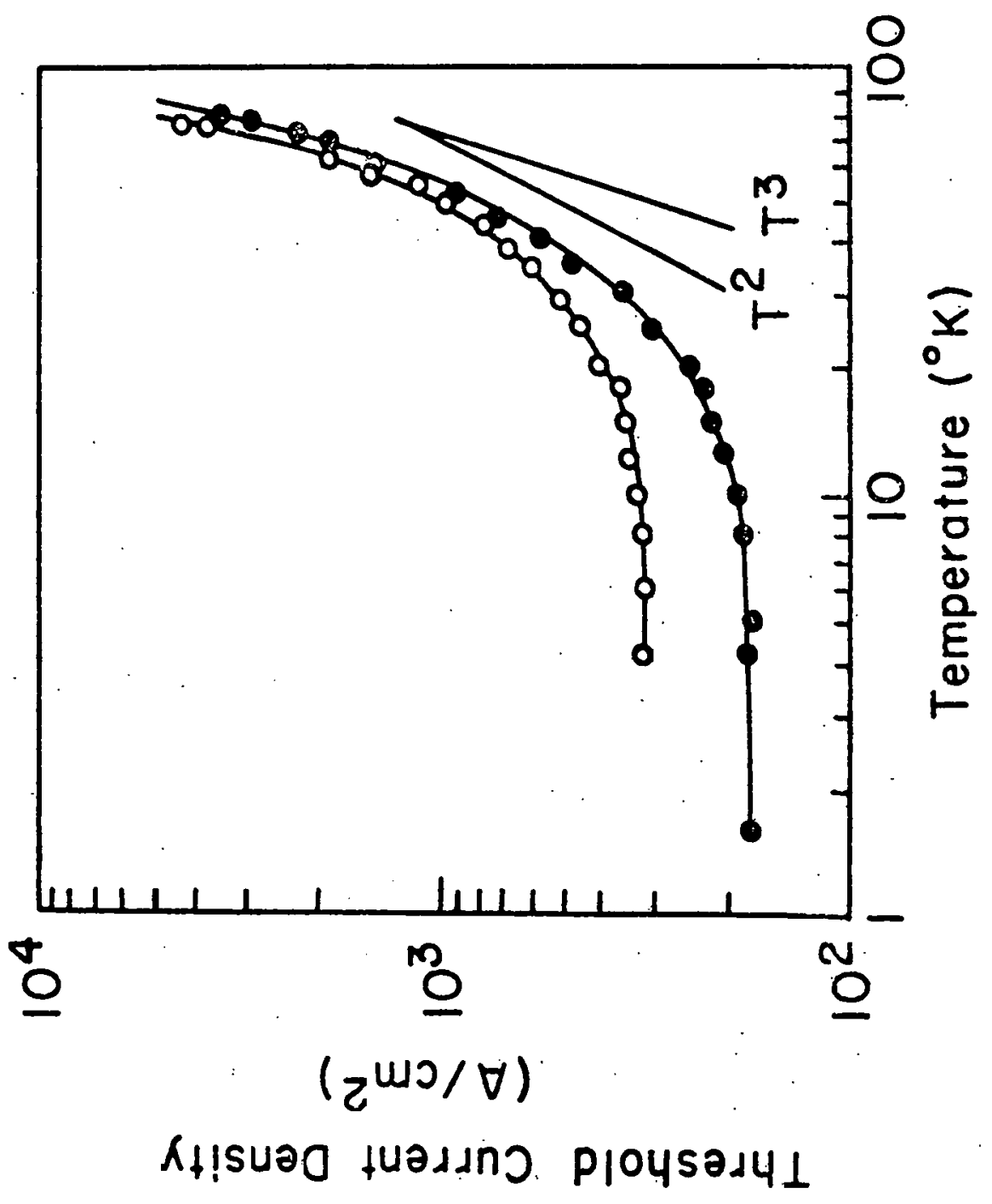


Figure 4. Various tuning methods (20). 


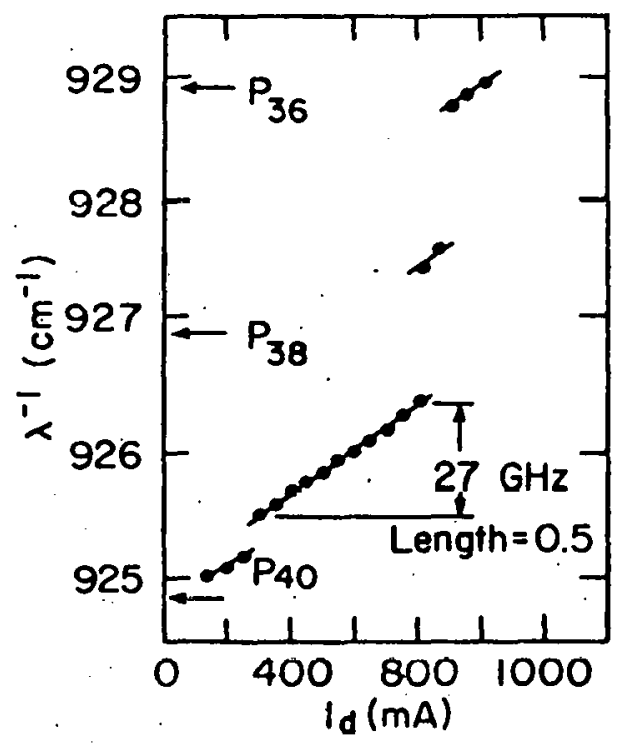

o.

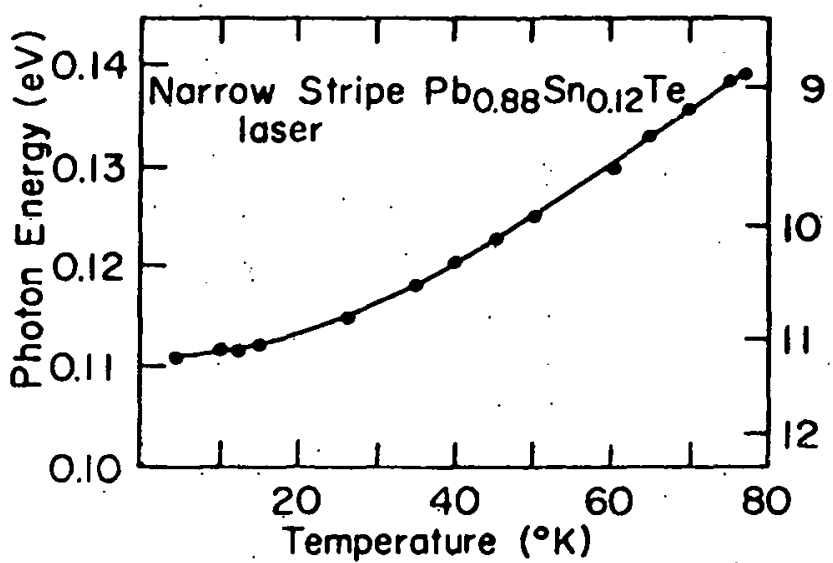

b.

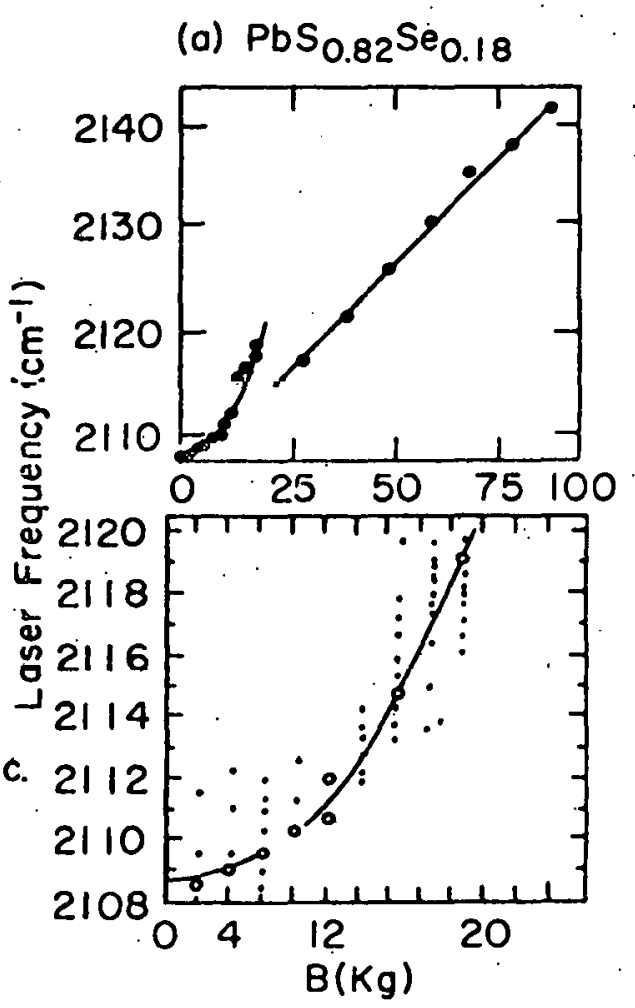


is the most commonly used form of tuning. Current tuning occurs because, as the current increases, the temperature at the junction also increases slightly. This increase in temperature affects both the bandgap energy and the index of refraction. Assuming a laser's stimulated and spontaneous outputs are as shown in Figure $5 a$, the increase in junction temperature causes the bandgap energy and thus the spontaneous output to increase in frequency. At the same time, this causes the index of refraction and thus the wavelength to decrease with a corresponding increase in frequency of stimulated emission. But the rate at which both increase is not the same (Figure $5 b$ ). The spontaneous emission may move so far ahead of the stimulated emission that the stimulated emission can no longer occur at the mode where it was occurring and must shift to a mode which is with in the spontaneous band (Figure 5c). The difference in energy between the modes corresponds to the equation in Figure $2 c$. This results in laser output similar to that described in Figure 6 . Continuous tuning of the laser output occurs as the diode current is tuned and then a discontinuous jump takes place. This is followed by another region of continuous tuning and another discontinuous jump, etc. Although the same effect can be obtained by temperature tuning, it is difficult to tune the temperature in the narrow region required and with the uniformity required to obtain uniform and reproducible wavelength tuning. Magnetic field tuning is similar in that it affects both the bandgap energy and the index of refraction of the semiconductor. However, the ratio of the rate of change of the bandgap energy to the rate of decrease of the index of refraction is much greater for magnetic field tuning than for current 
Figure 5a. Positions of spontaneous and stimulated outputs before current is increased.

Figure 5b. Shifting positions of spontaneous and stimulated outputs as current is increased.

Figure 5c. Stimulated output shift to a new mode. 
20

TUNING

$I=$ Light Intensity

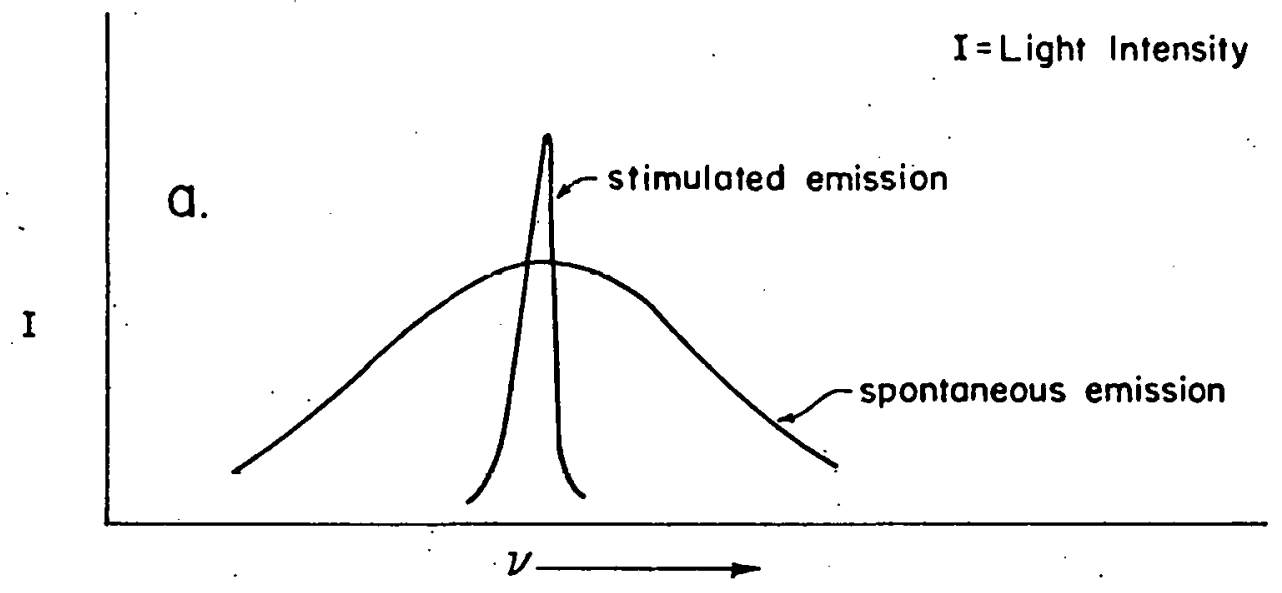

b.

I

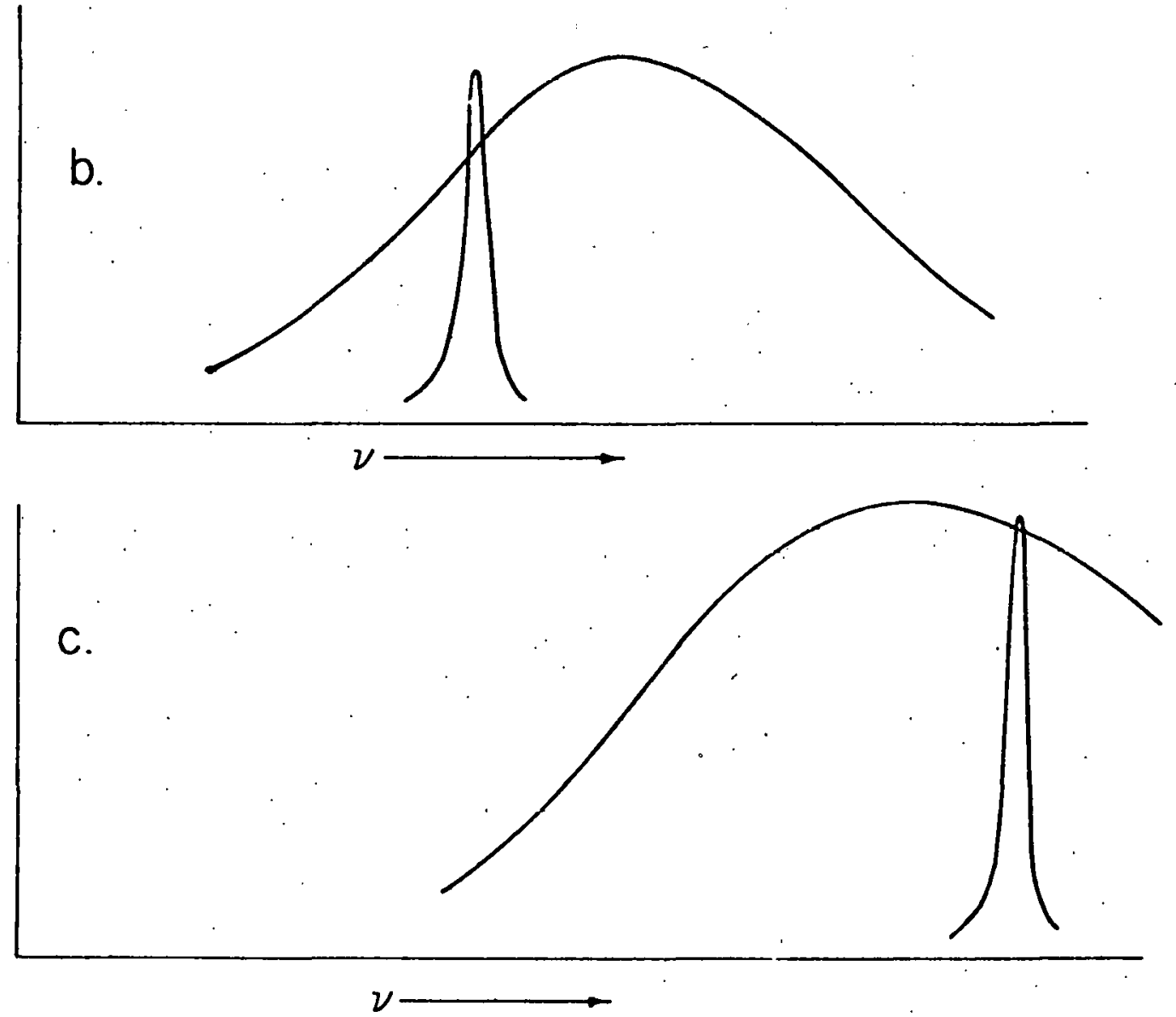


Figure 6. Example of current tuning versus output of a semiconductor laser (21). 


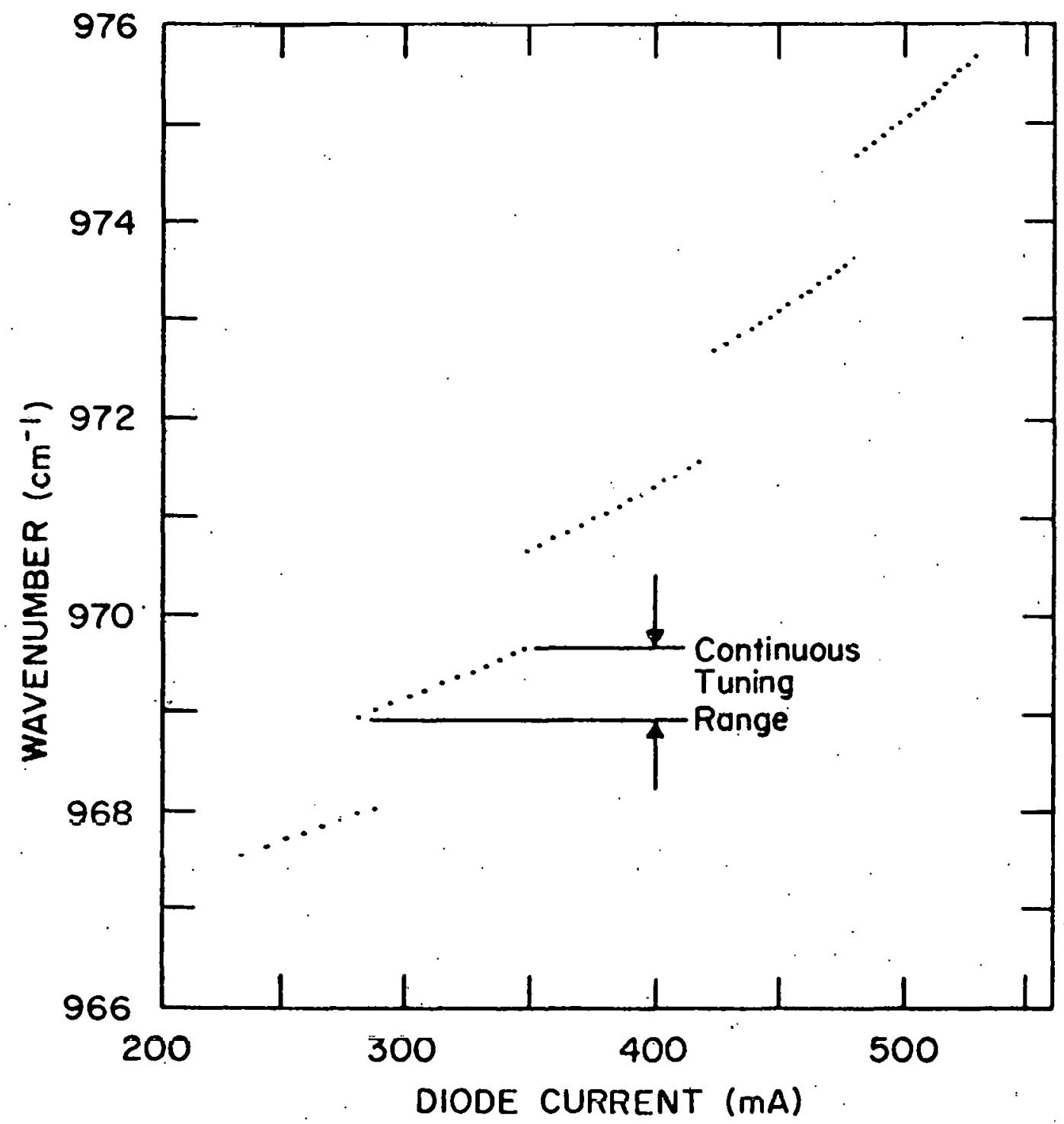


tuning. Therefore, magnetic field tuning is better suited for gross tuning to the region of interest followed by fine tuning with current.

\section{B. Semiconductor Laser Output Regions and Gas Absorption Bands}

Figure 7 indicates the band centers of some of the atmospheric molecules and pollutants of possible interest, together with some of the semiconductor materials which have shown lasing action and the regions where their output is likely to occur. Because of the large normal concentrations of $\mathrm{H}_{2} \mathrm{O}$ and $\mathrm{CO}_{2}$ at the locations shown, long distance air pollution monitoring is normally done in the infrared region beyond $8 \mu . \mathrm{Pb}_{1-x} \mathrm{Sn}_{x}$ $\mathrm{Te}, \mathrm{Pb}_{1-x} \mathrm{Sn} \mathrm{Se}_{\mathrm{x}}$, and some $\mathrm{Pb}_{1-x} \mathrm{~S}_{1-x} \mathrm{Se}_{x}$ lasers give output in the appropriate region for doing this type of long-distance monitoring. However, these lasers have to be cooled to near liquid He temperatures for continuous-wave output or liquid $\mathrm{N}_{2}$ temperatures for pulsed output, at this stage of their development. The unreliability of pulsing current to give reproducible outputs necessitates the use of continuous output for high resolution spectroscopy.

\section{Spectroscopy with Semiconductor Lasers}

Semiconductor lasers have been used for high resolution spectroscopy. Hinkley observed the absorption spectra for $\mathrm{SF}_{6}, \mathrm{NH}_{3}$, and ethylene using a $\mathrm{Pb}_{0.88} \mathrm{Sn}_{0.12} \mathrm{Te}$ semiconductor 1 aser $(22,23)$. By doing a heterodyne experiment involving a carbon dioxide laser, the linewidth of the semiconductor laser was shown to be $1.8 \times 10^{-6} \mathrm{~cm}^{-1}$ at $0.24 \mathrm{~mW}(24)$. This value is in agreement with theoretical calculations. The $\operatorname{SP}(1,0)$ line of 
Figure 7. Wavelength ranges for semiconductor lasers made from different alloys and compositions. 
WAVENUMBER $(\mathrm{cm}-1)$

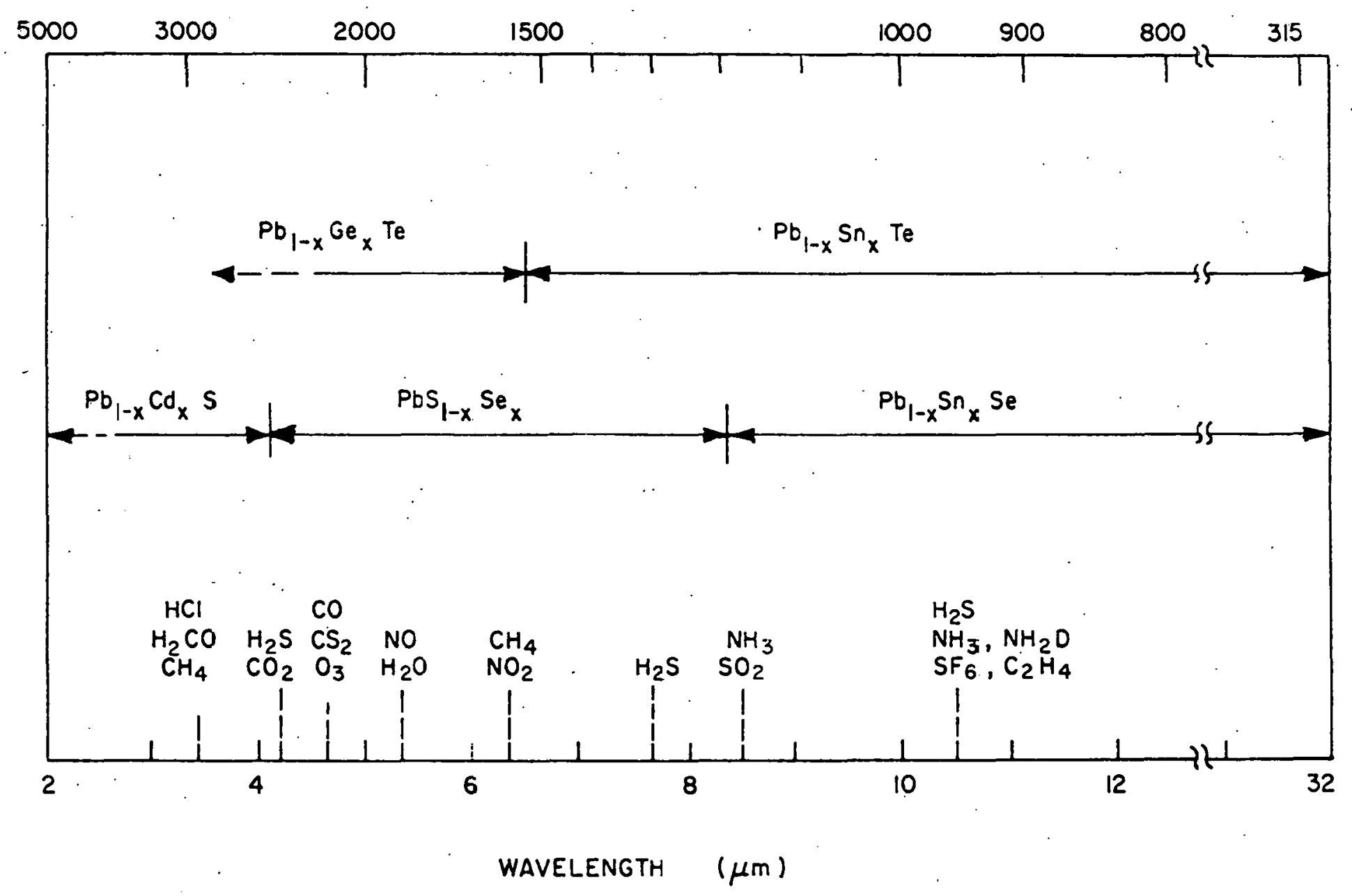


$\mathrm{NH}_{3}$ at $948.25 \mathrm{~cm}^{-1}$ was observed at $300^{\circ} \mathrm{K}$ with a $10-\mathrm{cm}$ path length at pressures as low as 0.005 torr, and the linewidth was observed to increase with increasing pressure. An absorption coefficient per unit pressure at line center of about $2 \mathrm{~cm}^{-1} /$ torr was determined. This laser was also used to obtain a resolved spectrum of $\mathrm{SF}_{6}$ in the region around $947.8 \mathrm{~cm}^{-1}$ at 0.1 torr of pressure and of ethylene using a $30-\mathrm{cm}$ path length at a pressure of $25 \times 10^{-3}$ torr. Derivative spectra of ethylene standards were taken, and derivative spectra of automobile exhaust showed concentrations from 2.2 to $74 \mathrm{ppm}$. Antcliffe and Parker observed the SQ $(5,5)$ lines of $\mathrm{NH}_{3}$ at about $966.50 \mathrm{~cm}^{-1}$ using a $\mathrm{Pb}_{1-x} \mathrm{Sn}_{x}$ Te laser (25). The laser output was directed through a grating spectrometer to separate modes and the scan rate of the laser was determined by calibration with the spectrometer. Within the limits of the scan rate calibration, the $\mathrm{NH}_{3}$ line separation was the same as accepted values. A line strength of $2.3 \mathrm{~cm}^{-1} /$ torr was determined. Weber et al. used a thin-film PbTe diode laser to do Doppler-limited Stark spectroscopy on some lines of $\mathrm{NH}_{3}$ in the $\mathrm{V}_{4}$ vibration-rotation band in the $1545-1595 \mathrm{~cm}^{-1}$. region (26). Weber and Maker used three thin-film PbTe diode lasers to look at the $v_{4}$ asymmetric stretch band of $\mathrm{C}_{3} \mathrm{O}_{2}$ in the region $1565-1600 \mathrm{~cm}^{-1}$ (27). Calibration of the laser outputs was obtained using known spectral lines from $\mathrm{NH}_{3}$ and $\mathrm{H}_{2} \mathrm{O}$, and the rotational constants were determined for the $v_{4}$ band and several hot bands. Blum et al. observed three absorption lines from the $\nu_{2}$ band of water vapor in the region of $5.32 \mu \mathrm{m}(28) . \mathrm{A} \mathrm{PbS}_{0.6} \mathrm{Se}_{0.4}$ semiconductor laser was used and the path length was 7.4 meters. The ambient relative humidity was $18 \%$, yielding a water vapor partial pressure 
of 3.6 torr in the air. The tuning rate was obtained by calibration with a.grating spectrometer which was also used to separate possible modes. Identification of the water lines was easy, as they were the only ones in that region. Theoretical intensities for the lines were similar to the experimental values obtained, but the linewidths were 2 to 4 times narrower than the generally accepted widths. Nill et al. obtained an absorption spectrum for a $\mathrm{CO}$ line at $2107.425 \mathrm{~cm}^{-1}$ using a $\mathrm{PbS}_{0.82} \mathrm{Se}_{0.18}$ diode laser (29). The line strength was determined to be $2.1 \mathrm{~cm}^{-1} /$ torr. Identification was made from the spectrometer reading since there was only one line reasonably close to the reading. Later, Nill et al., using the same laser and magnetic field tuning up to $90 \mathrm{KG}$, were able to cover several additional lines of $\mathrm{CO}(30)$. $\mathrm{A} \mathrm{PbS}_{0.61} \mathrm{Se}_{0.39}$ laser was used to obtain spectra of NO near $5.3 \mu \mathrm{m}$ and a PbTe laser was used to obtain spectra of $\mathrm{CH}_{4}$ and $\mathrm{NO}_{2}$ near $6.5 \mu \mathrm{m}$. Using a change in the magnetic field to tune off an absorption line and using current tuning to tune back onto the absorption line allowed studies of magnetic tuning rates to be conducted. The results showed magnetic tuning rates to be fast but nonlinear, requiring stable current sources and sometimes having an effect on the linewidth of the laser. The No molecule was also studied by Antcliffe et al. (31). An absorption doublet of $N O$ was identified as the $R\left(\frac{3}{2}\right)_{\frac{1}{2}}$ line split by the strong $\lambda$-doubling in the, NO molecule. $\mathrm{APb}_{0.975} \mathrm{Ge}_{0.025} \mathrm{Te}$ laser was used and the tuning rate was determined using a grating spectrometer and found to be much slower than the tuning rate of $\mathrm{Pb}_{1-x} \mathrm{Sn}_{x}{ }^{T e}$ lasers. Antcliffe and Wrobel had six lasers fabricated with the rough composition $\mathrm{Pb}_{0.92}$ $\mathrm{Sn}_{0.08} \mathrm{Te}$ which emitted radiation near $8.8 \mu \mathrm{m}(32) . \mathrm{SO}_{2}$ absorption 1 ines 
were observed and some self-broadening and nitrogen-broadening studies were undertaken. The line strength of the strongest lines was $0.05 \mathrm{~cm}^{-1} /$ torr and $20 \mathrm{ppm}$ of $\mathrm{SO}_{2}$ in a $10-\mathrm{cm}$ cell were readily detectable. The tuning rate was determined using a grating spectrometer, and a $\mathrm{SO}_{2}$ selfbroadening value of $38 \pm 4 \mathrm{MHz} /$ torr (FWHM) and a nitrogen-broadening (of $\mathrm{SO}_{2}$ ) rate of $8.7 \pm 0.7 \mathrm{MHz} /$ torr (FWHM) were obtained. Hinkley et al. used $\mathrm{Pb}_{1-x} \mathrm{Sn}_{x} \mathrm{Te}$ lasers of three different compositions $(x=0.0575,0.0700$, and 0.0745 ) to $100 \mathrm{k}$ at $\mathrm{SO}_{2}$ in three different regions from $1115 \mathrm{~cm}^{-1}$ to 1163 $\mathrm{cm}^{-1}$ in the $P$ branch of the $\nu_{1}$ band (33). $\mathrm{NH}_{3}$ lines were used to calibrate the positions of the laser output and the $\mathrm{SO}_{2}$ transitions were identified by comparing their relative positions and intensities with theory. The measured intensities ranged from $.66 \times 10^{-21}$ to $2.51 \times 10^{-21}$ $\left(\mathrm{cm}^{-1}\right.$ molecule $\left.\mathrm{cm}^{2}\right)$. A self-broadening rate of $20 \pm 3 \mathrm{MH} \geq /$ torr (half

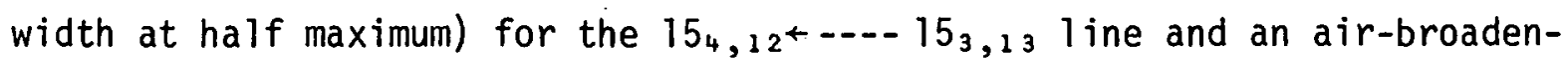
ing rate of $6.0 \pm 0.6 \mathrm{MHz} /$ torr (half width at half maximum) for the $80,8^{+}---3_{1,7}$ transition were determined. Measurements on other lines were similar. Allario et al. looked at the $\mathrm{R}$ branch of the $\nu_{1}$ band of $\mathrm{SO}_{2}$ using a PbSe laser and a combination of current and magnetic field tuning (34). Computer-generated spectra of $\mathrm{SO}_{2}$ based on a line compilation of R. F. Calfee were used as reference spectra for comparison with spectra obtained with the laser scan. Most of the region from $1176.0 \mathrm{~cm}^{-1}$ to $1265.8 \mathrm{~cm}^{-1}$ was covered and all lines in the theoretical spectra were matched to lines in the experimental spectra, with additional experimental lines either attributed to hot bands or impurities in the $\mathrm{SO}_{2}$. Self-broadening rates of $40.0 \mathrm{MHz} /$ torr (FWHM) and $\mathrm{N}_{2}$ broadening rates of 
$11.5 \mathrm{MHz} /$ torr (FWHM) were determined. Magnetic field tuning up to $50 \mathrm{KG}$ was shown to increase the laser output to higher wavenumbers, but the tuning characteristics of the laser became more nonlinear with increased magnetic field. These nonlinear effects, which were determined by comparison of theoretical and experimental spectra, were substantiated by using a Fabry-Perot etalon to directly measure the tuning rates. Although magnetic fields can be used to obtain useful spectroscopic data, care must be taken in analysis because of the nonlinear effects. Hinkley et al., using a widely tunable diode laser fabriacated by compositional interdiffusion and coarsely tuned by adjusting temperature from about 10 to $90^{\circ} \mathrm{K}$, succeeded in observing lines in several different gases (35). The gases included $\mathrm{NH}_{3}$ at $1085 \mathrm{~cm}^{-1}, 0_{3}$ at $1052 \mathrm{~cm}^{-1}, \mathrm{C}_{2} \mathrm{H}_{4}$ at $950 \mathrm{~cm}^{-1}$, $\mathrm{C}_{2} \mathrm{H}_{3} \mathrm{Cl}$ at $940 \mathrm{~cm}^{-1}$, freon-12 at $921 \mathrm{~cm}^{-1}$, and freon- 11 ai $847 \mathrm{~cm}^{-1}$. Relative frequency calibration was obtained by means of a Fabry-Perot etalon. Semiconductor lasers have been used in infrared experiments to observe absorption lines of samples at conditions other than gases at ambient temperature. Dubs and Günthard measured the lineshape of the $\nu_{3}\left(b_{1}\right)$ vibrational transition of $\mathrm{SO}_{2}$ at about $1351 \mathrm{~cm}^{-1}$ isolated in an $\mathrm{Ar}$ matrix (36). The laser was $\mathrm{PbS}_{0.11} \mathrm{Se}_{0.89}$ and frequency measurements were made using a Ge Fabry-Perot etalon calibrated with an absorption line of $\mathrm{CH}_{4}$ at $1351.383 \mathrm{~cm}^{-1}$. Hanson used a diode laser to observe the $\mathrm{CO}$ absorption line $\left[V=0 \rightarrow 1, P(11)\right.$ at $\left.v=2099.0 \mathrm{~cm}^{-1}\right]$ behind a shock wave in a $\mathrm{CO}-\mathrm{H}_{2}-\mathrm{Ar}$ mixture (37). The shock wave creates a post shock temperature of $3340^{\circ} \mathrm{K}$ and the values obtained were the line-strength and line- 
shape at the high temperature. The laser scanned over the absorption line in about $100 \mu \mathrm{sec}$.

Ku et al. have accomplished long-path measurements of carbon monoxide in the atmosphere (16). Using a $\mathrm{PbS}_{0.82} \mathrm{Se}_{0.18}$ diode laser mounted inside a closed-cycle cryogenic cooler, they collimated the laser beam by an offaxis, parabolic mirror $12 \mathrm{~cm}$ in diameter, and transmitted it across a 305 meter path to a corner-cube retroreflector of the same size. The return beam was reflected from the collimating mirror to a beam splitter, finally impinging on the infrared detector. Atmospheric turbulence effects were reduced considerably by frequency modulating the laser emission at $10 \mathrm{KHz}$ and dividing the resulting derivative signal by the direct transmission. CO 1 ines chosen for observation were based on intensity and distance from possible interfering lines from gases such as water vapor. The minimum detectable concentration was $5 \mathrm{ppb}$ and continuous around-the-crock monitoring was performed. The range of co concentrations was from about 400 to $1000 \mathrm{ppb}$. The $\mathrm{CO}$ concentration was observed to increase as automobiles in the area passed by or during certain times of the day when commuter traffic was high.

All of these studies showed that semiconductor lasers can be used to do high resolution spectroscopy and to analyze complex gas mixtures. Although only a few studies of pressure broadening effects were done, the results clearly indicate that semiconductor lasers can be used to do very accurate linewidth studies. Also, using absorption lines of well-characterized gases, one should be able to accurately calibrate the laser and in 
turn accurately determine the absorption line parameters of less wellcharacterized gases.

Finally, the use of semiconductor lasers to do continuous air pollution monitoring seems quite practical and, in fact, has been done in at least one case. 


\section{EXPERIMENTAL}

A. Growing Semiconductor Crystals for Possible Use as Laser Crystals

\section{Glassware preparation}

All glassware used in growing crystals was quartz. Glassware was cleaned by washing in soapy water, soaking in $\mathrm{HNO}_{3}$ for at least one hour, and finally rinsing in HF for about 5 minutes. The glassware was rinsed with distilled water between each wash. All samples once placed in their quartz containers were evacuated on a vacuum system containing a trapped oil diffusion pump and heated with a hand torch to help outgas adsorbed gases from the surface of the sample before sealing off the sample. If the sample began vaporizing and forming a mirror coating on a cooler portion of the quartz container during outgasing, the heating of the sample was reduced. At the completion of outgasing, the quartz tube was sealed off while the sample was still under vacuum.

2. Making the starting samples of $\mathrm{PbTe}$ or $\mathrm{Pb}_{1-\mathrm{x}} \mathrm{Sn}_{\mathrm{x}} \mathrm{Te}$

The appropriate quantities of at least $99.999 \%$ pure $\mathrm{Pb}, \mathrm{Sn}$, and $\mathrm{Te}$ required to make the composition of the compound desired for a particular experiment were placed in a quartz tube and vacuum sealed. The samples were agitated to insure mixing and then the samples were heated to melting inside the tubes. The elements react exothermically to form the compound. To insure a homogeneous compound, the sample was then placed in a wirewound resistive element rocking furnace of Ames Laboratory design, and the temperature was raised to above the compound's melting point (approxi- 
mately $1000^{\circ} \mathrm{C}$ ) for at least one hour. The compound was then removed from the rocking furnace and the quartz ampoule was quickly cooled by immersion in water. The quartz ampoule was broken and the compound removed and broken into the appropriate size pieces for further use.

3. Vapor transport

For the vapor transport experiments, the sample containers used are shown in Figure 8a and Figure 8b. Figure 8a samples were placed in a horizontal one-zone furnace with the round end resting in the center of the oven and the tapered end near an end of the furnace. Several runs were made where the plug surrounded by glass wool in the end of the furnace closest to the sample container was only partially sealing the end of the furnace. This created a temperature gradient where the tapered end of the container was cooler than the end with the sample, and the sample migrated to the tapered end by vapor transport. The temperature range was from $900^{\circ} \mathrm{C}$ to $910^{\circ} \mathrm{C}$ and times ranged from one to three days. The 1 argest crystals obtained were about $2 \mathrm{~mm}$ square. So many crystal seeds were started that if they became any larger they came into contact and fused together. The same container was used in a three-zone furnace where the tapered end rested between an end zone and the center zone and the sample rested in the center zone. The temperature of the center zone was $925^{\circ} \mathrm{C}$, the zone next to the taper was $924^{\circ} \mathrm{C}$, and the other end zone was $926^{\circ} \mathrm{C}$. Times were from one to three days and the results were similar to those with the one-zone furnace. Also, the container in Figure $8 \mathrm{~b}$ was used in the three-zone furnace in the vertical position $(38,39)$. A hole was drilled through the center of an end plug and two strands of twisted 
Figure 8a. Quartz ampoule used in vapor transport studies.

Figure 8b. Quartz ampoule used in vertical vapor transport studies.

Figure 8c. Quartz ampoule used in annealing and solid state recrystallization studies.

Figure $8 d$. Quartz ampoule used in vertical solid state recrystallization studies. 


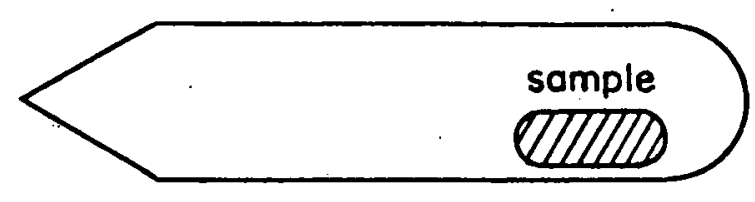

o.
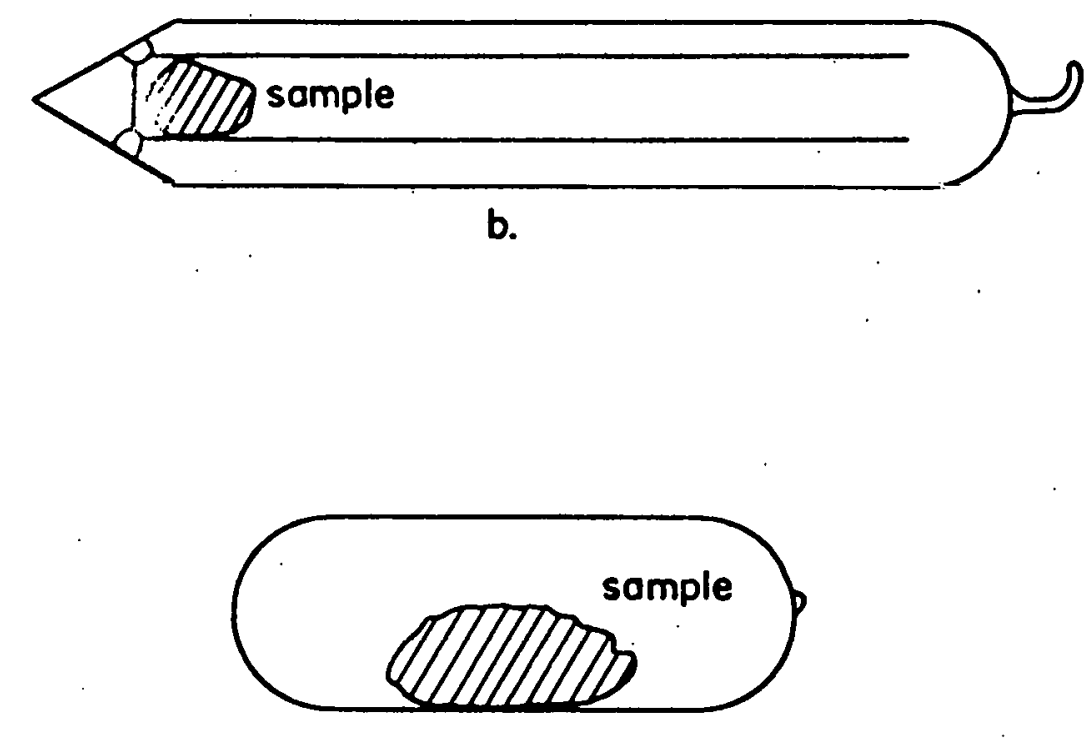

c.

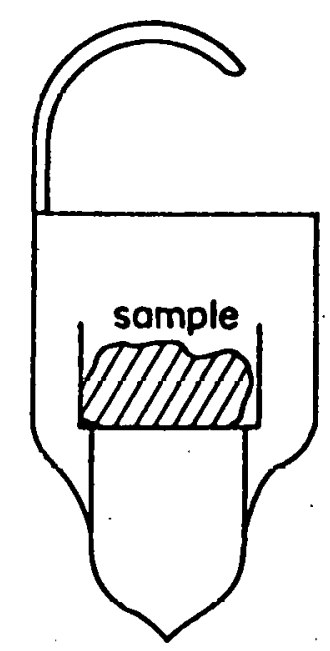

d. 
chromel wire were passed through the plug and attached to the hook on the container. The height of the container in the oven was such that the tapered end rested between the bottom zone and the center zone as in the horizontal position. The temperature and time spans were also the same. The results were also substantially the same.

4. Solid state recrystallization

For the solid state recrystallization experiments the containers in Figure $8 c$ and Figure $8 d$ were used $(40)$. The Figure $8 c$ container was placed in the center of a horizontal one-zone furnace and the temperature was raised to $925^{\circ} \mathrm{C}$. The temperature of the oven at the edges appears to be hotter than the temperature at the center, so the material is hotter near the bottom than near the top, and the sample recrystallizes upon its cooler portions. The figure $8 \mathrm{~d}$ container was centered in a veriical three-zone furnace with the upper zone $924^{\circ} \mathrm{C}$, the center zone $925^{\circ} \mathrm{C}$, and the bottom zone $926^{\circ} \mathrm{C}$. The solid state recrystallization runs produced crystals that were only slightly larger. The ovens used were a Hevi Duty MK-2018-S single zone furnace, a Hevi Duty M-5024-S three-zone furnace, and a Lindberg 54356 three-zone furnace. The Hevi Duty furnaces use Honeywell Type $K$ temperature controllers and the Lindberg furnace has its own temperature controller.

The main reason for poor crystal growth is believed to be due to the instability of the ovens available at maintaining a constant and uniform temperature. 
5. Annealing studies

For the annealing studies, the sample (approximately $1 \mathrm{~g}$ ) that was to be annealed was placed on one side of a quartz ampoule (Figure $8 \mathrm{c}$ ), and 20 to $30 \mathrm{~g}$ of coarsely ground annealing material was placed on the other side of the quartz ampoule. Times and temperatures of the studies ranged from 15 minutes to 3 days and from $500^{\circ}$ to $800^{\circ} \mathrm{C}$.

\section{B. Spectroscopic Setups and Transfer System}

1. Spectroscopic setup with the magnetic field cryostat

Shown in Figure 9 is the experimental setup that was used to examine the laser output when the laser was in the cryostat with the magnet. The laser was focused onto the entrance slits of the Perkin Elmer Model E-l monochromator in the following manner. A flashlight bulb was positioned in the center of the back mirror of the monochromator opposite the entrance slits, and the light from the bulb was focused onto the entrance slits of the monochromator. As the light diverged from the entrance slits, it was refocused using a $11 / 2 " \mathrm{NaCl}$ lens until, by moving the cryostat and the lens, the focused beam fell right at the entrance of the light pipe in the cryostat window. The laser beam was chopped using a mechanical chopper operated by air pressure. The photoconductive detector was placed directly in front of the exitslits of the monochromator and the output of the detector's preamplifier went into a Tektronix, Inc. 7904 oscilloscope. The oscilloscope has a camera attachment for taking Polaroid pictures. The pictures were used to record the spectra. The magnetic field cryostat and semiconductor laser package are described in detail in section $C$. 
Figure 9. Optical setup with the cryostat containing the magnet. 





2. Spectroscopic setup with the Andonian cryostat

An Andonian cryostat became available to us and it used liquid helium more efficiently than the cryostat with the magnet. Because the initial experiments would be done with current tuning and not magnetic tuning, the Andonian cryostat was used in subsequent experiments with the setup in Figure 10. The laser and cryostat were positioned using the same technique as was used above. However, in this setup the beam was refocused on the laser, which was observable through the cryostat window. The Andonian cryostat mount was bolted to the table on which the monochromator rests to heip insure that nothing would be knocked out of alignment. A Bulova tuning fork light chopper with $1 / 2$ " by $1 / 4$ " vanes and an oscillating frequency of one kilohertz was mounted directly behind the entrance slits of the monochromator. The equilibrium opening between the vanes is $1 \mathrm{~mm}$ and the opening was oriented as much as possible parallel to the opening of the entrance slits.

After the laser light passes out of the monochromator, the light passes through a Wilks' 40 meter multiple pass gas cell and is finally focused onto the detector. The alignment of this portion of the optical setup is achieved by shining a Nernst glower on the entrance slits of the monochromator and turning the monochromator grating to the visible (red) portion of the spectrum. Visible light is then traced through the course of the optical path and adjustments are made.

Output from the detector's preamplifier goes into a Princeton Applied Research lock-in amplifier along with a reference signal from the tuning fork driver. Output from the lock-in amplifier goes into the $Y$-axis of a Moseley Autograph Model 7000A X-Y plotter. The power supply system which 
Figure 10. Optical setup with the. Andonian cryostat and the Wilks' 40 meter multiple pass gas cell. 


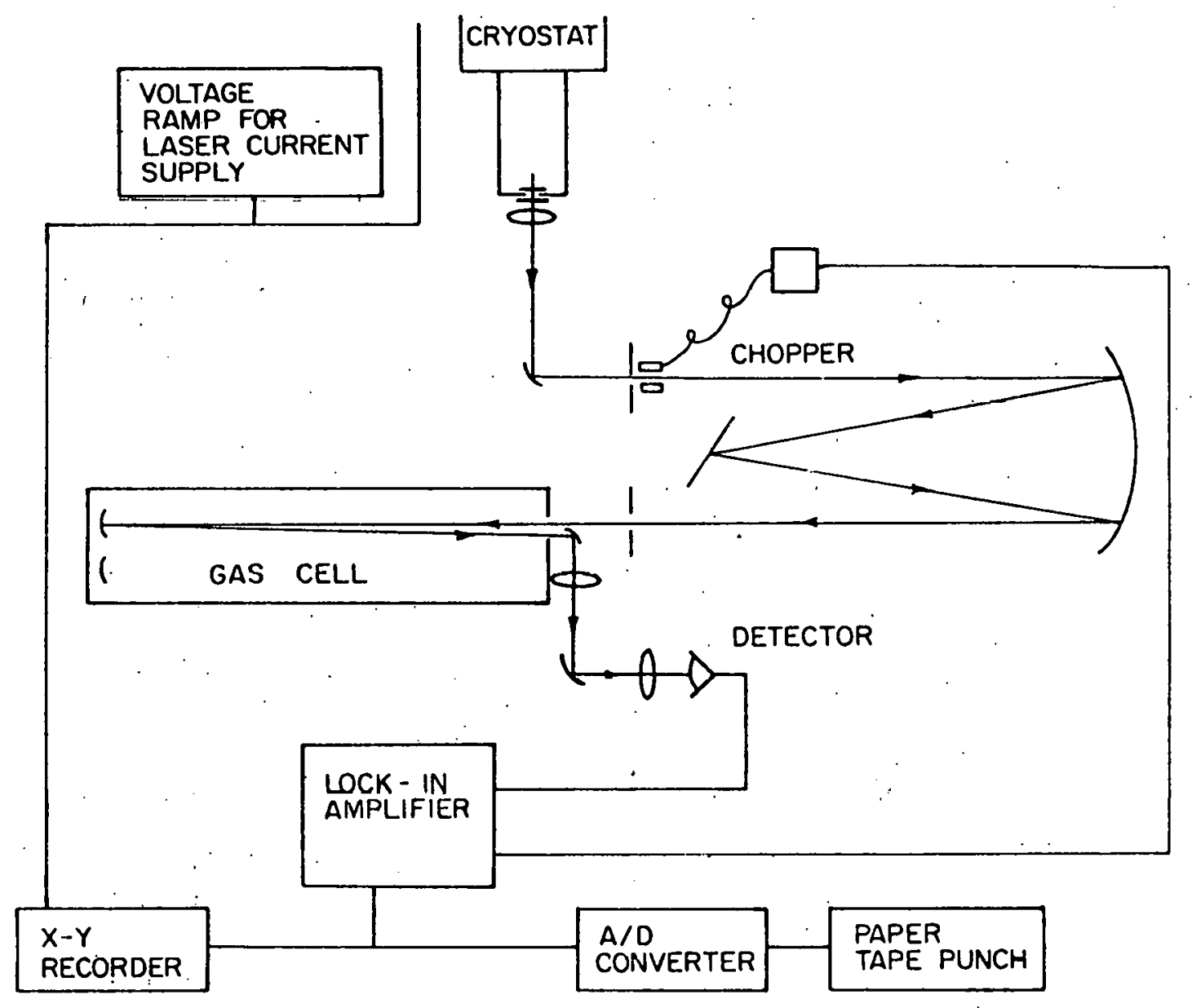


drives the semiconductor provides the $X$-axis for the $X-Y$ plotter. The output of the lock-in amplifier also goes to the $A / D$ converter and ultimately onto paper tape. Details of how the laser is mounted in the Andonian cryostat and of the construction of the laser power supply, the detector preamplifier, and the $A / D$ converter and paper tape punch circuit are described in detail in section C. For details of instrument adjustments, consult Appendix $C$.

3. Spectroscopic setup with the low temperature gas cell

In the low temperature pressure broadening experiments of $\mathrm{N}_{2} \mathrm{O}$ by $\mathrm{SF}_{6}$, the experimental setup was the same as the previous one from the laser to the exit slits of the monochromator. The alignment from the monochromator exit slits to the detector is shown in Figure 11 . The gas cell is constructed of glass and the vacuum portion of the gas cell was silvered using the Brashear process (41). The inner windows of the gas cell are of Irtran II $(4.5 \mathrm{~cm}$ dia. $\times 0.2 \mathrm{~cm})$ because of this material's ability to withstand thermal cycling. The windows are held onto the gas cell using Armstrong 12-A epoxy mixed in the proportion 1 part $A$ to 3 parts $B$. The outer windows of the gas cell are $\mathrm{NaCl}$ windows $(8.3 \mathrm{~cm}$ dia. $\times 0.6 \mathrm{~cm}$ ) and are held onto the gas cell with Armstrong A-12 epoxy mixed 1 part A to 1 part B. The actual optical path for the spectroscopic experiments is 10 $\mathrm{cm}$.

Alignment of the gas cell and detector was accomplished in a similar manner to the setup described above.

After appropriate quantities of the gases under investigation were introduced into the sample compartment of the gas cell, methylcyclohexane 
Figure 11. Optical path when the low temperature gas cell was used. 


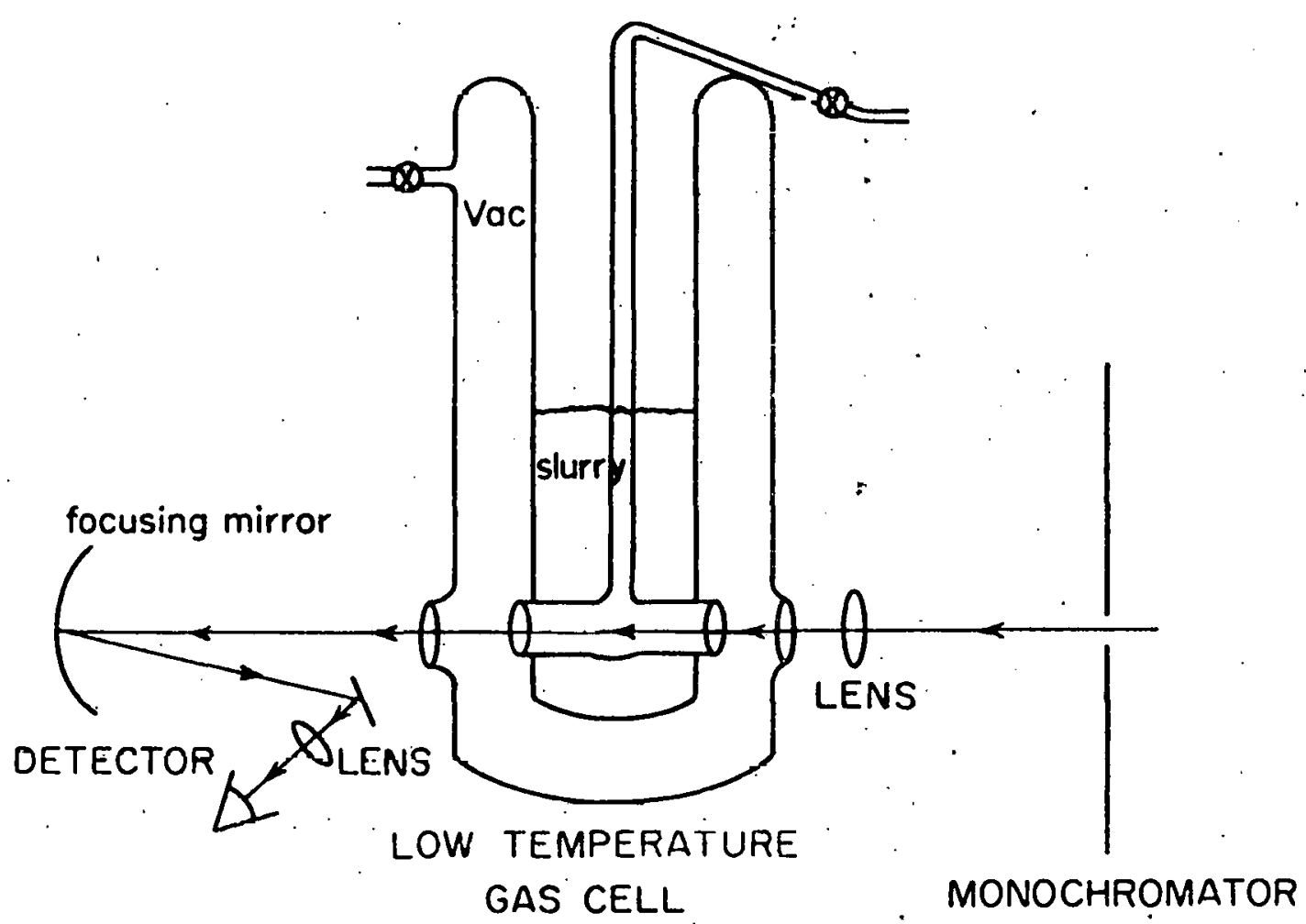


was poured in the slurry compartment of the gas cell. Liquid nitrogen was then slowly poured into the methylcyclohexane with stirring until the temperature of the methylcyclohexane was reduced to its freezing point. A slurry of solid and liquid methycyclohexane was formed. A chromelalumel thermocouple was then placed in the slurry near the bottom of the compartment for monitoring the temperature.

The $\mathrm{N}_{2} \mathrm{O}$ gas pressure in the gas cell was always less than the vapor pressure of $\mathrm{N}_{2} \mathrm{O}$ at even the lowest temperature reached. However, the quantity of $\mathrm{SF}_{6}$ introduced into the gas cell prior to cooling was enough to cause a liquid-vapor equilibrium to exist on cooling. The pressure of $S_{6}$ was determined from vapor pressure tables at the recorded temperature (42). For details of instrument adjustments, consult Appendix $C$.

\section{Vacuum and gas transfer system}

For all situations requiring a vacuum pump or gas transfer, except for the cryostat with the magnet, the vacuum system in Figure 12 was used. To pump down the Andonian cryostat prior to a run, the oil diffusion pump system was used and all valves not needing to be opened for pumping the cryostal were turned off. If for some reason the cryostat was known to be at atmospheric pressure in its vacuum compartment, then the cryostat was first pumped down with the vacuum pump which is not connected to the oil diffusion pump. After this vacuum pump had pumped out the cryostat as best it could, then the pumping was switched to the oil diffusion pump. When the vacuum system was used to introduce gases into the gas cell, the valive to the cryostat was shut off, the valve to the diffusion pump was shut off, and the mechanical pump was used. 
Figure 12. Vacuum and gas transfer system. 


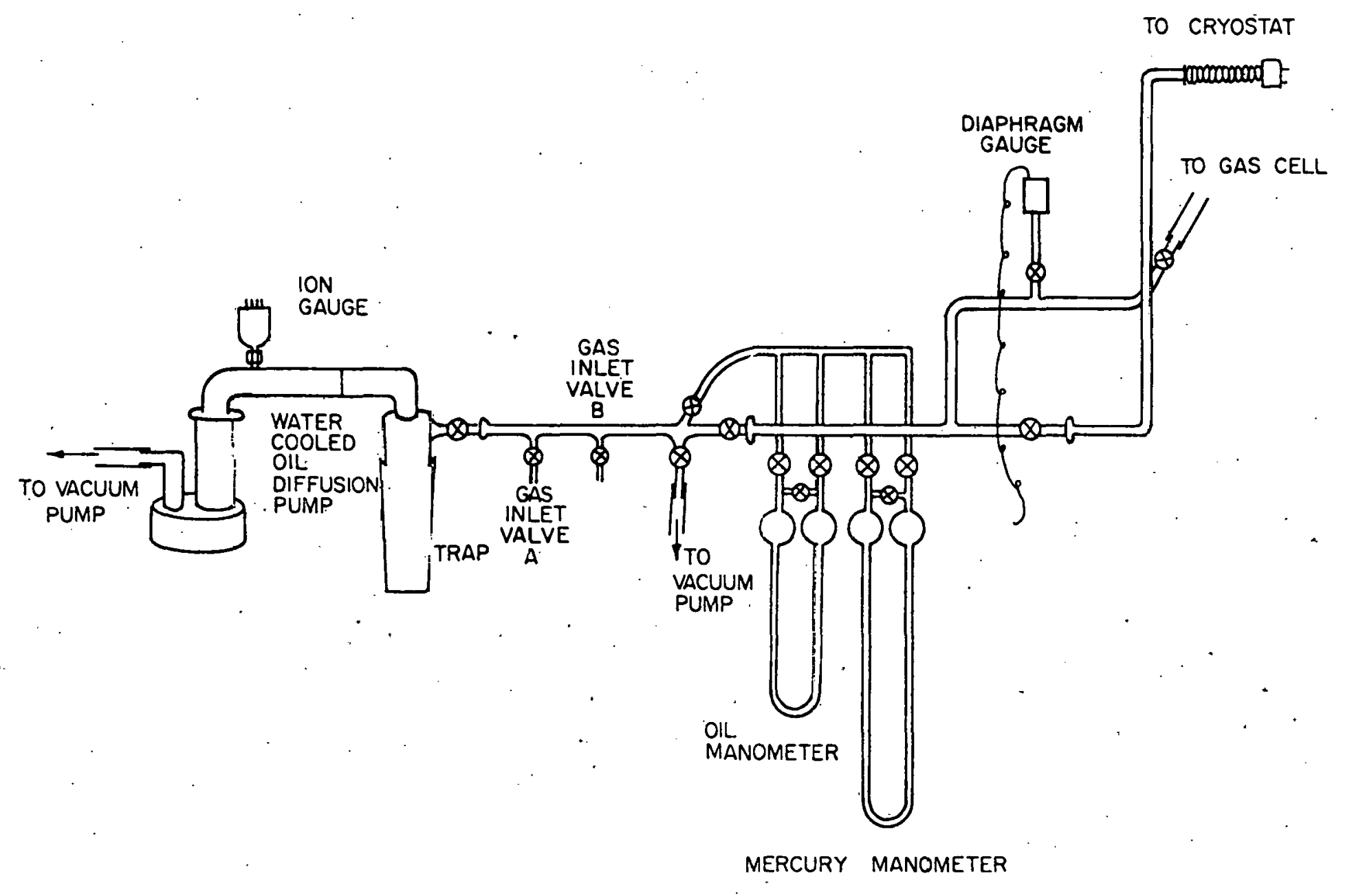


Sample gases or air were introduced into the vacuum system through gas inlet valves $A$ and $B$. For reading pressure of less than 10 torr, the diaphragm gauge was used. For reading pressures greater than 10 torr, the oil filled manometer was used. When the pressures were to large to be read off the oil filled manometer, the mercury manometer was used. When the low temperature gas cell was used, it was more convenient to run a vacuum line from gas inlet valve $A$ to the low temperature gas cell. Because this presents only one valve for gas introduction, the first gas was introduced finto the vacuum system and gas cell. The gas cell valve was closed and the vacuum system was evacuated. The second gas was then introduced into the vacuum system, the gas cell valve opened allowing the gases to come to equilibrium on both sides of the valve, and the valve was then closed.

\section{Components of the Laser System}

\section{Semiconductor laser package}

The semiconductor laser was purchased from Arthur D. Little, Inc. and comes mounted in a microwave package as shown in Figure 13. The top contact and the base contact are made of brass and the center of the microwave package is a ceramic spacer used to separate the contacts. One laser contact is made directly to the base contact with a cold solder joint and thc other laser contact is a cold soldered gold wire which extends from the laser to the top contact. Electrical contact to the laser is then made with the positive lead of the current supply attached to the base and the negative lead attached to the top. Cooling of the laser is by thermal 
Figure 13. Microwave package in which the semiconductor laser is mounted. 


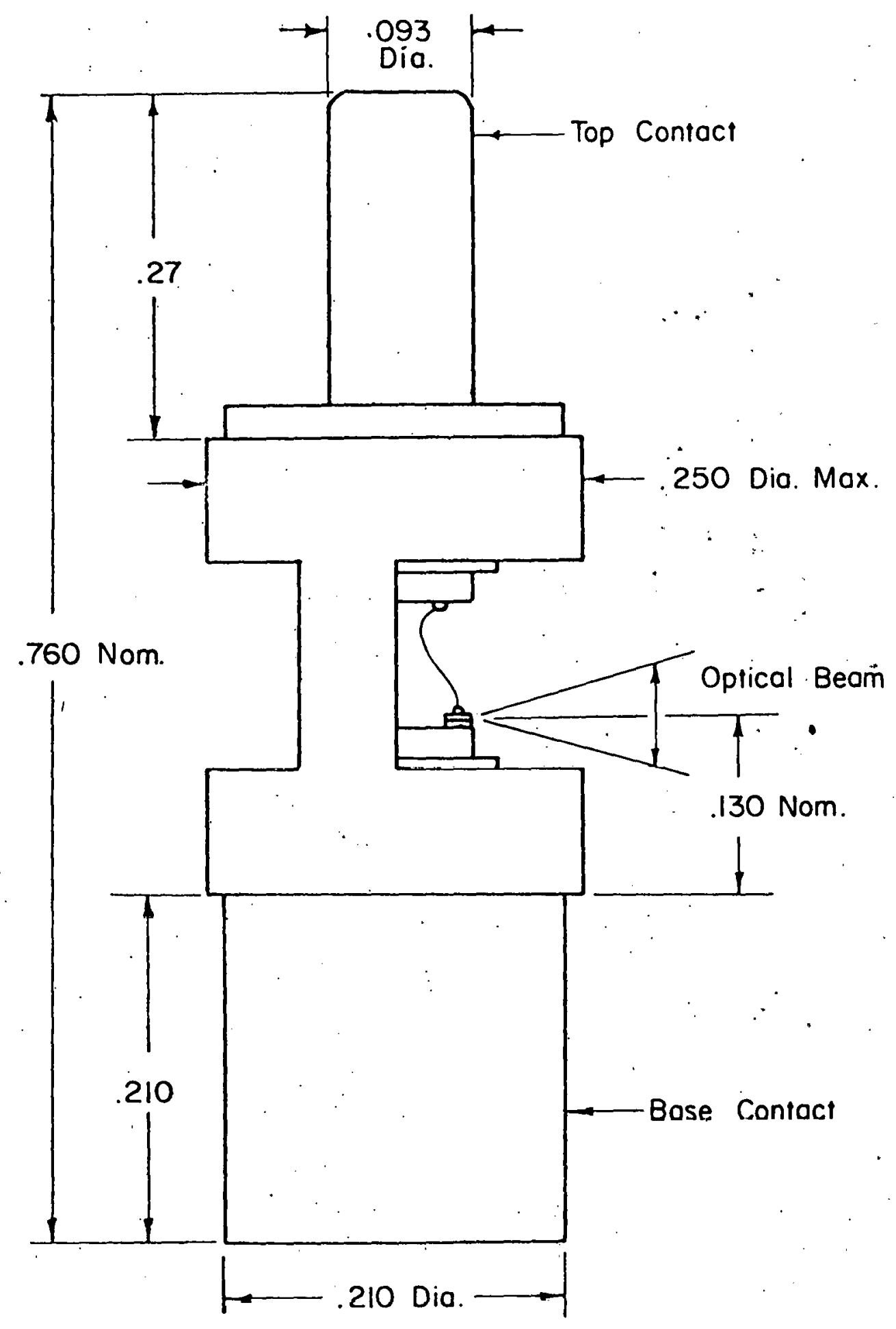


conductivity through the base. Any design for holding this package in a cryogenic system must insure excellent contact to reduce electrical and thermal resistance and must not have the laser too far from the liquid helium reservoir.

\section{Magnetic field cryostat}

The cryogenic system built for the semiconductor laser is shown in Figure 14. The cryostat was built using stainless steel tubing which was available at the Ames Laboratory Metals Development Machine Shop (43). The diameters of the tubing used are as indicated and the overall height of the cryostat minus the access tube at the top is approximately $95 \mathrm{~cm}$. The height of the access tube above the cryostat is approximately $17 \mathrm{~cm}$. The cryostat is mounted on a stand also made in the machine shop. The stand and the cryostat can be raised or lowered with a crank to any desired height. Mounted in the rear of the stand is a vacuum system with an oil diffusion pump and liquid nitrogen trap for pumping down the cryostat. All vacuum chambers are connected and are pumped down at the port near the top of the cryostat. Vacuum separates room air from the liquid nitrogen chamber and also separates the liquid nitrogen chamber from the liquid helium chamber. The liquid nitrogen chamber does not extend below the windows near the bottom of the cryostat, but a copper heat shield is bolted to the bottom of the liquid nitrogen chamber. Readily observable in Figure 14 are two exit windows on either side of the cryostat and two more exit windows not seen coming into and out of the paper. The vacuum seals at the top of the cryostat are made using copper gaskets and the liquid helium chamber seals at the top are made with rubber 0 -rings. 
Figure 14. The cryostat with the magnet. 


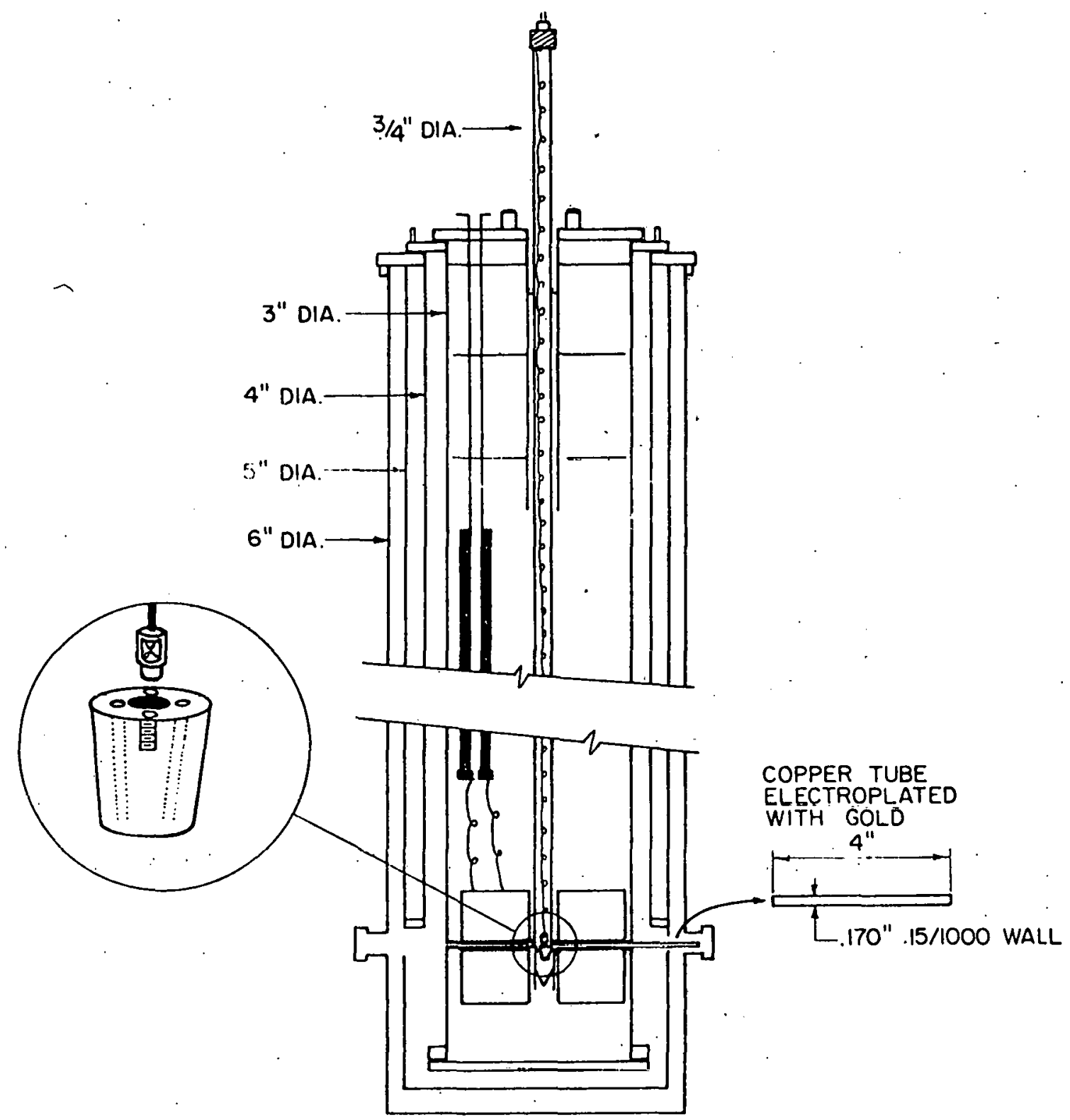


In order to place the split coil magnet such that one portion is above the laser crystal and the other is below the crystal and both are immersed in liquid He, a seal is also present in the bottom of the liquid He chamber. This seal must use an indium gasket because of the extreme temperature cycling.

Laser output is in a diverging beam (not collimated) which means much of the light would not make it through the narrow exit port and out the window of the cryostat. Therefore a copper tube is placed through the port and close to but not touching the laser crystal. Looking through the copper tube, one gets correct alignment if the laser is situated near the center of the tube. The inside of the copper tube was polished and is electroplated with gold which is an excellent reflector of infrared light. The laser mount shown in the inset is composed of copper and has a hole in the center in which the microwave package containing the laser is placed. A set screw (not shown) in the side of the mount holds the microwave package firmly in the mount. Two threaded holes on either side of the laser are present such that a long rod with a threaded end can be attached to either threaded hole, and the laser mount can be lowered from the top of the cryostat access tube to rest in the position as shown in Figure 14. Two bolts fit through the other two holes in the mount and are bolted into the base of the mount holder using the appropriate tool attached to a rod which extends from the top to the bottom of the cryostat. The contacts for the laser are the base (and hence the metal cryostat) and a \#30 gauge magnet wire which extends from the top of the microwave package to the top of the cryostat access tube. There, the wire is 
soldered to an insulated electrical contact which feeds through the top vacuum seal. The electrical contacts for the split magnet are composed of two hollow steel tubes which extend just below the heat baffles in the liquid He chamber. Small copper blocks are press-fitted to each end of the steel tubes and the outside, braided part of a RG-174/U coaxial cable is removed from the cable and placed through the inside of each tube, These are then soldered to the copper blocks in a manner such that helium gas that boils off must pass through the center of the tubes cooling the braided cable (44). Extending from the bottom copper block on each tube to about three inches above the coil magnet is a $1 / 4$ inch wide sheet of 12 gauge copper, which has soldered to it for its entire length a strand of superconducting wire. Superconducting wire then runs from the bottom of each copper strip to the split coil magret. The superconducting.wire was obtained from Supercon, Inc. and has an inner core of $\mathrm{Nb}-48 \% \mathrm{Ti}$ to a diameter of 0.0057 inch, a coating of copper to a diameter of 0.0075 inch, and a Formvar insulation to a diameter of 0.0088 inch. The calculations for determining the size of the split coil and the length of wire needed follow.

For square-ended solenoids with uniform current density, the axial field at the center, Hoo, in gauss is

$$
\text { Hoo }=\frac{a_{1} F(\alpha, \beta) i}{A}
$$

where $\mathrm{a}$ is the inner winding radius in centimeters, and $A$ the cross sectional area per turn in square centimeters (45). The current is $i$ and $F(\alpha, \beta)$ is the Fabry factor. The equation for the Fabry factor is 


$$
F(\alpha, \beta)=\frac{4 \pi}{10} \beta \ln \frac{\alpha+\sqrt{\alpha^{2}+\beta^{2}}}{1+\sqrt{1+\beta^{2}}}
$$

where $\alpha=2 a_{2} / 2 a_{1}=$ winding $0 . d . /$ winding i.d. and $\beta=2 b / 2 a_{1}=$ winding length/winding i.d. The spools on which the magnet wire was wound were made from aluminum milled to a thickness of $1 / 16$ inch. The inside diameter of the spools was just larger than $3 / 4$ inch so that they would slide over the $3 / 4$ inch access tube of the cryostat. This makes, an inner winding radius of $1.11 \mathrm{~cm}$. A magnetic field of about $50 \mathrm{KG}$ at $20 \mathrm{~A}$ was desired. The wire had an external diameter of $.022 \mathrm{~cm}$, and thus A was about $5.0 \times 10^{-4} \mathrm{~cm}^{2}$. Using these values in Equation 1, a Fabry factor of 1.12 was obtained. A reasonable winding length of $5.7 \mathrm{~cm}$ was decided upon which gives a $\beta$ of 2.6 and from Equation 2 an $\alpha$ of 2.1. The wire length was determined by dividing the coil volume by $A$ to obtain a value of $1.4 \times 10^{5} \mathrm{~cm}$. The number of turns was found by dividing $2 \mathrm{~b}$ $\left(a_{2}-a_{1}\right)$ by $A$ to obtain 13,347 turns. The magnetic field of a split coil is the magnetic field of a coil that would exist if the magnet were continuous through the split region minus the field of a coil that is only the size of the split region (46). Because for small separations the continuous coil and the split coils would not be too different and because a coil cannot be wound with perfect overlap of the magnet wire, the values calculated for the single coil were considered to be a reasonable guideline. The coil spools were identical. Their outside diameter was $7.0 \mathrm{~cm}$ and their inside width was $2.9 \mathrm{~cm}$. One thousand more feet of wire than were calculated were ordered and each spool was wound with 6674 turns of wire. One coil was placed above the light output ports and the other coil was placed below the light output ports. The two spools were then 
bolted together. Care was taken to make sure that the proper connections were made to the coils and all connections were soldered with electrical solder.

After the split coil magnet was made and placed in the cryostat the actual magnetic field was determined as a function of current. A constant variable current source was placed across the leads of the magnetic coil with a $1 \% 1 \mathrm{~K}$ resistor attached in series. The voltage across the resistor was measured at different currents and a Bell Hall effect magnetic flux meter was used to record the magnetic flux when the probe was placed in the location where the laser would normally be situated. Several points were taken and a least squares fit obtained for the points. A value of 2.076 gauss/mA was determined.

3. Andonian cryostat

The commercially available Andonian cryostat pictured in Figure 15 was later used for cooling the laser to do spectroscopic experiments. A conical mount was made of copper for holding the microwave package, which is held in place with a set screw. The conical mount was then bolted to the tail piece of the Andonian cryostat with an indium gasket between the two to help insure good thermal contact. The cryostat has a heater wrapped around the bottom of the helium exhaust tube next to the tail piece for doing temperature variation experiments and a valve for regulating the rate at which helium can flow into the tail piece. The windows of the cryostat are $\mathrm{NaCl}$ crystals. 
Figure 15. The Andonian cryostat with the laser mounted. 


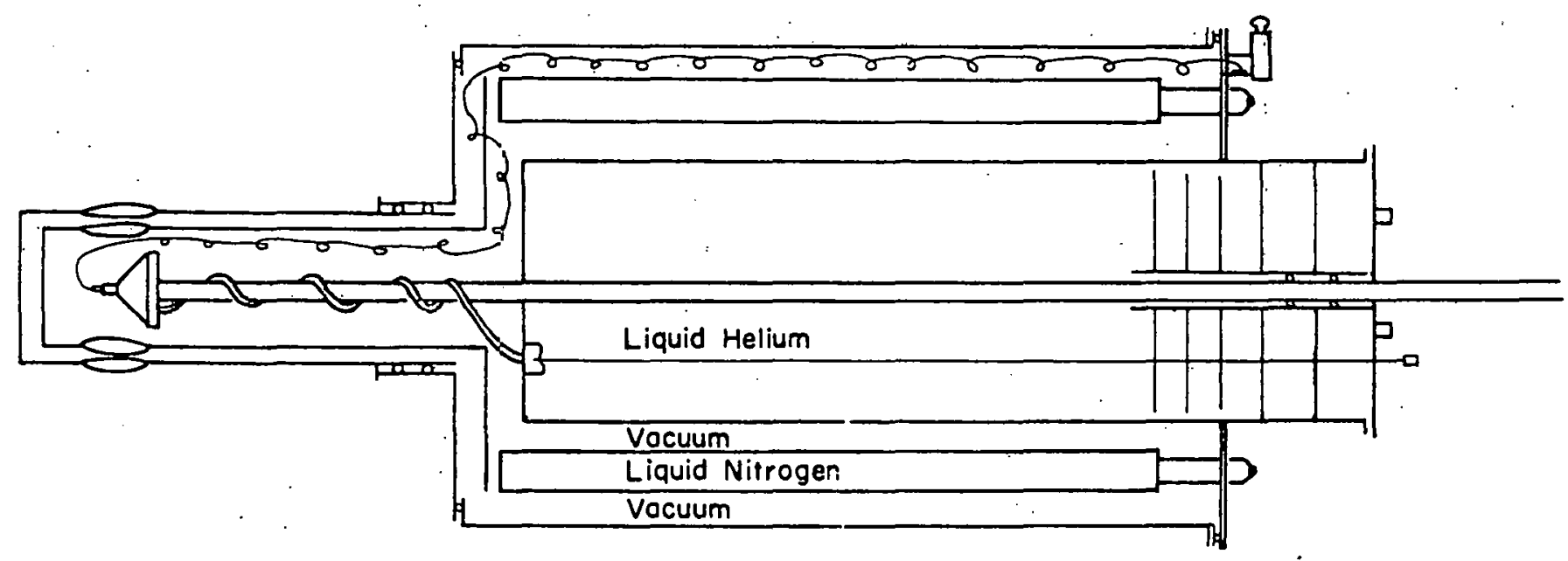




\section{Detector system}

The photoconductive detector manufactured by Princeton InfraRed Equipment is a HgCdTe semiconductor which operates at liquid nitrogen temperature. A constant current is applied to the detector, and, as light strikes the detector, the resistance and hence the voltage is reduced. The reduction is directly related to the amount of light striking the detector. The current supply and preamplifier for the photoconductive infrared detector are shown in Figure 16. During operation, the current is kept relatively constant and, as the conductance of the detector increases with increasing photon density striking the detector, the voltage across the detector decreases. As the light striking the detector is chopped, the voltage across the detector changes with the chopping frequency and the amplitude is proportional to the intensity of the light. The capacitor allows only the ac signal due to chopping to pass to the transformer and the transformer impedance matches the low resistance of the detector ( 50 to $150 \Omega$ ) to the much higher resistance of the operational amplifier (47). The transformer is a miniature audio transformer with listed impedance values of $500 \Omega$ and $20 \mathrm{~K} \Omega$. Capacitor size was determined by placing various size capacitors in the circuit until an increase in size produced no increase in the preamplifier output. The first amplifier stage is a 301 operational amplifier wired as a voltage follower with a gain of 4.48. The second amplifier stage is a 741 operational amplifier wired as an inverter with a gain of 4.3. Originally, a constant current circuit was purchased to provide constant current for the detector, but the circuit called for 12 volts and, when 15 volts were used, the circuit 
Figure 16. Current supply and Freamplifier for the detector. 


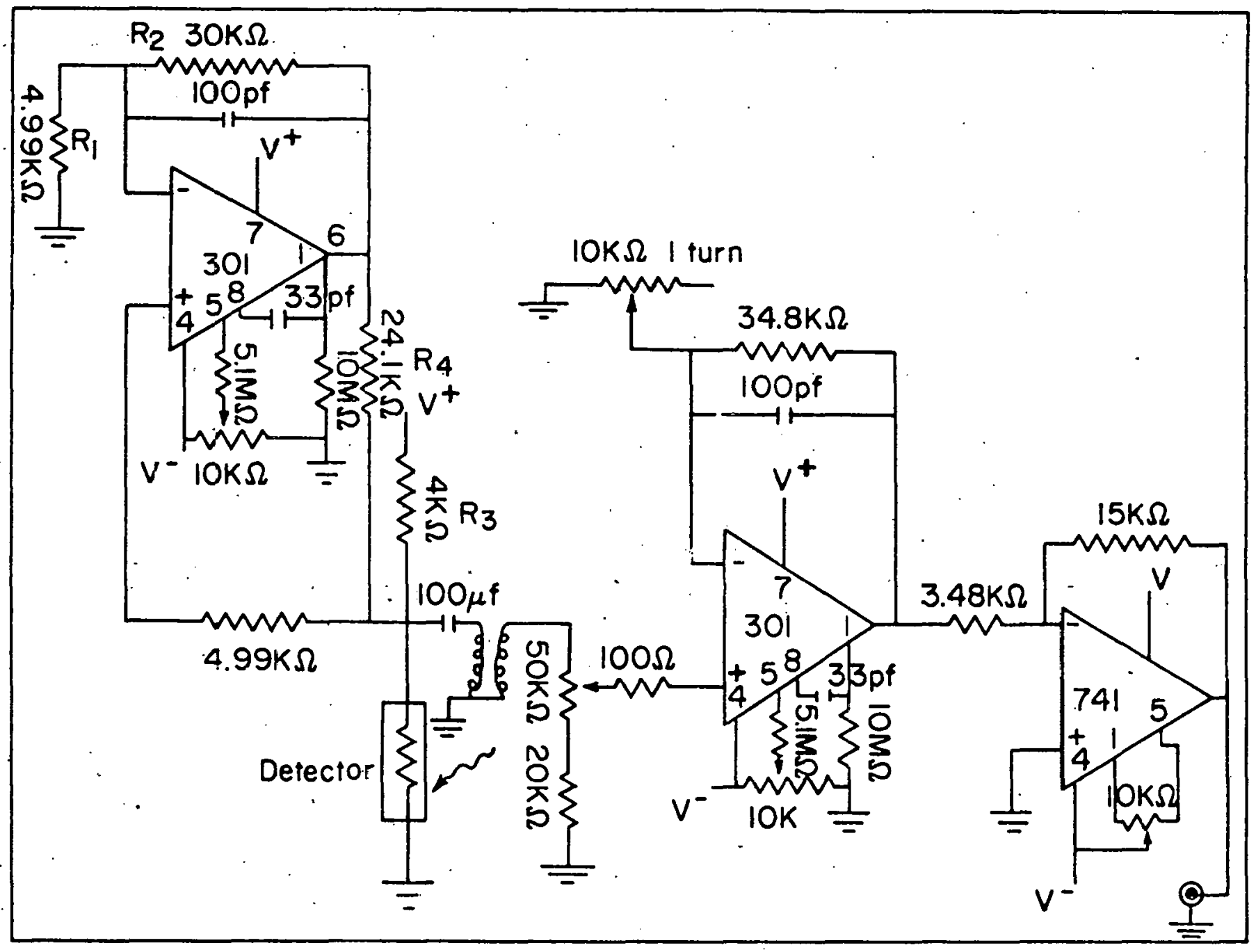


was damaged. A second constant current circuit purchased with a second detector was used for some time with both detectors but was eventually damaged by thermal cycling. The constant current source in the circuit was made to replace the damaged ones. Although the circuit seems a little unconventional, it was desirable to have the detector attached to ground to reduce the probability of shorting. The following equations apply to determine the appropriate resistors.

$$
\begin{aligned}
& e_{\text {out }}=e_{-}=e_{+} \\
& \frac{e_{\text {out }}}{R_{2}+R_{1}}=\frac{e_{-}}{R_{1}} \\
& e_{\text {out }}=\frac{e_{-}\left(R_{1}+R_{2}\right)}{R_{1}}=\frac{e_{-}(5 K+30 K)}{5 K}=e_{+}(7)=3_{+} \\
& i_{\text {load }}=\frac{v^{+}-e_{+}}{R_{3}}+\frac{e_{\text {out }}-e_{+}}{R_{4}}=\frac{v^{+}}{R_{3}}-\frac{e_{+}}{R_{3}}+\frac{7 e_{+}-e_{+}}{R_{4}}= \\
& \quad \frac{v^{+}}{R_{3}}+\left(\frac{6}{R_{4}}-\frac{1}{R_{3}}\right) e_{+}
\end{aligned}
$$

In order to insure that the $i_{\text {load }}$ is independent of $e_{+}$and therefore constant, $6 / R_{4}-1 / R_{3}=0$. The detector operates best at $300 \mathrm{~mA}$ and this requires that $R_{3}=4 \mathrm{~K}$ and $R_{4}=24 \mathrm{~K}$. Metal film resistors were chosen such that their values were as close as possible to the calculated values. Electronic components were mounted on a universal 301-741 circuit board. The vacuum dewar in which the photoconductor is mounted and the circuit board are both mounted in a metal 4 inch $\times 5$ inch $\times 6$ inch box. The power supply for the system is composed of 4 six volt batteries wired to produce $+12 \mathrm{~V},-12 \mathrm{~V}$, and ground. 


\section{Laser power supply}

The regulated current supply for the semiconductor laser is shown in Figure 17. The circuit at the top is the portion of the supply that provides the current for the semiconductor laser. To prevent the possibility of accidental shorting due to the exposed nature of the positive contact of the laser (the metal cryostat), the cryostat was made ground. A short switch is available for shorting the contacts to the laser when one wishes to make sure no current is flowing through the laser. A second switch provides a referenre voltage either from a voltage divider shown in the top circuit or from an external source to the positive input of a 741 operational amplifier. The voltage drop across a $1 \Omega$ resistor is applied to the negative input of the 741 operational amplifier. When the reference voltage is higher in potential than the voltage at the negative input, the 741 operational amplifier turns on a cascaded transistor pair allowing more current to flow across the $1 \Omega$ resistor. When the voltage across the $1 \Omega$ resistor equals the reference voltage, the 741 operational amplifier reduces its current to the cascaded transistors to a point where total current flow across the $1 \Omega$ resistor remains constant, with the voltage drop across the resistor equal to the reference voltage. The Zeltex power supply provides power for the 741 operational amplifier and voltage for the voltage divider circuit. At first, the external reference voltage came from the saw-tooth output of a Tektronix, Inc. oscilloscope, but later the dc offset circuit and voltage ramp in the rest of Figure 17 were made to provide an external reference voltage. The dc offset circuit (center) contains a $1.5 \mathrm{~V}$ battery with a voltage divider for providing any voltage from 0 to $1.5 \mathrm{~V}$. A second voltage divider in 
Figure 17. Power supply system for the semiconductor laser. 

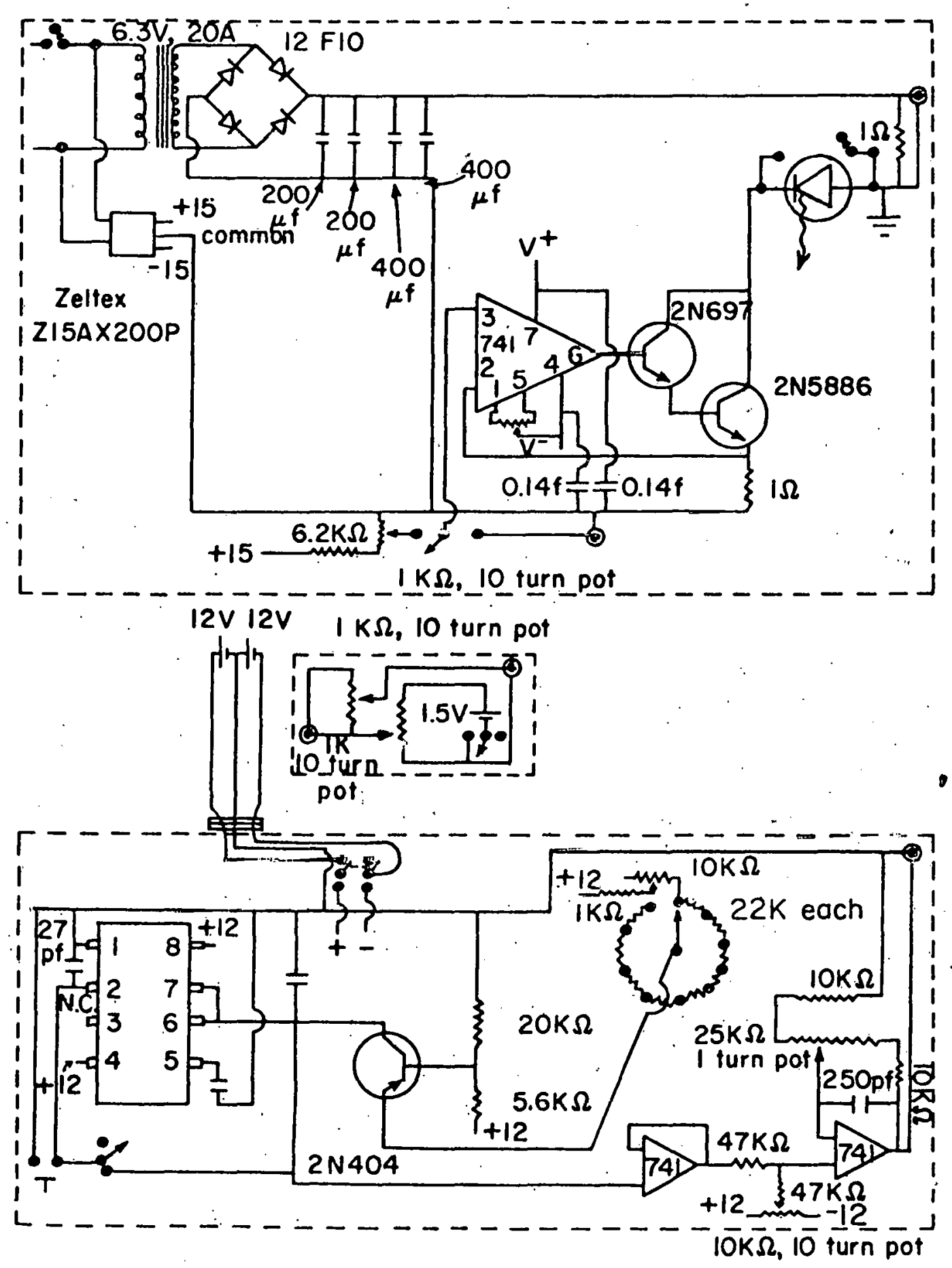
the dc offset circuit provides any voltage applied to it (usually the saw-tooth from the voltage ramp) and places it on top of the voltage provided by the first voltage divider circuit.

The heart of the voltage ramp circuit (bottom) is a 555 integrated circuit timer. Pin 7 and thus pin 6 and the capacitor are maintained at the same potential as pin 1 until the voltage at pin 2 drops below 1/3 of the supply voltage $\left(V_{s}\right)$ relative to pin 1 . This can occur in two ways. When the switch attached to pin 2 is in the up position (single sweep), the pushbutton switch must be momentarily depressed to drop the voltage al pln 2. When the switch is in the down position (continuous sweep), the potential at pin 2 is the same as the potential at pins 6 and 7 . In either case this starts the timing sequence by isolating pins 6 and 7 from pin 1, and allows the capacitor to charge at a constant current provided by the transistor and the resistor network attached to the emitter of the transistor. A constant current flowing into a capacitor causes the potential across the capacitor to increase uniformly. When the voltage at pin 6 is $2 / 3$ of $v_{s}$, pin 7 again shorts to pin 1 , discharging the capacitor quite rapidly. If the switch at pin 2 is up, the capacitor discharges completely and will begin to charge again only when the pushbutton is depressed. If the switch at pin 2 is down, the capacitor discharges to $1 / 3$ $V_{s}$, at which time pin 2 isolates pin 7 from pin 1 and the capacitor starts to recharge again. The voltage from the capacitor goes to a voltage follower. The output of the voltage follower and a voltage divider circuit are applied to a 741 operational amplifier wired as a voltage follower with gain from 1.3 to 4.5 . The reason for the voltage divider 
applied to the input of the last 741 operational amplifier is that, when the timer is operating in continuous sweep, the saw-tooth range is from $1 / 3 V_{s}$ to $2 / 3 V_{s}$ and the divider offsets the saw-tooth so that it can begin at 0 volts relative to pin 1 . The power supply for the voltage ramp is 4 six volt batteries wired for +12 volts, -12 volts, and ground. The resistors in the multiposition switch and the variable resistor provide variable ramp time from about five seconds to eighteen minutes.

The voltage ramp circuit is housed in a 4 inch $\times 5$ inch $\times 6$ inch metal gray box and the dc offset circuit is housed in a 6 inch $x$ inch $x$ 6 inch melal gray box. The circuit that provides the current to the laser is housed in a 12 inch $\times 7$ inch $\times 6$ inch metal gray box and al1 connections between the boxes are made with BNC cable to floating BNC chassismounted connectors. A twisted wire pair provides the cornection to the laser with the wire grounded to the cryostat attached to the grounded lug on the current supply. The other wire which comes out of an electrical feed through connector on the cryostat is attached to the lug floating off of the metal current supply box.

6. A/D conversion and paper tape punch circuit

The circuit which changes the analog output of the lock-in amplifier into a digital signal and sends the digital signal to a paper tape punch is shown in Figure 18. The $A / D$ converter is a Datel System, Inc. ADCERI2B model with an analog input range of \pm 1 volt and a 12 bit binary output. The generator start pulse rate is adjustable from 4 pulses per second to 23 pulses per second and the pulses are applied to the decade counters shown in the upper left. The first two decade counters are wired for divide by ten operation and are in operation when the switches below 
Figure 18. A/D converter and paper tape punch circuit. 


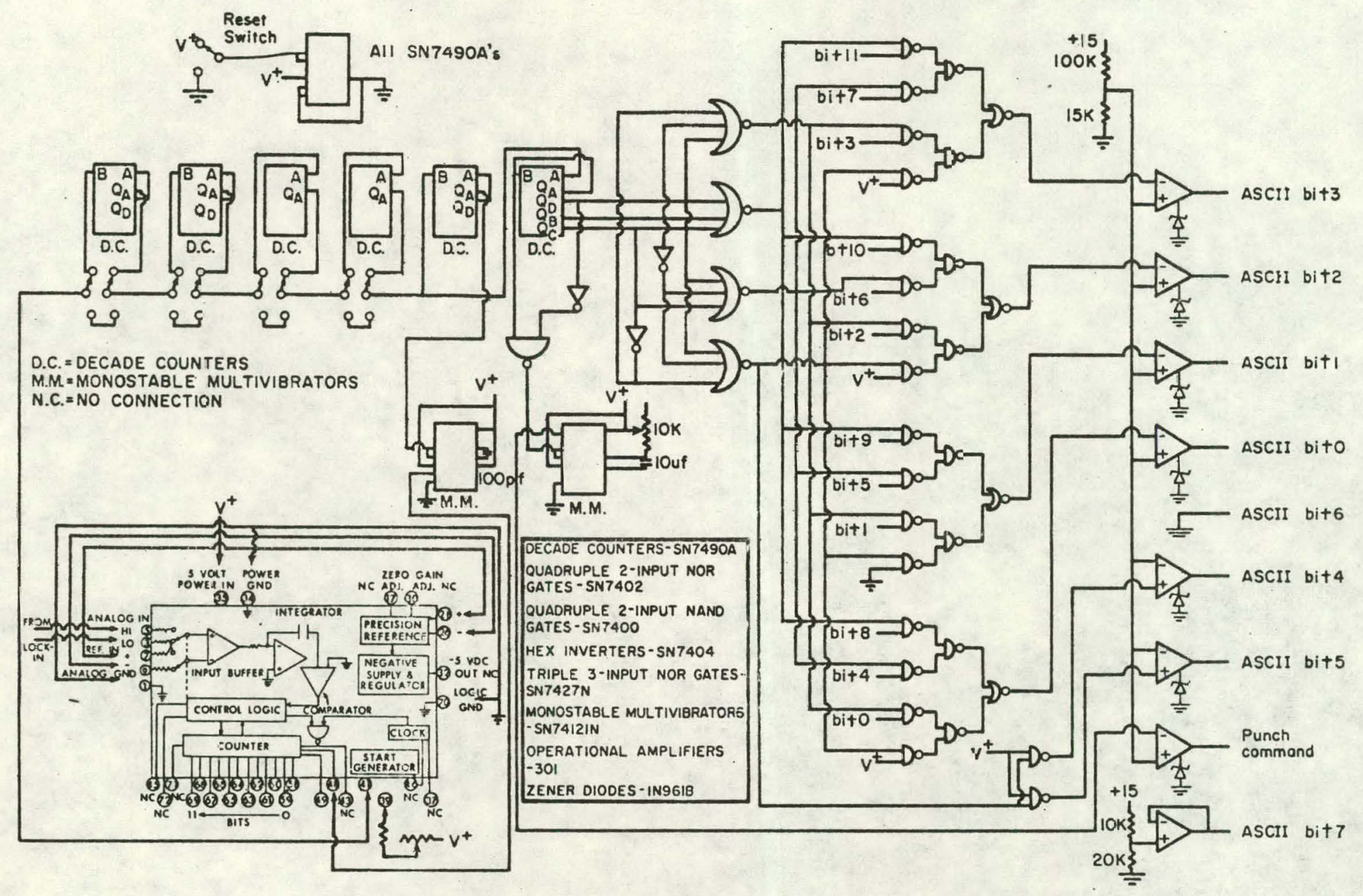


them are in the up position. The second two decade counters are wired for divide by two operation and are in operation when the switches below them are in the up position. All twelve bits cannot be punched on paper tape at the same time, therefore four bits at a time are punched onto paper tape. The fifth decade counter is wired such that $Q_{A}$ is low for pulses 0 through 4 and high for pulses 5 through 9. Pulse 10 repeats the cycle. When $Q_{A}$ goes from high to low, the attached monostable multivibrator is triggered, and it sends a short pulse to the $A / D$ converter to begin conversion.

Pulse 0 on the sixth decade counter has pins $Q_{D}, Q_{C}, Q_{B}$, and $Q_{A}$ all low. Pins $Q_{D}, Q_{C}$, and $Q_{B}$ all low causes high output on only one of the 3input nor gates following the decade counter. Pulse 1 has pins $Q_{D}, Q_{C}$, and $Q_{B}$ still low and $Q_{A}$ high. When $Q_{A}$ goes high, the moriostable multivibrator is triggered and a pulse is sent to the paper tape punch. Pulse 2 has $Q_{D}=$ Low, $Q_{C}=$ Low, $Q_{B}=$ High, and $Q_{A}=$ Low. The new situation at pins $Q_{D}, Q_{C}$, and $Q_{B}$ causes a different 3-input nor gate to go high. Pulse 3 produces no change in $Q_{D}, Q_{C}$, and $Q_{B}$, but $Q_{A}$ goes high. $A$ pulse is again sent to the paper tape punch. In a similar manner, pulse 4 activates a different 3-input nor gate and pulse 5 causes a paper tape punch. Pulse 6 activates the final different 3 -input nor gate and pulse 7 causes a paper tape punch. Pulse 8 produces low input on all 3-input nor gates and pulse 9 causes no paper tape punch. Pulse 10 repeats the process. Eight 301 operational amplifiers are used to interface the paper tape punch (which uses ten volts) to the logic circuit (which uses five volts). The Zener diode provides an output of zero volts when the inputs of the 
operational amplifier would normally have produced negative maximum output. The Zener diode provides an output at the operational amplifier equal to the Zener diode voltage when the amplifier's inputs would normally produce fuli positive output. The punch command must have first gone through the monostable multivibrator to provide a pulse just long enough to allow only one punch from the paper tape for each set of four bits. A five volt power supply from Power-One, Inc. is used to provide five volts to all of the logic chips and the $A / D$ converter, and a Datel Systems, Inc. BPM15/200 \pm 15 volt power supply is used to drive the operational amplifiers in the circuit. 
IV. RESULTS

\section{A. Attempts at Making Seniconductor Lasers}

The attempts to convert the carrier type of a particular crystal to the opposite carrier type were successful for both $\mathrm{PbTe}$ and $\mathrm{Pb} .{ }_{9} \mathrm{Sn} .{ }_{0} \mathrm{Te}$ $(38,39)$. Also, indications were that, in the studies where crystals of one type were annealed only for a short time in the presence of the appropriate material for converting the crystal type, $P-N$ junctions did exist in the crystals. However, the largest crystals produced were no bigger than $2 \mathrm{~mm}$ on a side for either the vapor transport or the solid state recrystallization methods. This size was too small to do the necessary cleavage and chemical etching required for producing useful diodes. The reason for the poor crystal growth is believed to be due to the inability of the furnaces to maintain a very stable temperature and maintain a very small temperature gradient along the length of the furnace. Also, the cleaning techniques may have had something to do with the seeding ability on a quartz ampule. In order that research into the spectroscopic and experimental properties of semiconductor laser use was not delayed, a semiconductor laser was purchased for use in the spectroscopic experiments:

B. Preliminary Investigation of Semiconductor Laser Characteristics

The first thing that was done, after the laser was mounted and laser light was detected after passing through the monochromator, was to determine the output modes of the semiconductor laser. In the cryostat with 
the magnet, the laser was current ramped while the monochromator setting was changed in small increments. An oscilloscope photograph was taken and the current which gave the maximum on the photograph was assumed to be the current which gave the frequency output indicated by the monochromator setting. The results showed that in this cryostat the output region was from about $1184 \mathrm{~cm}^{-1}$ to $1194 \mathrm{~cm}^{-1}$ in modes separated by about $1.5 \mathrm{~cm}^{-1}$. The lowest energy mode had a value of $1185.0 \mathrm{~cm}^{-1}$ at $1 \mathrm{~A}$ based on the spectrometer readings. The threshold current for lasing was about 0.8 amps and a tuning rate of about $2.5 \mathrm{~cm}^{-1} / A$ was determined.

When the Andonian cryostat was used, the method of tuning was to hold the current through the laser constant and scan the monochromator grating. The throughput maxima at each current setting was assumed to correspond to the laser frequency at that current. The lowest energy mode had a value of about $1180.4 \mathrm{~cm}^{-1}$ at $1 \mathrm{~A}$. The mode spacing was the same as above and the threshold current was aiso about $0.8 \mathrm{~A}$. However, the tuning rate was about $.66 \mathrm{~cm}^{-1} / A$. This difference in tuning rates is due to the difference at which heat can be dissipated from the laser into the liquid helium reservoir.

Also, as the current is raised above about $1.2 \mathrm{~A}$, the population inversion becomes great enough that many new modes appear (which incorporate the sides of the laser as the optical path). From one cycling of the cryostat to liquid helium temperatures to the next cycling, the output of the laser changes with current. However, the tuning rate remains the same. This output change is most likely due to small changes in materials adsorbed onto the surface of the laser, such as an oil film from the oil 
diffusion pump (25). The Andonian cryostat has a heater for raising the temperature above liquid helium temperatures. With this heating, the laser output frequency was raised in energy to a mode as high as 1205 $\mathrm{cm}^{-1}$. However, the current required was about $1.4 \mathrm{~A}$ and many modes were overlapping each other, making spectroscopic measurements difficult.

Prior to using the semiconductor laser to look for gas absorption lines, a helium-neon laser was used to determine how far off the monochromator readings were from the true band centers passing through the monochromator. The helium-neon laser was shone directly onto the entrance slits of the monochromator with the multiple pass gas cell and the detector in the optical path. The laser output is at $6328.15 \AA$ and the true monochromator readings should therefore be $1316.87 \mathrm{~cm}^{-1}$ while observing the laser in the 12 th order, $1215.57 \mathrm{~cm}^{-1}$ while observing the laser in the 13 th order, and $1128.74 \mathrm{~cm}^{-1}$ while observing the laser in the 14 th order. The monochromator grating was scanned beginning at energies a few $\mathrm{cm}^{-1}$ above these values and the spectra of the throughput were recorded. Monochromator readings were $1317.32 \mathrm{~cm}^{-1}, 1215.26 \mathrm{~cm}^{-1}$, and $1127.55 \mathrm{~cm}^{-1}$ for the 12th, 13th, and 14 th orders respectively. Plotting true values versus monochromator readings, the monochromator reading in the region of 1180 $\mathrm{cm}^{-1}$ was determined to be about $.66 \mathrm{~cm}^{-1}$ less than the true value. Also, the intensity of the laser throughput was plotted versus the slit width and the point of zero intensity occurred at about $200 \mu$. . This means that the slits are actually closed at $200^{\circ} \mu$. Further spectroscopic experiments were conducted with the slits set at $900 \mu$. Therefore, using a value of $700 \mu$ and the equations relating to bandpass from the 
monochromator operating manual, the bandpass was calculated to be about $.43 \mathrm{~cm}^{-1}$. This is quite sufficient to separate one mode from another and allow adequate intensity to pass for reasonable detection.

C. Investigation of Gases Suitable for Spectroscopic Analysis Using the Semiconductor Laser

Various gases were tried next in the multiple pass gas cell in order to see if an absorption spectrum could be observed. The gases tried were chosen based on their well-known absorption lines which san be used as reference lines. $\mathrm{NH}_{3}$ and $\mathrm{CH}_{4}$ were tried first, but no absorption lines were observed for these gases in the two lowest energy modes of laser output which do not require that the laser be heated or that a current greater than $1.2 \mathrm{~A}$ be used.

When $\mathrm{N}_{2} \mathrm{O}$ was tried, absorption 1 ines were observed in both of the lowest energy modes. The spectrum in Figure 19 is an example of $\mathrm{N}_{2} \mathrm{O}$ absorption. This is actually a single beam transmission spectrum and the envelope which represents the actual laser output is sloping because of both the laser intensity and the slit function of the monochromator change. The absorption lines of the $\mathrm{N}_{2} \mathrm{O}$ gas which were observed readily fell into three categories based on absorption strengths, each category differing by about an order of magnitude. This compared favorably with the tabulated values obtained from reference 13. Not shown in Figure 19 is another absorption peak just to the left which is about ten times as strong as the peak on the right. 
Figure 19. Spectrum of $\mathrm{N}_{2} \mathrm{O}$ in the laser mode occurring at about $1183.6 \mathrm{~cm}^{-1}$. 
$\mathrm{N}_{2} \mathrm{O}$

7.5 Meters

2.63 torr

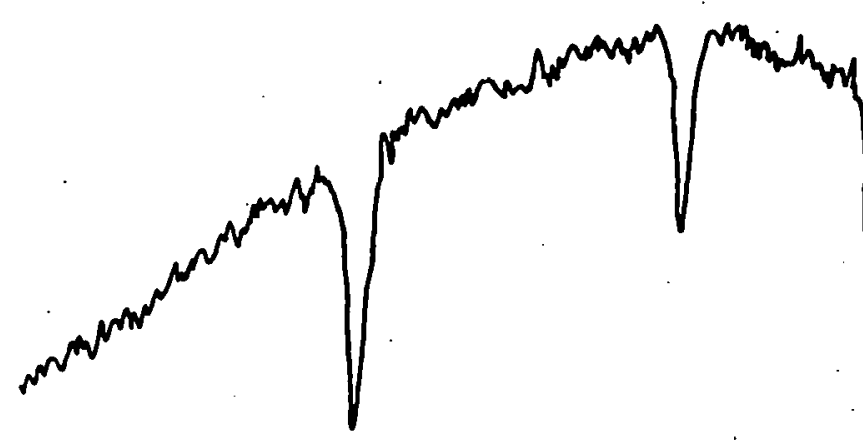

$1183.588 \mathrm{~cm}^{-1}$

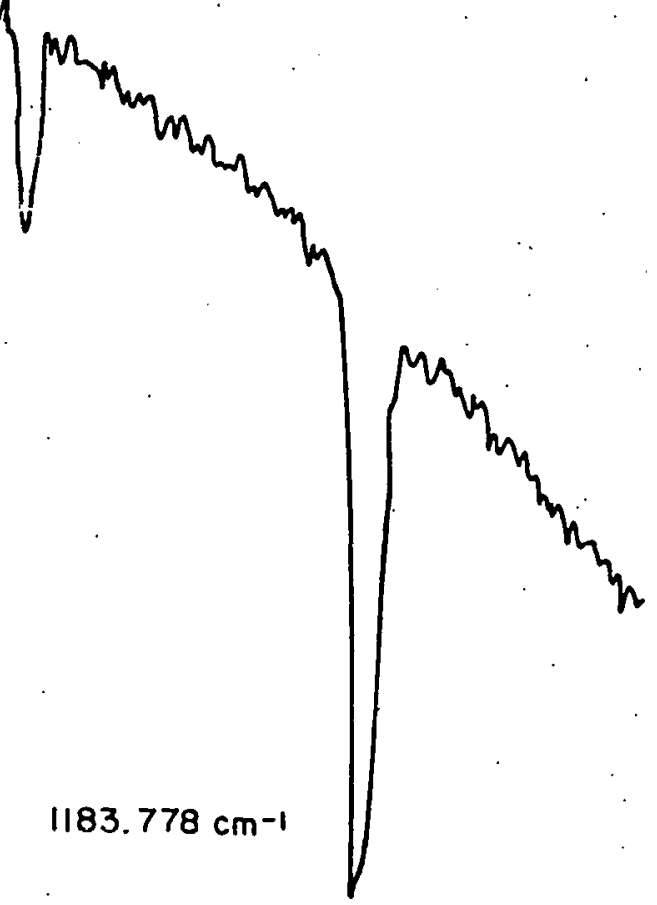

current 
Based on this categorization of peak intensities and knowing roughly where the region must be due to the monochromator calibration, the values for the absorption peaks were assigned as shown. The larger peak to the left (not shown) is at $1183.517 \mathrm{~cm}^{-1}$. The absorption lines not identified are most likely due to the isotopes other than ${ }^{14} N_{2}{ }^{16} 0$ as they were not listed in the reference. In this region of the laser scan, the rate of change of frequency with current is not uniform. Therefore, a tuning rate was established by fitting the absorption lines of $\mathrm{N}_{2} \mathrm{O}$ and the current at those lines to a second degree polynomial and then taking the first derivative as the tuning rate at each current location. Drawing a line across the base of the peak approximating the laser output with no absorption line and drawing a line across the bottom of the spectrum where no laser output would occur, a value for the absorption maximum of each of the two labeled peaks was obtained. From this value a half absorption maximum location was obtained and the full width at that location was measured. From this measured value and the tuning rate, full widths at half maximum of $2.68 \times 10^{-3} \mathrm{~cm}^{-1}$ for the $1183.588 \mathrm{~cm}^{-1}$ peak and $3.39 \times 10^{-3}$ $\mathrm{cm}^{-1}$ for the $1183.778 \mathrm{~cm}^{-1}$ peak were calculated. The theoretical Dopplerlimited value for $\mathrm{N}_{2} \mathrm{O}$ full widths at halfmaximum is $2.64 \times 10^{-3} \mathrm{~cm}^{-1}$ (18). This is reasonable when one considers that at a pressure of 2.63 torr, most lines should be at their Doppler limit. The $1183.517 \mathrm{~cm}^{-1}$ line was saturated and a half width could not be determined for it.

$\mathrm{N}_{2} \mathrm{O}$ absorption lines in the other low energy mode at the same pressure were $1181.858 \mathrm{~cm}^{-1}$ and $1181.988 \mathrm{~cm}^{-1}$ with full widths at half maximum of $3.78 \times 10^{-3} \mathrm{~cm}^{-1}$ and $4.47 \times 10^{-3} \mathrm{~cm}^{-1}$ respectively. $\mathrm{N}_{2} \mathrm{O} \mathrm{ab}-$ surption lines were readily observable in all the laser modes in the 
region from $1181 \mathrm{~cm}^{-1}$ to $1187 \mathrm{~cm}^{-1}$. From knowing the output versus the current for the two lowest energy modes, the difference in corresponding frequencies in each mode at a specific current was taken and this difference was $0.56 \mathrm{~cm}^{-1}$. Using the equation in Figure $2 \mathrm{c}\left(\Delta \mathrm{cm}^{-1}=1 / 2 \mathrm{~nL}\right)$ and measuring the crystal length as $.05 \mathrm{~cm}$, a value of 6.40 was calculated for the index of refraction.

The next gas tested was $\mathrm{H}_{2} \mathrm{~S}$. No absorption lines were observed in the two lowest energy modes or in any modes until two modes at about $1195.5 \mathrm{~cm}^{-1}$ and $1197 \mathrm{~cm}^{-1}$ appeared by heating the Andonian cryostat. The spectrum at about $1195.5 \mathrm{~cm}^{-1}$ is shown in Figure 20 . An $\mathrm{N}_{2} \mathrm{O}$ peak and this $\mathrm{H}_{2} \mathrm{~S}$ peak are very close together as shown in the spectrum. $A$ second $\mathrm{N}_{2} \mathrm{O}$ peak not observed in the figure is just to the left of the spectrum shown and was determined to be $1195.232 \mathrm{~cm}^{-1}$. Obtaining a tuning rate basedupon the two $\mathrm{N}_{2} \mathrm{O}$ values, the $\mathrm{H}_{2} \mathrm{~S}$ line was calculated to be at $1195.555 \mathrm{~cm}^{-1}$ with a full width at half maximum of $3.64 \times 10^{-3} \mathrm{~cm}^{-1}$.

The other $\mathrm{H}_{2} \mathrm{~S}$ line observed is shown in Figure 21. Two $\mathrm{N}_{2} \mathrm{O}$ I ines could not be found in this mode and therefore a tuning rate was assumed that was identical to the tuning rate in the previous mode where $\mathrm{H}_{2} \mathrm{~S}$ absorbed. From the tuning rate and the one known $\mathrm{N}_{2} \mathrm{O}$ line, a value of $1197.039 \mathrm{~cm}^{-1}$ and a full width at half maximum of $5.09 \times 10^{-3} \mathrm{~cm}^{-1}$ was determined. In Figure 22, the $\mathrm{H}_{2} \mathrm{~S}$ peak at $1197.039 \mathrm{~cm}^{-1}$ is shown at several different pressures. Although in the left-most spectrum the absorption line is saturated, one can see a definite decrease in the full width at half maximum as the pressure decreases. From similar spectra at 5.58 torr, 3.04 torr, and 1.8 torr of $\mathrm{H}_{2} \mathrm{~S}$, full widths at half maximum of $10.08 \times 10^{-3}$ 
Figure 20. Spectra of $\mathrm{N}_{2} \mathrm{O}$ and $\mathrm{H}_{2} \mathrm{~S}$ in the laser mode occurring at about $1195.5 \mathrm{~cm}^{-1}$. 


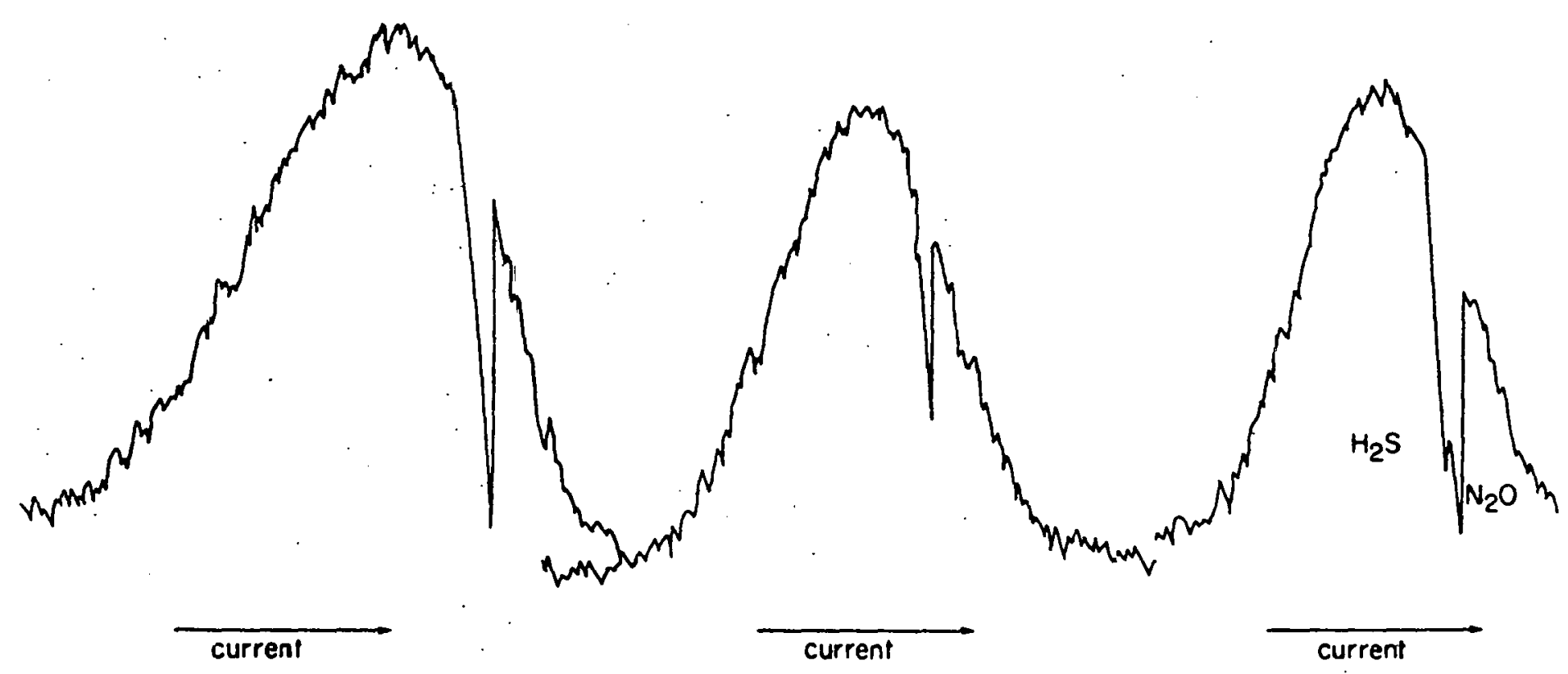


Figure 21. Spectrum of $\mathrm{N}_{2} \mathrm{O}$ and $\mathrm{H}_{2} \mathrm{~S}$ in the laser mode occurring at about $1197.0 \mathrm{~cm}^{-1}$. 


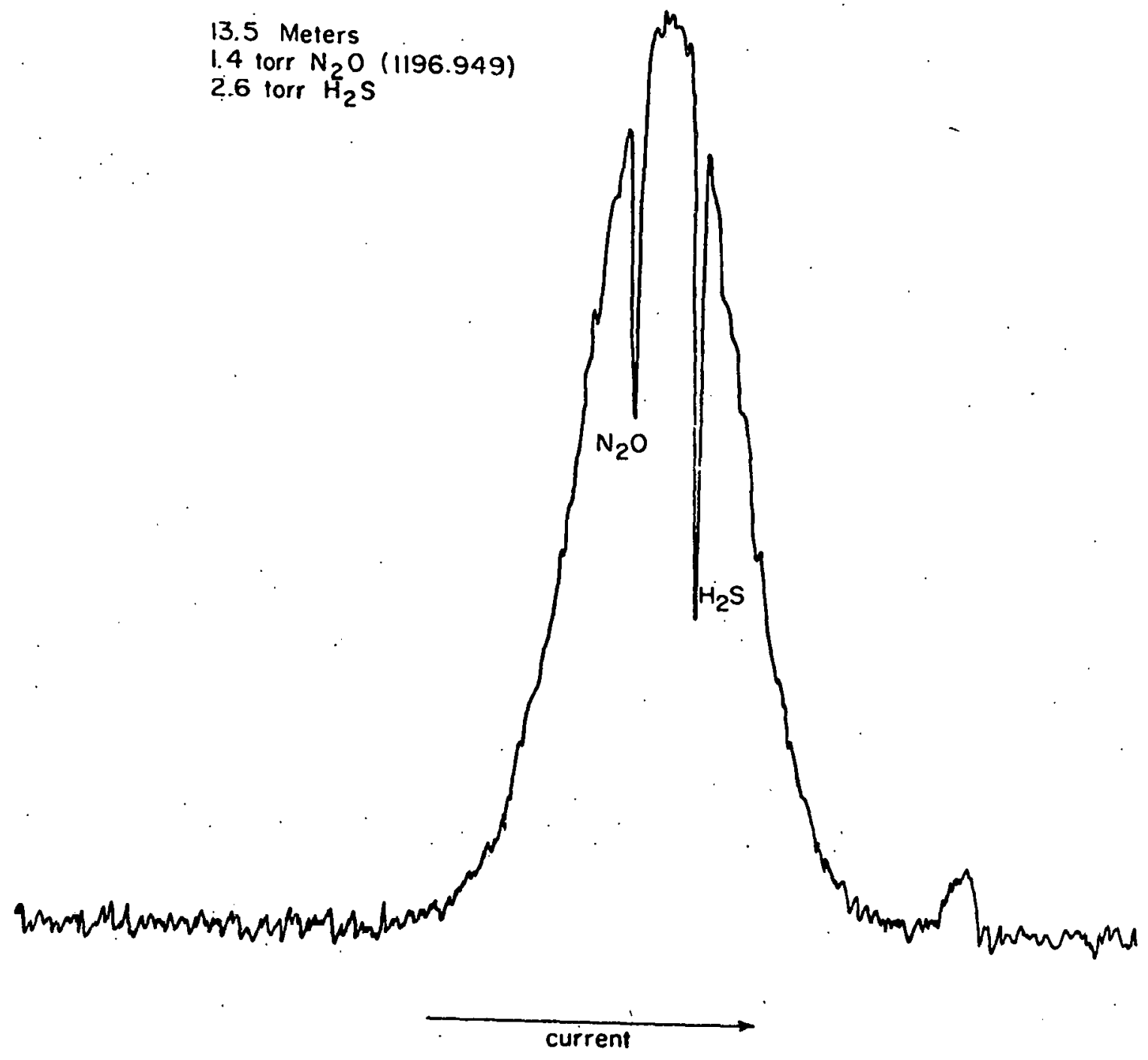


Figure 22. Spectra of the $\mathrm{H}_{2} \mathrm{~S}$ line occurring in the laser mode at about $1197.0 \mathrm{~cm}^{-1}$ at several different pressures: 


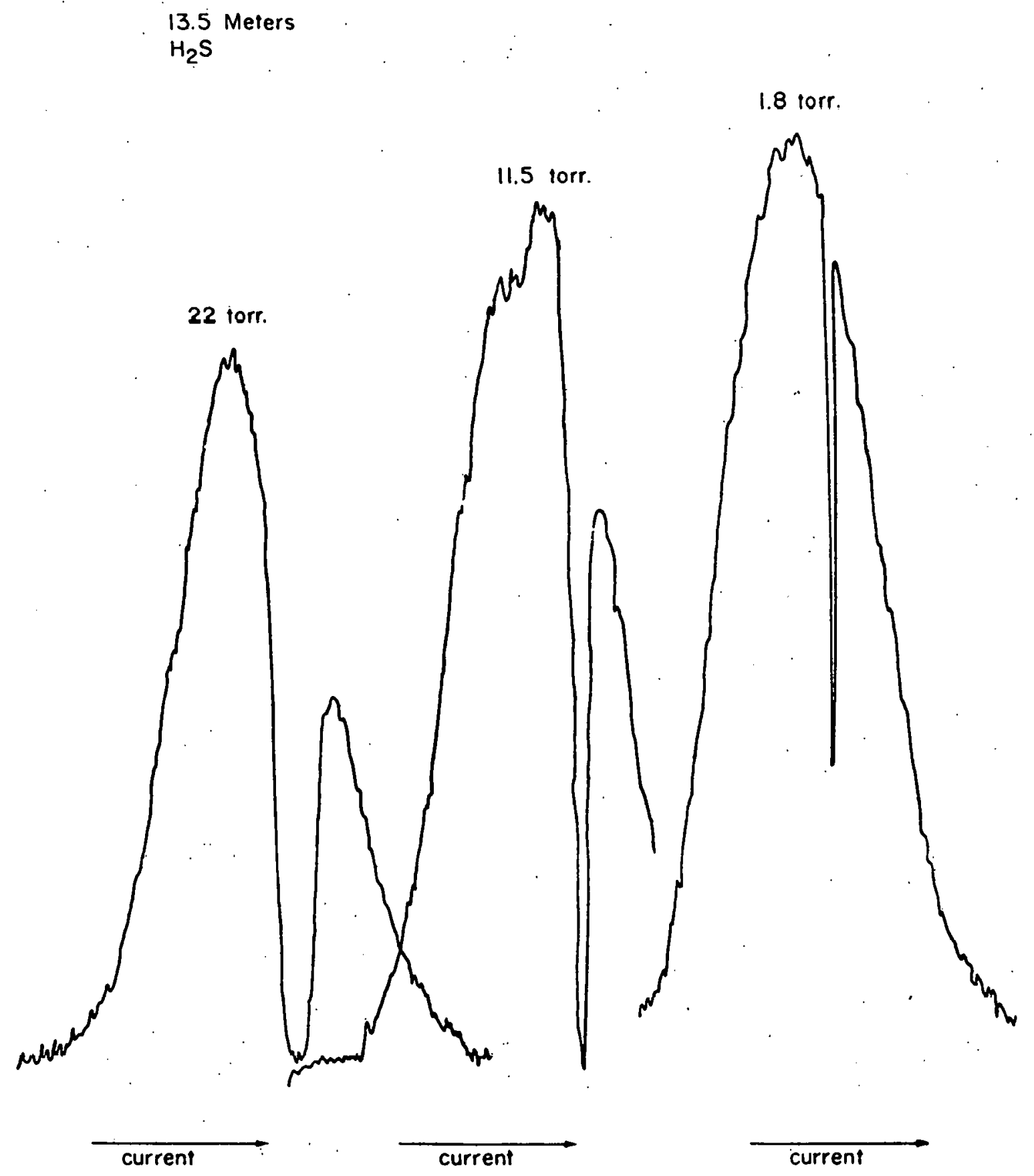


$\mathrm{cm}^{-1}, 7.81 \times 10^{-3} \mathrm{~cm}^{-1}$, and $4.54 \times 10^{-3} \mathrm{~cm}^{-1}$ respectively were obtained. From these points a self-broadening rate of $1.48 \times 10^{-3} \mathrm{~cm}^{-1} /$ torr was calculated.

- This method of determining half maximum locations and then measuring the width of the peak at these locations is not as exact as one would like and does not allow for instrument fluctuations. Also because of linewidth broadening, one cannot just use the absorption maximum for analytical measurements, but one needs to measure the total area under the absorption peak (intensity).

\section{Digitization and Computer Analysis of Experimental Data}

Because of the limitations just discussed in taking experimental measurements, it was decided that the analog information be digitized so that the information might be statistically treated to improve the results and obtain more exact parameters.

- An example of the digitized output is shown in Figure 23. This mode is centered at about $1180.1 \mathrm{~cm}^{-1}$. This new mode is lower in energy than the previously mentioned lowest energy mode and as stated earlier is most likely due to a large change in the adsorbed material on the laser. This output was generated by the program which reads the numbers off of paper tape (Appendix A). The numbers are punched on computer cards so that the numbers may be easily read into the computer by the second program which treats the data. Each run is separated on the computer cards by a flag card and four runs at a time are placed on a graph generated by the incremental plotter at the Computation Center. The timing rate for the 
Figure 23: Computerized spectra of $\mathrm{N}_{2} \mathrm{O}$ absorption lines and a transmission spectrum through an etalon at the laser mode occurring at about $1180.1 \mathrm{~cm}^{-1}$. 


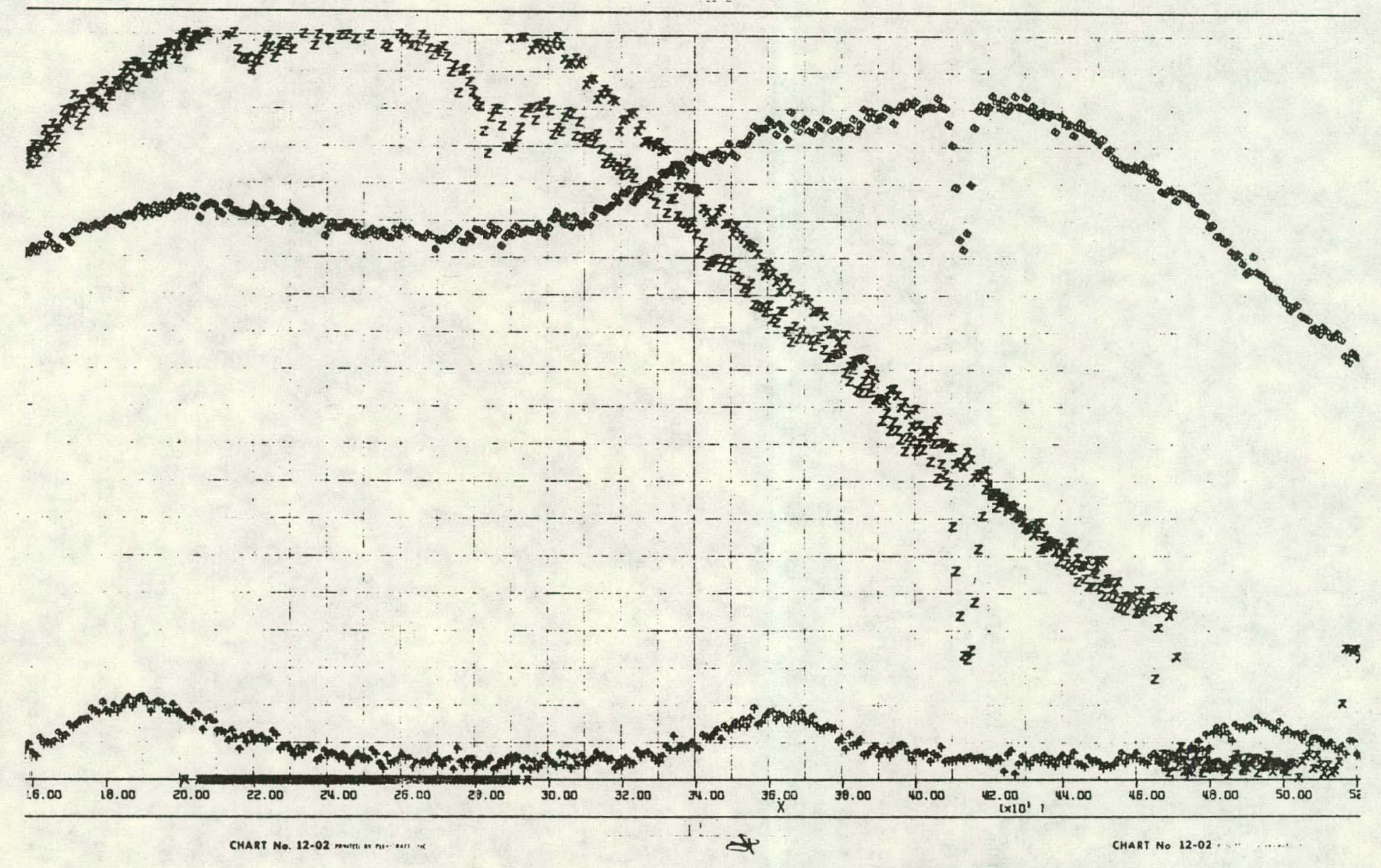


point sampling is about 1 per second and each run uses a different symbol to represent its points. This makes matching the computer graphs to the graphs from the $X-Y$ plotter easier. Two of the runs shown were allowed to exceed the one volt maximum into the $A / D$ converter and the output read zero when this occurred. The run along the bottom with the three humps is through a $2-\mathrm{cm}$ length germanium flat with $90 \%$ reflective coatings at $10 . \mu$ on each surface acting as a Fabry-Perot interferometer. The uneven locations of the three humps are an indication that the tuning rate is not constant with current. Using the equation $\Delta \mathrm{cm}^{-1}=1 / 2 \mathrm{~nL}$ for the mode separations of a Fabry-Perot interferometer, where $L=2.0 \mathrm{~cm}$ and $n=4.0$, the mode separation $\Delta \mathrm{cm}^{-1}$ of $0.063 \mathrm{~cm}^{-1}$ was obtained. The $\mathrm{N}_{2} \mathrm{O}$ lines are $1180.052 \mathrm{~cm}^{-1}$. for the left peak and $1180.206 \mathrm{~cm}^{-1}$ for the right peak for a difference of $.154 \mathrm{~cm}^{-1}$. This is a reasonable comparison as the interferometer has not been calibrated.

The Lorentzian line shape equation $K(\nu)=(S / \pi \gamma)\left[\left\{\left(\nu-\nu_{0}\right) / \gamma\right\}^{2}+1\right]^{-1}$ is a theoretical equation which describes the experimental shapes of pressure broadened absorption lines. $K(v)$ is the absorption at frequency $\nu, S$ is the intensity, $\gamma$ is the half width athalf absorption maximum, and $v_{0}$ is the frequency at the line center of the absorption peak. This equation is the form that the digitized absorption peaks are assumed to have by the statistical program which treats the experimental data points.

To begin, the programmer provides starting values, which are obtained by observation of the computer graphs generated by the paper tape reading program, for use by the statistical program. These values for each individual run include the number of points in the run, a beginning and an 
ending.point for a $0 \%$ transmission base line, the beginning and ending points for each absorption peak, a beginning and ending point for determining the $100 \%$ transmission curve, a first guess for each line center $\left(\nu_{0}\right)$, and a first guess for the half width at half maximum of each peak $(\gamma)$. Excluding the points within each peak, the rest of the points are fit to a 4th degree polynomial which determines the $100 \%$ transmission curve. This curve' is shown passing through the points in the envelope in Figure 24 . All of the transmission values are converted to absorption values and an iterative technique generates the area under the peak for a first guess. Using this value for $S$ in the Lorentzian equation and the first guesses for $\nu_{0}$ and $\gamma$, an absorption value $K(\nu)$ at each experimental point location is generated. A sum of the difference squared between each experimental point and the corresponding $K(\nu)$ for all experimental point locations is obtained. The values $S, v_{0}$, and $\gamma$ are independently changed by small increments with a sum of differences squared performed after each change. The $S, v_{0}$, and $\gamma$ values which generated the smallest sum of differences squared are the values which best fit the experimental results. These values are printed out, and $K(\nu)$ values generated from them are converted to transmission values and are represented by the continuous line through each experimental peak (Figure 24). This allows visual comparison of the accuracy of the $S, v_{0}$, and $\gamma$ values obtained with the experimental points.

\section{E. $\mathrm{N}_{2} \mathrm{O}$ Analysis}

Table 1 shows the experimental results of different runs of $\mathrm{N}_{2} \mathrm{O}$ and/ or air at different pressures for the $\mathrm{N}_{2} \mathrm{O}$ absorption 1 ines at 1180.052 $\mathrm{cm}^{-1}$ and $1180.206 \mathrm{~cm}^{-1}$. 
Figure 24. Computerized spectrum of $\mathrm{N}_{2} \mathrm{O}$ is the mode at $1180.1 \mathrm{~cm}^{-1}$ representing the results of a statistically treated run. 


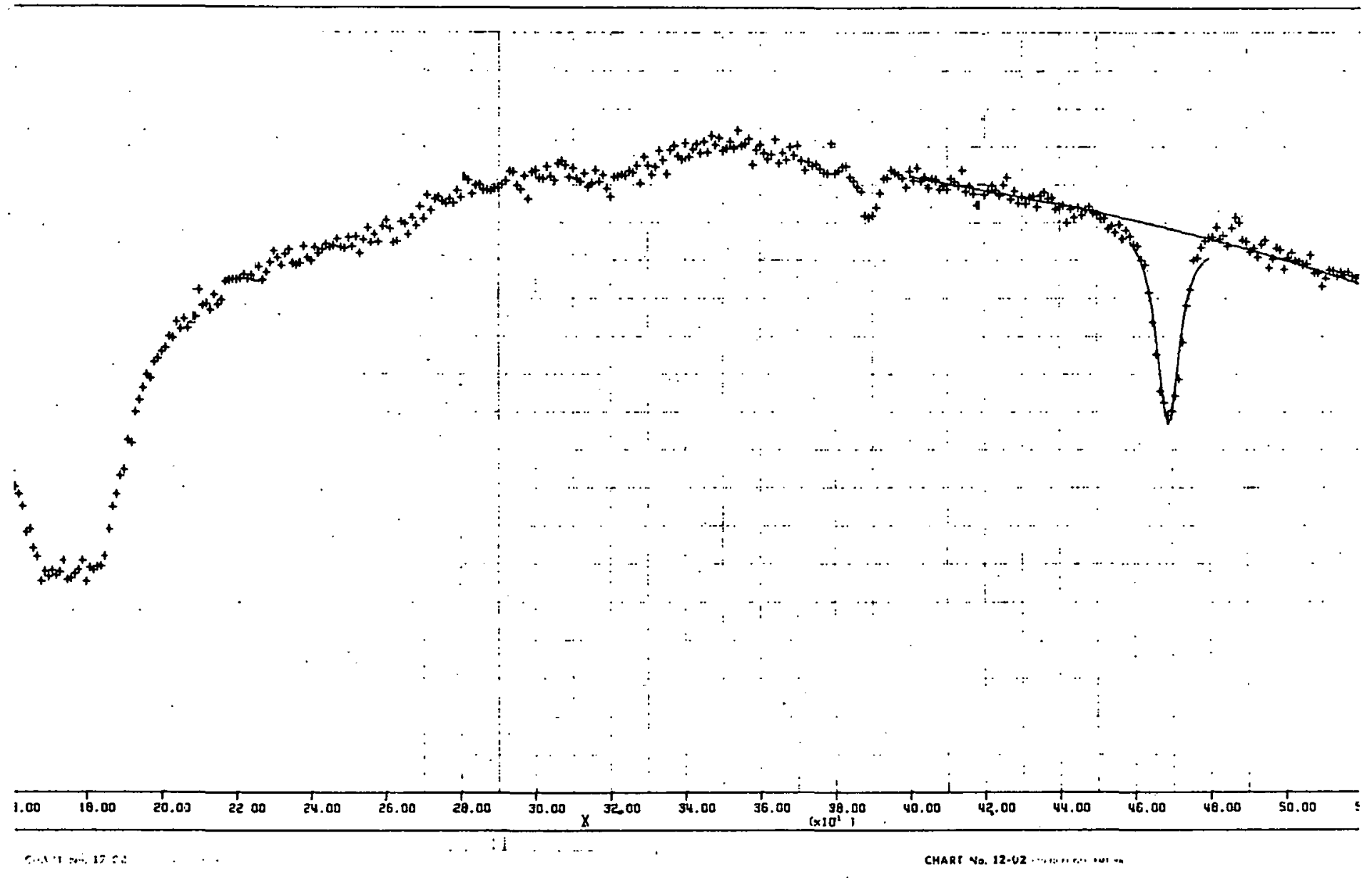


Table 1. $\mathrm{N}_{2} \mathrm{O}$ intensity data and line width broadened data

\begin{tabular}{|c|c|c|c|c|c|c|c|c|c|}
\hline \multicolumn{5}{|c|}{$\mathrm{N}_{2} \mathrm{O}\left(180.052 \mathrm{~cm}^{-1}\right)$} & \multicolumn{5}{|c|}{$\mathrm{N}_{2} \mathrm{O}\left(1180.206 \mathrm{~cm}^{-1}\right)$} \\
\hline$\overline{\mathrm{N}_{2} \mathrm{O}}$ & Air & Total & $S$ & $\gamma$ & $\mathrm{N}_{2} \mathrm{O}$ & Air & Total & $S$ & $\gamma$ \\
\hline \multicolumn{5}{|c|}{$150 \mathrm{~cm}$ path length } & \multicolumn{5}{|c|}{$150 \mathrm{~cm}$ path length } \\
\hline .08 & .09 & .17 & 10.61 & 2.20 & 4.23 & - & 4.23 & 19.75 & 1.85 \\
\hline .08 & 3.91 & 3.99 & 10.36 & 3.00 & 3.12 & - & 3.12 & 14.02 & 1.90 \\
\hline .08 & 9.44 & 9.52 & 9.79 & 4.00 & 2.03 & - & 2.03 & 9.42 & 1.90 \\
\hline .08 & 18.92 & 19.0 & 9.35 & 5.80 & 1.06 & - & 1.06 & 5.11 & 2.05 \\
\hline .08 & 31.42 & 31.5 & 7.22 & 8.20 & 5.04 & - & 5.04 & 23.58 & 1.85 \\
\hline 4.71 & - & 4.11 & 283.05 & 2.85 & 5.04 & 4.19 & 9.23 & 23.41 & 2.70 \\
\hline \multirow[t]{7}{*}{5.14} & - & 5.14 & .328 .05 & 2.90 & 5.04 & 17.96 & 23.0 & 19.15 & 5.00 \\
\hline & & & & & 5.04 & 32.96 & 38.0 & 16.80 & 8.00 \\
\hline & & & & & 7.44 & - & 7.44 & 33.30 & 2.65 \\
\hline & & & & & 5.30 & - & 5.30 & 23.98 & 2.30 \\
\hline & & & & & 5.30 & 4.49 & 9.79 & 24.72 & 3.00 \\
\hline & & & & & 5.30 & 14.2 & 19.5 & 21.54 & 4.60 \\
\hline & & & & & 1.25 & 8.46 & 9.71 & 4.84 & 3.00 \\
\hline
\end{tabular}


Table 1. (Continued)

\begin{tabular}{|c|c|c|c|c|c|c|c|c|c|c|}
\hline \multicolumn{5}{|c|}{$\mathrm{N}_{2} \mathrm{O}\left(1180.206 \mathrm{~cm}^{-1}\right)$} & \multicolumn{6}{|c|}{$\mathrm{N}_{2} \mathrm{O}\left(11180.052 \mathrm{~cm}^{-1}\right)$} \\
\hline $\mathrm{N}_{2} \mathrm{O}$ & $\mathrm{SF}_{6}$ & Total & $S$ & $\gamma$ & Temp & $\mathrm{N}_{2} \mathrm{O}$ & $\mathrm{SF}_{\epsilon}$ & Total & $S$ & $\gamma$ \\
\hline \multicolumn{5}{|c|}{$150 \mathrm{~cm}$ path length } & \multicolumn{6}{|c|}{$10 \mathrm{~cm}$ path length } \\
\hline 2.93 & 4.93 & 7.86 & 12.57 & 2.5 & room & .90 & 60.8 & 61.70 & 10.44 & 15.70 \\
\hline 1.75 & 1.14 & 2.89 & 7.57 & 2.3 & room & .90 & 60.8 & 61.70 & 9.09 & 12.65 \\
\hline 1.75 & 2.75 & 4.50 & 6.43 & 2.3 & $-121^{\circ} \mathrm{C}$ & .46 & 4.8 & 5.26 & 14.61 & 3.49 \\
\hline 1.75 & 5.00 & 6.75 & 6.85 & 2.8 & $-120^{\circ} \mathrm{C}$ & .47 & 5.4 & 5.87 & 12.69 & 4.53 \\
\hline 1.75 & 6.70 & 8.45 & 7.25 & 3.5 & $-116^{\circ} \mathrm{C}$ & .48 & 8.5 & 8.98 & 14.52 & 7.12 \\
\hline 2.84 & 6.70 & 9.54 & 9.05 & 2.7 & $-111^{\circ} \mathrm{C}$ & .49 & 15.2 & 15.69 & 14.69 & 8.64 \\
\hline 2.84 & 14.66 & 17.5 & 8.91 & 4.1 & $-105^{\circ} \mathrm{C}$ & .51 & 29.8 & 30.31 & 12.90 & 11.04 \\
\hline \multirow[t]{3}{*}{2.84} & 24.66 & 27.5 & 7.99 & 5.6 & $-101^{\circ} \mathrm{C}$ & .53 & 35.3 & 35.83 & 14.15 & 13.80 \\
\hline & & & & & $-94^{\circ} \mathrm{C}$ & .55 & 36.8 & 37.35 & 13.08 & 12.22 \\
\hline & & & & & $-85^{\circ} \mathrm{C}$ & .57 & 38.6 & 39.17 & 15.83 & 13.10 \\
\hline
\end{tabular}

Note 1: Concentrations are in torr.

Note 2: $S$ is in computer-units.

Note 3: $\gamma$ is in computer-units. 
- Air is used to broaden the linewidths so that a true atmospheric broadened linewidth can be obtained for use in air pollution studies. Figures 25 and 26 show plots of intensity $(S)$ versus $\mathrm{N}_{2} \mathrm{O}$ gas pressure and plots of HWHM versus total pressure $\left(\mathrm{N}_{2} \mathrm{O}\right.$ gas and air) for the values in Table 1 .

For the graphs of intensity $(S)$ versus $\mathrm{N}_{2} \mathrm{O}$ gas pressure, all the points shown, except where noted, are fitted to a straight line by a least squares technique, and the $r^{2}$ value is a measure of the degree of correlation of the points. $r^{2}$ equal to 1 is complete correlation and $r^{2}$ equal to zero is no correlation. The slope of the resulting equation which defines the line is the intensity (S) per torr of $\mathrm{N}_{2} \mathrm{O}$ in a $150 \mathrm{~cm}$ path length. How close the intercept is to zero and the $r^{2}$ value indicate how good the results are. For the graphs of HWHM( $\gamma$ ) versuis total pressure, all points which include the pressure broadening gas, except where noted, are fitted to a straight line by a least squares technique, as was done for the intensity versus $\mathrm{N}_{2} \mathrm{O}$ gas pressure graphs. The slope of the resulting equation which defines the 1 ine is the HWHM versus pressure in torr.

However the units if $S$ and $\gamma$ include the computer-units which are part of the computer generated outputs. These computer-units must be converted to $\mathrm{cm}^{-1}$ before the $S$ and $\gamma$ values are usefur.

To do this a computer spectrum was chosen which contained the following identified lines in one scan. The $1180.052 \mathrm{~cm}^{-1}$ line had a computer-unit value of 252 , the $1180.128 \mathrm{~cm}^{-1}$ line had a computer-unit value of 472 , and the $1180.206 \mathrm{~cm}^{-1}$ line had a computer-unit value of 616 . No studies were 
Figure $2 b$. Graphs of intensity (S) versus $\mathrm{N}_{2} \mathrm{O}$ concentration in torr and $\operatorname{HWHM}(\gamma)$ versus total pressure $\left(\mathrm{N}_{2} \mathrm{O}\right.$ and air) at $1180.052 \mathrm{~cm}^{-1}$. The line generated in the intensity versus $\mathrm{N}_{2} \mathrm{O}$ concentration graph is an average of the intensity values at 4.11 torr $\mathrm{N}_{2} \mathrm{O}$ and at 5.14 torr $\mathrm{N}_{2} \mathrm{O}$. 


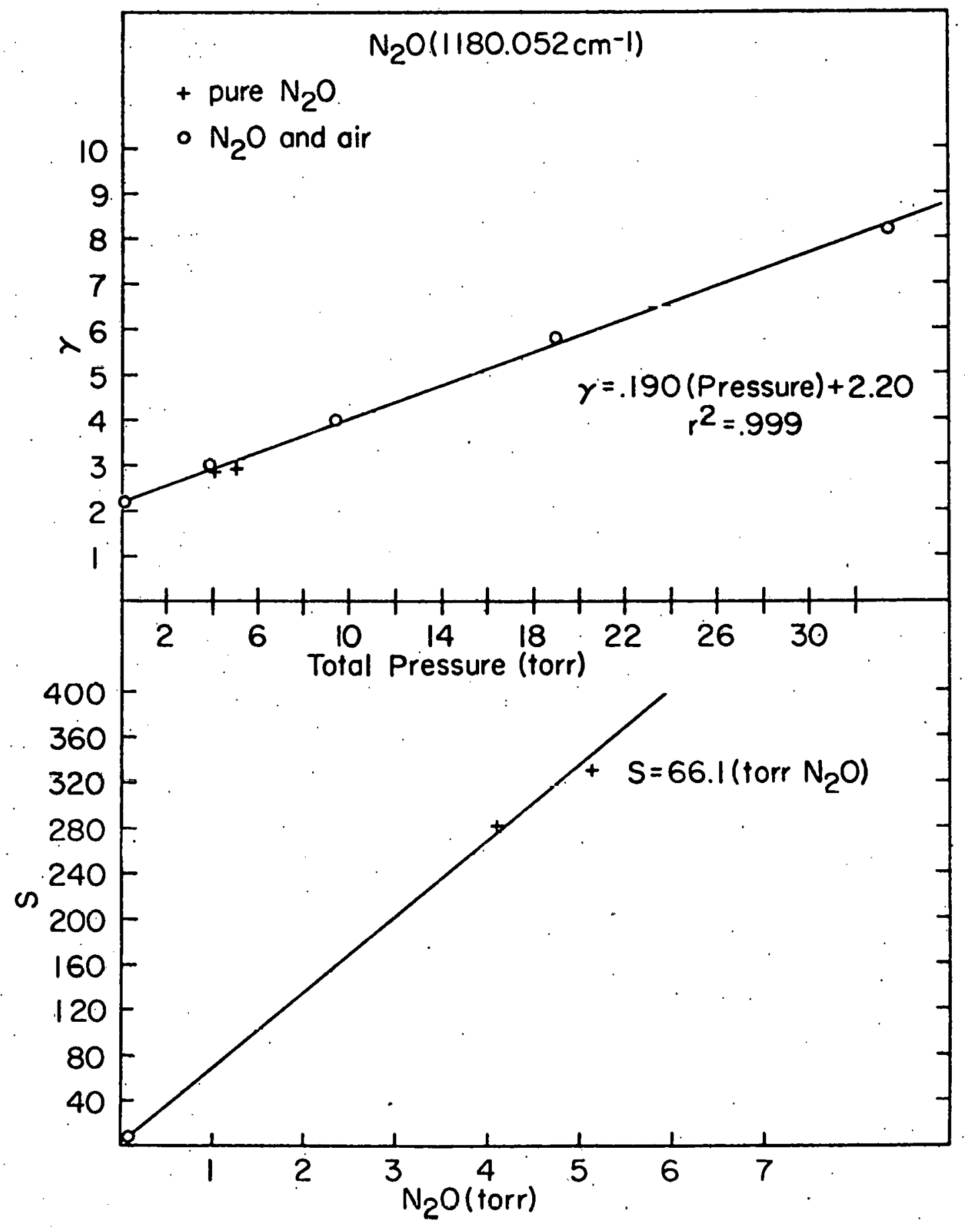


Figure 26. Graphs of intensity (S) versus $\mathrm{N}_{2} \mathrm{O}$ concentration in torr and $H W H M(\gamma)$ versus total pressure $\left(\mathrm{N}_{2} \mathrm{O}\right.$ and air) at $1180.206 \mathrm{~cm}^{-1}$. 


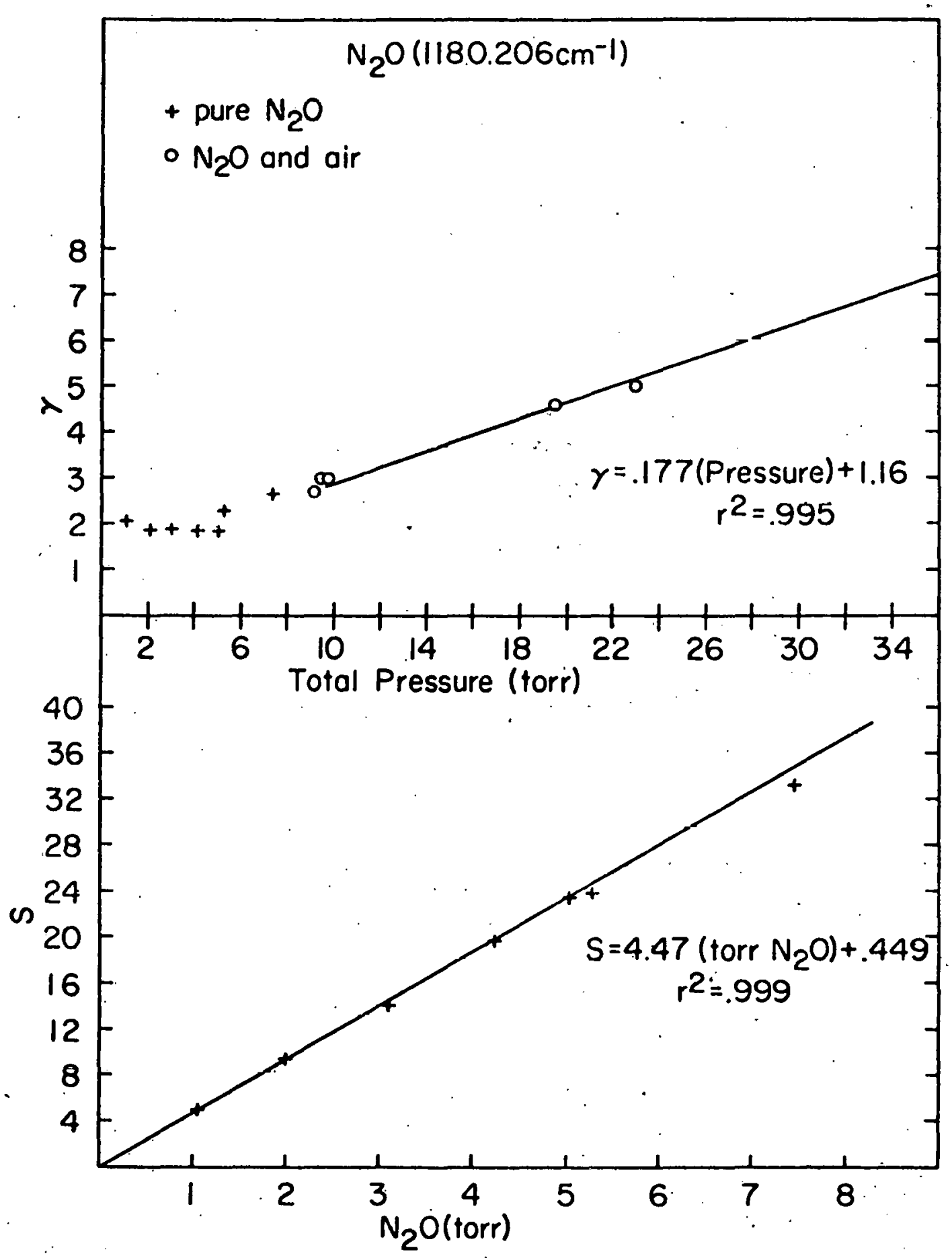


done on the $1180.128 \mathrm{~cm}^{-1}$ line because the intensity was too small, but the peak was easily observable at about 3 torr of $\mathrm{N}_{2} \mathrm{O}$ pressure or greater.

Fitting these sets of numbers to a second degree polynomial, one obtains the equation

$$
\begin{aligned}
\text { frequency }\left(\mathrm{cm}^{-1}\right) & =5.39 \times 10^{-7} \text { (computer-units) }-4.48 \times 10^{-5} \\
\text { (computer-units) } & +1180.029
\end{aligned}
$$

The derivative of frequency with respect to computer-units is

frequency $\left(\mathrm{cm}^{-1}\right) /$ computer-units $=10.8 \times 10^{-7}$ (computer-units)

$-4.43 \times 10^{-5}$

Using this equation, a value of $2.27 \times 10^{-4} \mathrm{~cm}^{-1} /$ computer-units at the $1180.052 \mathrm{~cm}^{-1}$ line and a value of $6.19 \times 10^{-4} \mathrm{~cm}^{-1} /$ computer-units at the $1180.206 \mathrm{~cm}^{-1}$ line were obtained. The limiting values for the $\gamma$ at low pressure were observed from Figures 25 and 26 to be about 2.90 computerunits for the $1180.052 \mathrm{~cm}^{-1}$ line and 1.90 for the $1180.206 \mathrm{~cm}^{-1}$ line. Because the limiting half width for each line should be similar, a conversion from the computer-units to $\mathrm{cm}^{-1}$ using the appropriate conversion values above should give similar values. In fact, the values obtained $\left(6.58 \times 10^{-4} \mathrm{~cm}^{-1}\right.$ for the $1180.052 \mathrm{~cm}^{-1}$ line and $1.18 \times 10^{-3} \mathrm{~cm}^{-1}$ for the $1180.206 \mathrm{~cm}^{-1}$ line) are not a reasonable comparison.

Using the same computer graph and values tried above with the second degree polynomial fit, a series of three straight line slopes ranging from the $1180.052 \mathrm{~cm}^{-1}$ line to $1180.206 \mathrm{~cm}^{-1}$ line were tried. The first slope in the region of the $1180.052 \mathrm{~cm}^{-1}$ line was determined from the computerunit values for the $1180.052 \mathrm{~cm}^{-1}$ line and the $1180.123 \mathrm{~cm}^{-1}$ line. 
$\left(1180.128 \mathrm{~cm}^{-1}-1180.052 \mathrm{~cm}^{-1}\right) /(472-252)=3.45 \times 10^{-4} \mathrm{~cm}^{-1} /$

computer-unit (Slope 1)

Slope three was determined from the computer-unit values for the 1180.128 $\mathrm{cm}^{-1}$ line and the $1180.206 \mathrm{~cm}^{-1}$ line.

$\left(1180.206 \mathrm{~cm}^{-1}-1180.128 \mathrm{~cm}^{-1}\right) /(616-472)=5.42 \times 10^{-4} \mathrm{~cm}^{-1} /$

computer-unit (Slope 3)

Slope 2 in the region of the $1180.128 \mathrm{~cm}^{-1}$ line was arbitrarily chosen to be half-way between slopes 1 and 3 .

$\left(3.45 \times 10^{-4} \mathrm{~cm}^{-1} /\right.$ computer-unit $+5.42 \times 10^{-4} \mathrm{~cm}^{-1} /$ computer-unit $) / 2$

$=4.44 \times 10^{-4} \mathrm{~cm}^{-1} /$ computer-unit (Slope 2)

The computer-unit value at which slope 1 changes to slope 2 was chosen to be 400 computer-units. The computer-unit value at which slope 2 changes to slope 3 was then determined by calculation to be 543 computer-units.

Using the same method as above for checking the reasonableness of the slopes, $1.00 \times 10^{-3} \mathrm{~cm}^{-1}$ for the $1180.052 \mathrm{~cm}^{-1}$ line and $1.03 \times 10^{-3} \mathrm{~cm}^{-1}$ for the $1180.206 \mathrm{~cm}^{-1}$ line were obtained. This is a much better comparison.

Using these better slope values for converting from computer-units to $\mathrm{cm}^{-1}$ and the slope values from the $S$ versus $\mathrm{N}_{2} \mathrm{O}$ pressure and $\gamma$ versus total pressure graphs, one can now obtain intensities in $\mathrm{cm}^{-1}$ and half widths is $\mathrm{cm}^{-1}$. For example, .190 computer-units/torr from Figure 25 is multiplied by slope 1 to give $6.56 \times 10^{-5} \mathrm{~cm}^{-1} /$ torr. At one atmosphere (760 torr) the value is $5.00 \times 10^{-2} \mathrm{~cm}^{-1} /$ atmosphere. To obtain the intensity per molecule in the units of reference $18\left(\mathrm{~cm}^{-1} / \mathrm{molecule} \mathrm{cm}^{-2}\right)$, the following conversions are done. From Figure 25 a value of 66.1 computer- 
units $/ 1$ torr $/ 150 \mathrm{~cm}$ is converted to $\mathrm{cm}^{-1}$ and STP from $296^{\circ} \mathrm{K}$.

$\frac{(66.1 \text { computer-units })\left(3.45 \times 10^{-4} \mathrm{~cm}^{-1} / \text { computer-unit) }\right.}{(1 \text { torr })(150 \mathrm{~cm})} \times \frac{760 \text { torr }}{1 \text { atmos }}$

$$
\begin{aligned}
& \times \frac{296^{\circ} \mathrm{K}}{273^{\circ} \mathrm{K}}=\frac{.125 \mathrm{~cm}^{-1}}{(\text { atmos }-\mathrm{cm})} \\
& \frac{.125 \mathrm{~cm}^{-1}}{\text { atmos }-\mathrm{cm}} \times \frac{1 \text { atmos-cm }}{2.69 \times 10^{19} \text { molecules } \mathrm{cm}^{-2}}=\frac{4.66 \times 10^{-21} \mathrm{~cm}^{-1}}{\text { molecule } \mathrm{cm}^{-2}}
\end{aligned}
$$

In a similar manner values for the $1180,206 \mathrm{~cm}^{-1}$ line were obtained and all results are shown in Table 2 .

In order to see how other gases compare with air in broadening $\mathrm{N}_{2} \mathrm{O}$ gas, $\mathrm{SF}_{6}$ broadening studies on $\mathrm{N}_{2} \mathrm{O}$ gas were also conducted at room temperature on the $1180.206 \mathrm{~cm}^{-1}$ line (Figure 27) and at low temperature on the $1180.052 \mathrm{~cm}^{-1}$ line (Figure 28). The tabulated results are in Table 1 and the calculated results are in iable 2.

\section{F. $\mathrm{SO}_{2}$ Analysis}

Similar experiments were conducted on $\mathrm{SO}_{2}$ in order to obtain intensities and air broadened half widths. Sample computer generated spectra are shown in Figures 29 and 30 and are identified as peaks 1 through 10. Figure 30 also shows the two $\mathrm{N}_{2} \mathrm{O}$ lines at $1180.052 \mathrm{~cm}^{-1}$ and $1180.206 \mathrm{~cm}^{-1}$ that were generated by placing a $10-\mathrm{cm}$ gas cell with about 3 torr $\mathrm{N}_{2} \mathrm{O}$ in the optical path at the same time that the Wilks' gas cell held the $\mathrm{SO}_{2}$. The spectra were computer fitted to give the best paraileters $S, \gamma$, and $\nu_{0}$ as was done with the $\mathrm{N}_{2} \mathrm{O}$ spectra eralier. These results are shown in Table 3 and graphs of $\mathrm{SO}_{2}$ peaks $1,2,3,5$, and 6 are plotted in Figures 31 through 35 . The graphs were also statistically treated the same as the $\mathrm{N}_{2} \mathrm{O}$ graphs. Peak 4 is not plotted because the 
Table 2. $\mathrm{N}_{2} \mathrm{O}$ intensities and atmospheric linewidths

\begin{tabular}{|c|c|c|c|c|c|c|}
\hline \multirow[b]{2}{*}{ Temperature } & \multirow{2}{*}{$\begin{array}{l}\text { Absorption } \\
\text { line }\left(\mathrm{cm}^{-1}\right)\end{array}$} & \multicolumn{2}{|c|}{ HWHM $\left(\mathrm{cm}^{-1} / \mathrm{atmos}\right)$} & \multirow{2}{*}{$\begin{array}{l}\text { Broadening } \\
\text { agen: }\end{array}$} & \multicolumn{2}{|c|}{$\begin{array}{c}\text { Intensity }\left(\mathrm{cm}^{-1} /\right. \\
\left.\text { molecule } \mathrm{cm}^{-2}\right)\end{array}$} \\
\hline & & Experimental & Reference & & Experimental & Reference \\
\hline Room $\left(\sim 296^{\circ} \mathrm{K}\right)$ & 1180.052 & $5.00 \times 10^{-2}$ & $8.50 \times 10^{-2}$ & Air & $4.66 \times 10^{-21}$ & $6.29 \times 10^{-21}$ \\
\hline Room & 1130.206 & $7.29 \times 10^{-2}$ & $7.90 \times 10^{-2}$ & Air & $4.95 \times 10^{-22}$ & $4.84 \times 10^{-22}$ \\
\hline Room & 1180.206 & $6.63 \times 10^{-2}$ & - & $\mathrm{SF}_{6}$ & - & - \\
\hline $153-183^{\circ} \mathrm{K}$ & 1180.052 & $6.71 \times 10^{-2}$ & - & $\mathrm{SF}_{6}$ & - & - \\
\hline
\end{tabular}


Figure 27. Graph of $\operatorname{HWHM}(\gamma)$ versus total pressure $\left(\mathrm{N}_{2} \mathrm{O}\right.$ and $\left.\mathrm{SF}_{6}\right)$ at $1180.206 \mathrm{~cm}^{-1}$. Only the points with 2.84 torr of $\mathrm{N}_{2} \mathrm{O}$ are included in the straight line plot. 


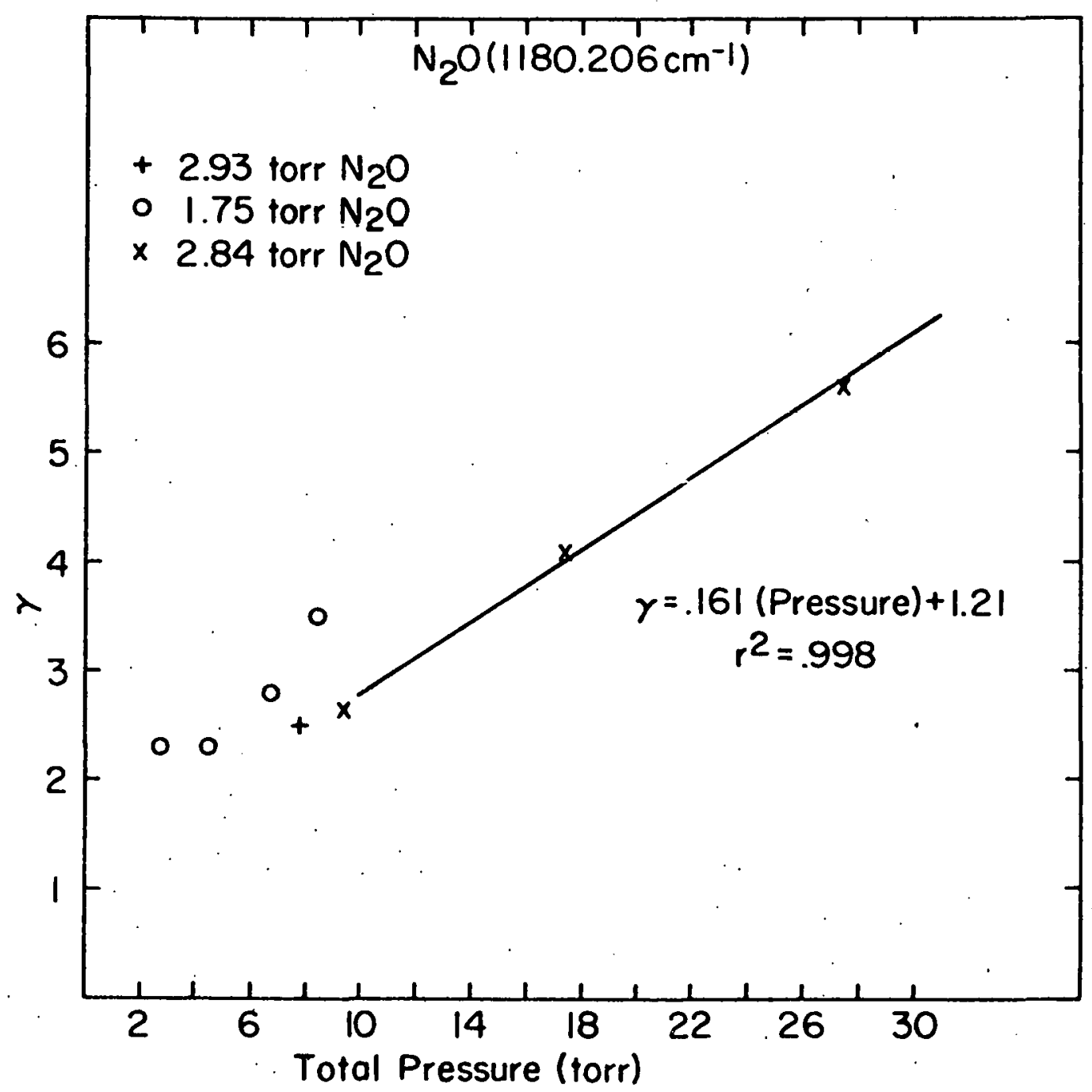


Figure 28. Graph of $\operatorname{HWHM}(\gamma)$ versus total pressure $\left(\mathrm{N}_{2} \mathrm{O}\right.$ and $\left.\mathrm{SF}_{6}\right)$ at low temperature at $1180.052 \mathrm{~cm}^{-1}$. 


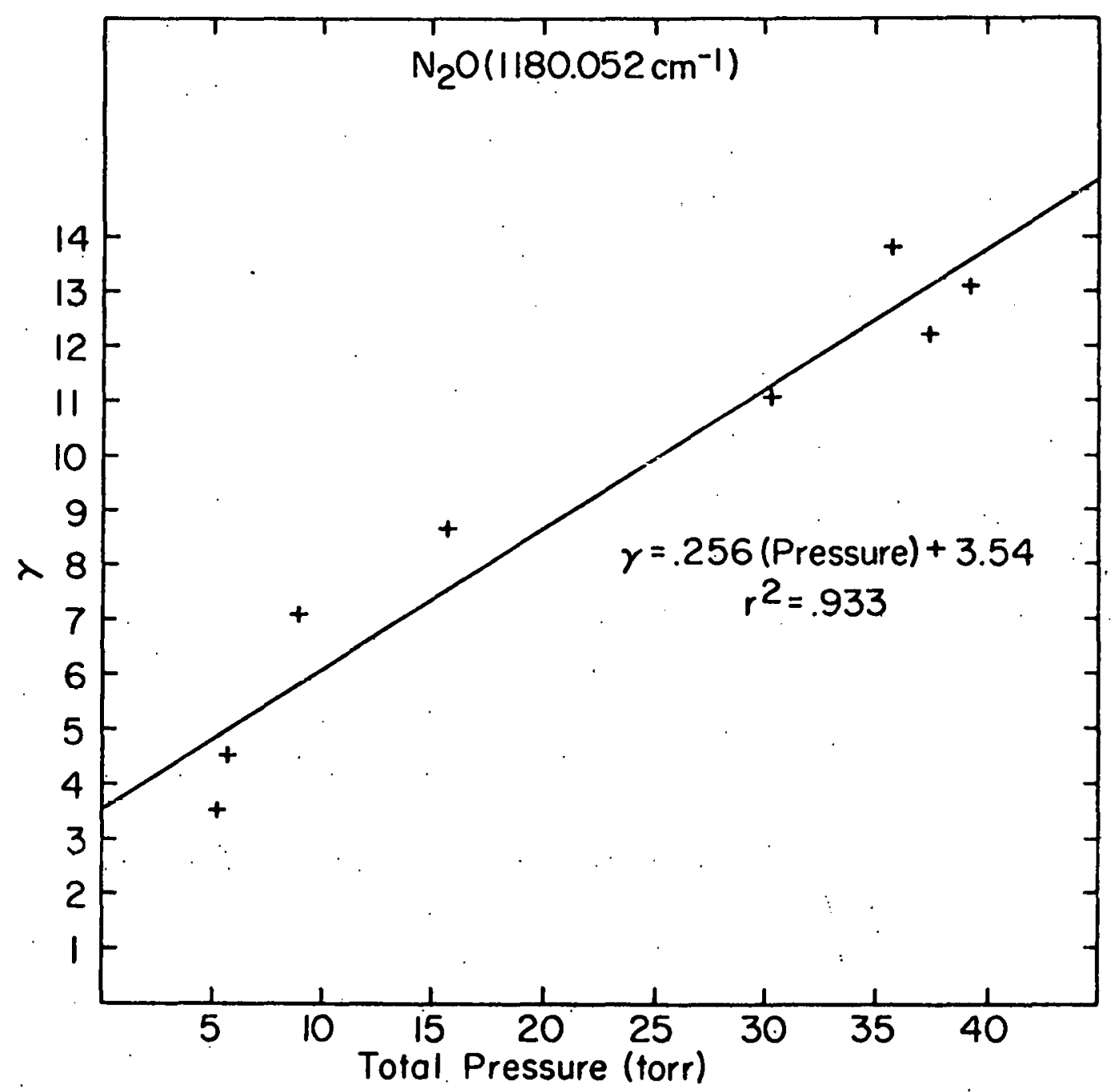


Figure 29. Computerized spectrum of $\mathrm{SO}_{2}$ in the mode at about $1180.1 \mathrm{~cm}^{-1}$ representing the results of a statistically treated run. 


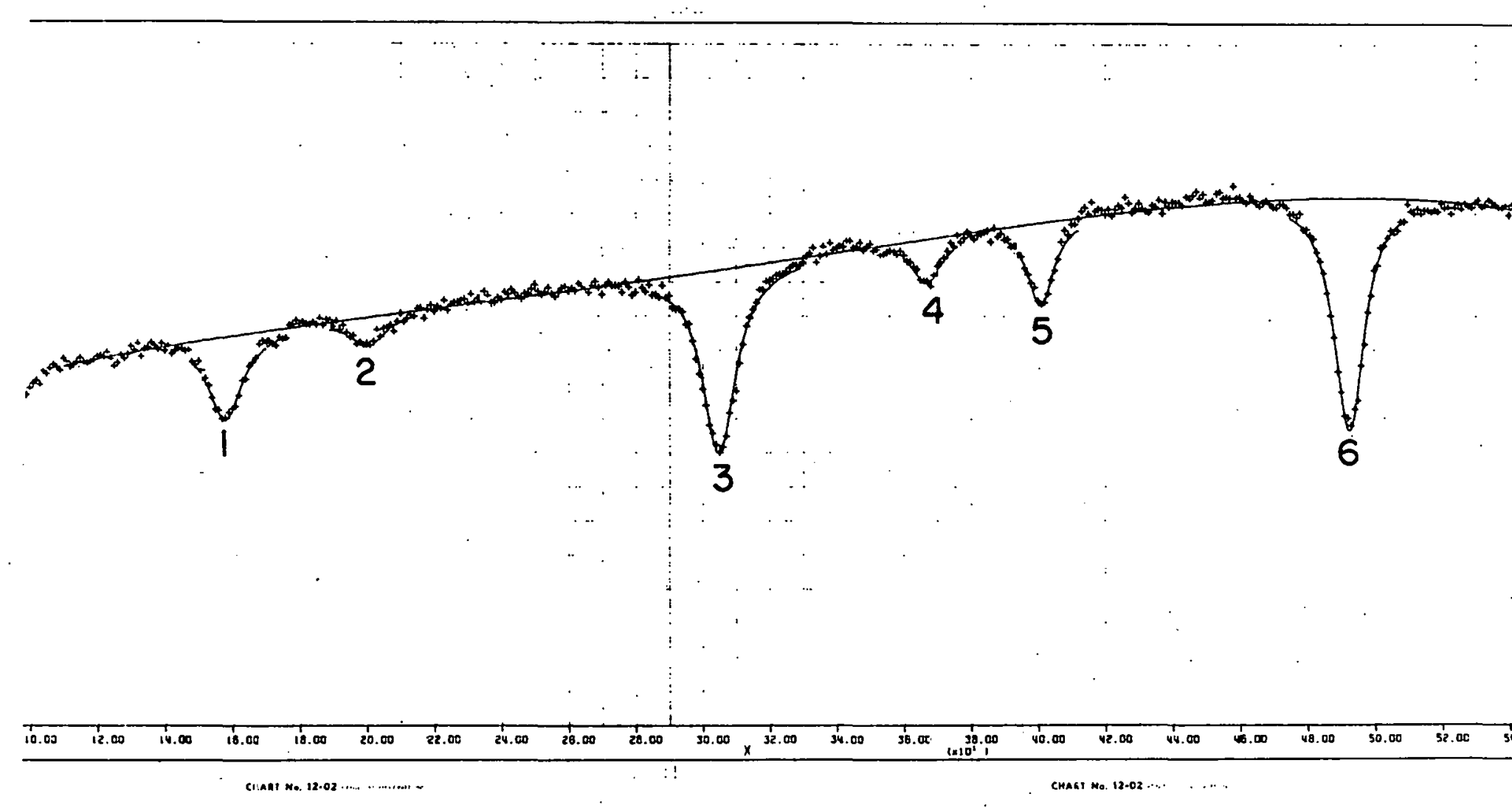

$=$ 
Figure 30. Computerized spectrum of $\mathrm{SO}_{2}$ with $\mathrm{N}_{2} \mathrm{O}$ reference 1 ines in the mode at about $1180.1 \mathrm{~cm}^{-1}$ representing the results of a statistically treated run. 


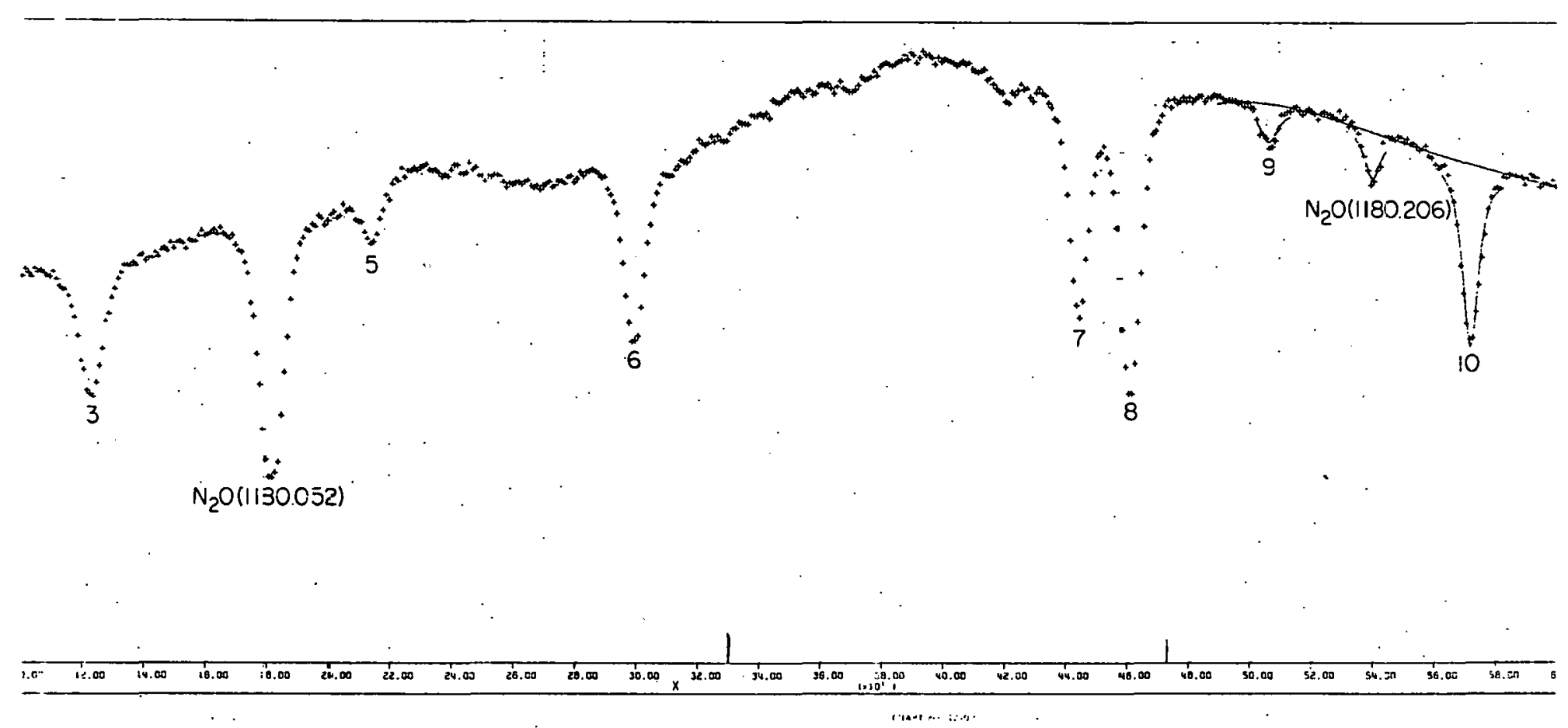


114

Table 3. $\mathrm{SO}_{2}$ intensity data and linewidth broadened data

\begin{tabular}{|c|c|c|c|c|c|c|c|c|c|}
\hline $\mathrm{SO}_{2}$ & Air & Total & $S$ & $\gamma$ & $\mathrm{SO}_{2}$ & Air & Total & $S$ & $\gamma$ \\
\hline \multicolumn{5}{|c|}{ Peak \#1 } & 1.99 & - & 1.99 & 36.10 & 5.3 \\
\hline 3.85 & - & 3.85 & - & 5.5 & 1.91 & - & 1.91 & 35.25 & 4.0 \\
\hline 1.77 & - & 1.77 & 16.59 & 3.6 & 1.91 & - & 1.91 & 33.39 & 3.4 \\
\hline 0.83 & - & 0.83 & 7.08 & 2.8 & 1.91 & - & 1.91 & 30.76 & 3.3 \\
\hline 0.83 & 3.73 & 4.56 & 8.13 & 4.2 & 0.44 & - & 0.44 & 9.21 & 2.2 \\
\hline 0.83 & 6.79 & 7.62 & 7.76 & 5.0 & 0.44 & 0.93 & 1.37 & 9.27 & 2.5 \\
\hline 0.83 & 9.14 & 9.97 & 7.267 & 5.4 & 0.71 & - & 0.71 & 12.93 & 2.25 \\
\hline 1.99 & - & 1.99 & 17.27 & 3.8 & 0.71 & 1.38 & 2.09 & 11.64 & 2.7 \\
\hline 1.91 & - & 1.91 & 16.82 & 3.7 & 0.71 & 4.33 & 5.04 & 12.00 & 3.7 \\
\hline 2.81 & - & 2.81 & 22.72 & 4.0 & 0.71 & 9.18 & 9.89 & 9.50 & 4.5 \\
\hline 1.91 & - & 1.91 & 16.48 & 3.5 & 0.71 & 10.59 & 19.30 & 7.58 & 6.3 \\
\hline \multicolumn{5}{|c|}{ Peak \#2 } & \multicolumn{5}{|c|}{ Peak \#4 } \\
\hline 3.85 & - & 3.85 & 8.56 & 5.5 & 0.83 & - & 0.83 & .64 & 2.3 \\
\hline 1.77 & - & 1.77 & 4.84 & 4.0 & 0.83 & 3.73 & 4.56 & 1.78 & 3.3 \\
\hline 0.83 & - & 0.83 & 2.30 & 2.2 & 0.83 & 6.79 & 7.62 & 2.20 & 5.2 \\
\hline 0.83 & 3.73 & 4.56 & 1.24 & 2.5 & 0.83 & 9.14 & 9.97 & 1.48 & 4.0 \\
\hline 0.83 & 6.79 & 7.62 & 2.16 & 6.2 & 1.99 & - & 1.99 & 1.87 & 4.4 \\
\hline 0.83 & 9.14 & 9.97 & 1.76 & 7,4 & \multicolumn{5}{|c|}{ Peak \#5 } \\
\hline 1.99 & - & 1.99 & 4.34 & 3.4 & & & rean $\pi J$ & & \\
\hline 2.81 & - & 2.81 & 6.32 & 4.0 & 0.83 & - & 0.83 & 4.26 & 2.6 \\
\hline 1.91 & - & 1.91 & 4.77 & 4.0 & 0.83 & 3.73 & 4.56 & 3.98 & 3.4 \\
\hline 1.91 & - & 1.97 & 4.95 & 3.7 & 0.83 & 6.79 & 7.62 & 3.91 & 4.2 \\
\hline \multirow{2}{*}{\multicolumn{5}{|c|}{ Peak \#3 }} & 0.83 & 9.14 & 9.97 & 3.52 & 4.8 \\
\hline & & & & & 1.99 & - & 1.99 & 9.33 & 3.2 \\
\hline 1.77 & - & 1.77 & 24.72 & 3.9 & 1.91 & - & 1.91 & 8.97 & 3.0 \\
\hline 0.83 & - & 0.83 & 17.25 & 2.7 & 1.91 & - & 1.91 & 8.98 & 3.2 \\
\hline 0.83 & 3.73 & 4.56 & 16.49 & 3.6 & 0.44 & - & 0.44 & 2.21 & 2.5 \\
\hline 0.83 & 6.79 & 7.62 & 15.68 & 4.55. & 0.44 & 0.93 & 1.37 & 2.08 & 2.7 \\
\hline 0.83 & 9.14 & 9.97 & 15.76 & 5.6 & 0.71 & - & 0.71 & 3.52 & 2.3 \\
\hline
\end{tabular}


Table 3. (Continued)

\begin{tabular}{|c|c|c|c|c|c|c|c|c|c|}
\hline $\mathrm{SO}_{2}$ & Air & Total & S & $\gamma$ & $\mathrm{SO}_{2}$ & Air & Total & $S$ & $r$ \\
\hline 0.71 & 1.38 & 2.09 & 3.01 & 2.45 & \multirow{4}{*}{0.44} & & Peak \#7 & \multirow{4}{*}{7.04} & \multirow{4}{*}{1.6} \\
\hline 0.71 & 4.33 & 5.04 & 2.63 & 3.1 & & - & 0.44 & & \\
\hline 0.71 & 9.18 & 9.89 & 3.53 & 4.9 & & \multirow{2}{*}{\multicolumn{2}{|c|}{ Peak \#8 }} & & \\
\hline \multirow[t]{2}{*}{0.71} & 18.59 & 19.30 & 2.84 & 7.1 & & & & & \\
\hline & & Peak \#6 & & & 0.44 & - & 0.44 & 11.47 & 1.5 \\
\hline 0.83 & - & 0.83 & 14.96 & 2.1 & & & Peak \#9 & & \\
\hline 0.83 & 3.73 & 4.56 & 16.13 & 3.4 & 0.44 & 5.27 & 5.71 & 1.27 & 3.8 \\
\hline 0.83 & 6.79 & 7.62 & 14.22 & 4.1 & 0.44 & 8.06 & 8.50 & 1.13 & 4.6 \\
\hline 0.83 & 9.14 & 9.97 & 13.45 & 4.6 & \multicolumn{5}{|c|}{ Peak \#10 } \\
\hline 1.99 & - & 1.99 & 32.09 & 4.3 & \multirow{4}{*}{$\begin{array}{l}0.44 \\
0.44\end{array}$} & & & & \\
\hline 1.91 & - & 1.91 & 27.47 & 3.6 & & 5.27 & 5.71 & 6.09 & 2.6 \\
\hline 1.91 & - & 1.91 & 25.90 & 3.3 & & 8.06 & $8.50^{\circ}$ & 5.92 & 3.3 \\
\hline 0.44 & - & 0.44 & 7.50 & 1.9 & & & & & \\
\hline $0: 44$ & 0.93 & 1.37 & 7.37 & 2.1 & & & & & \\
\hline
\end{tabular}

Note 1: Concentrations are in torr.

Note 2: $S$ is in computer-units.

Note 3: $\gamma$ is in computer-units.

Note 4: All path lengths are $150 \mathrm{~cm}$. 
Figure 31. Graphs of intensity (S) versus $\mathrm{SO}_{2}$ concentration in torr and $\mathrm{HWHM}(\gamma)$ versus total pressure $\left(\mathrm{SO}_{2}\right.$ and air $)$ for $\mathrm{SO}_{2}$ peak 1 . 


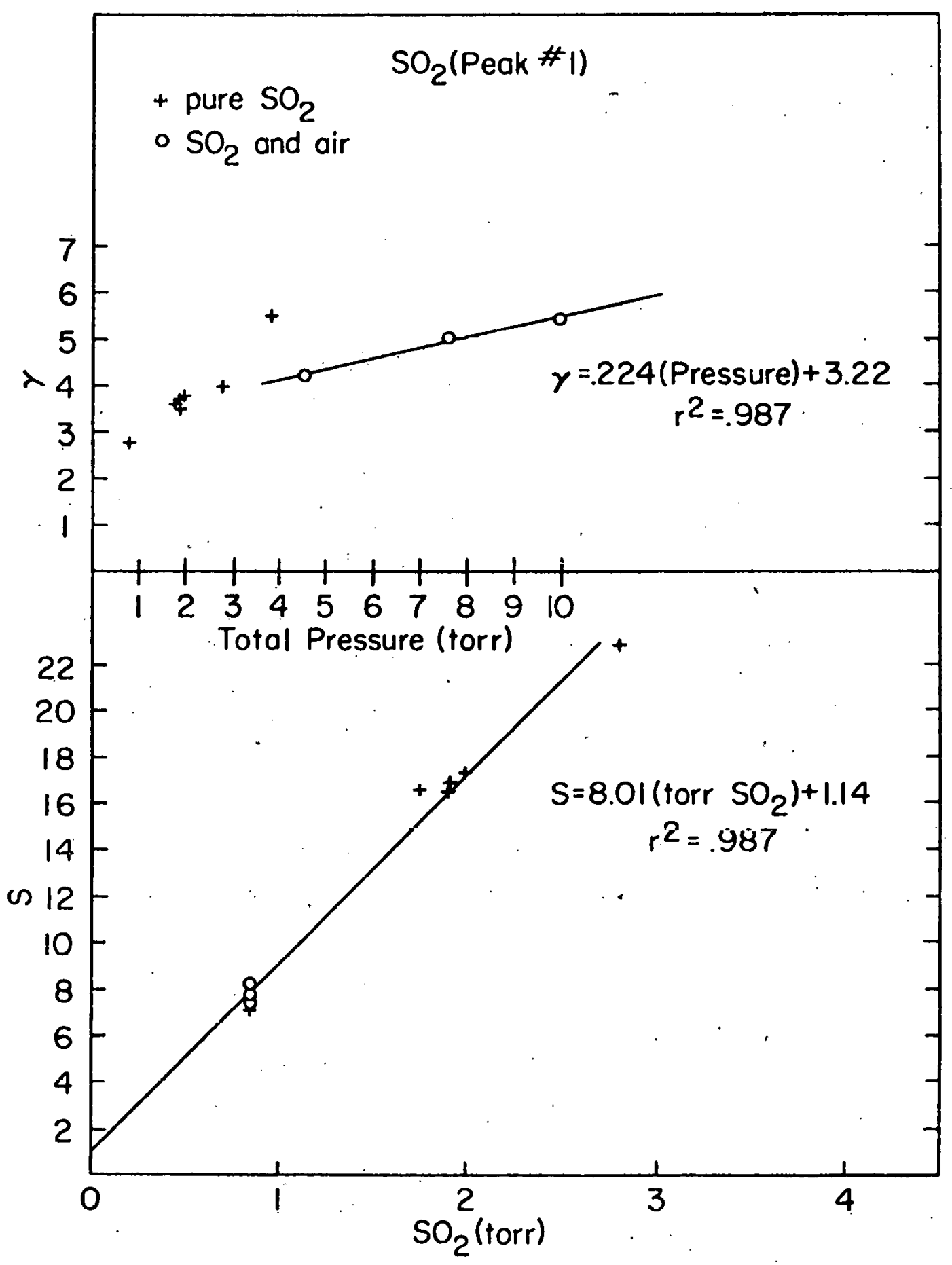


Figure 32. Graphs of intensity (S) versus $\mathrm{SO}_{2}$ concentration torr and $\mathrm{H} W H M(\gamma)$ versus total pressure $\left(\mathrm{SO}_{2}\right.$ and air $)$ for $\mathrm{SO}_{2}$. peak 2 . Only the two air broadened points through which the straight line passes are used to determine the line in the HWHM( $\gamma)$ versus total pressure graph. 


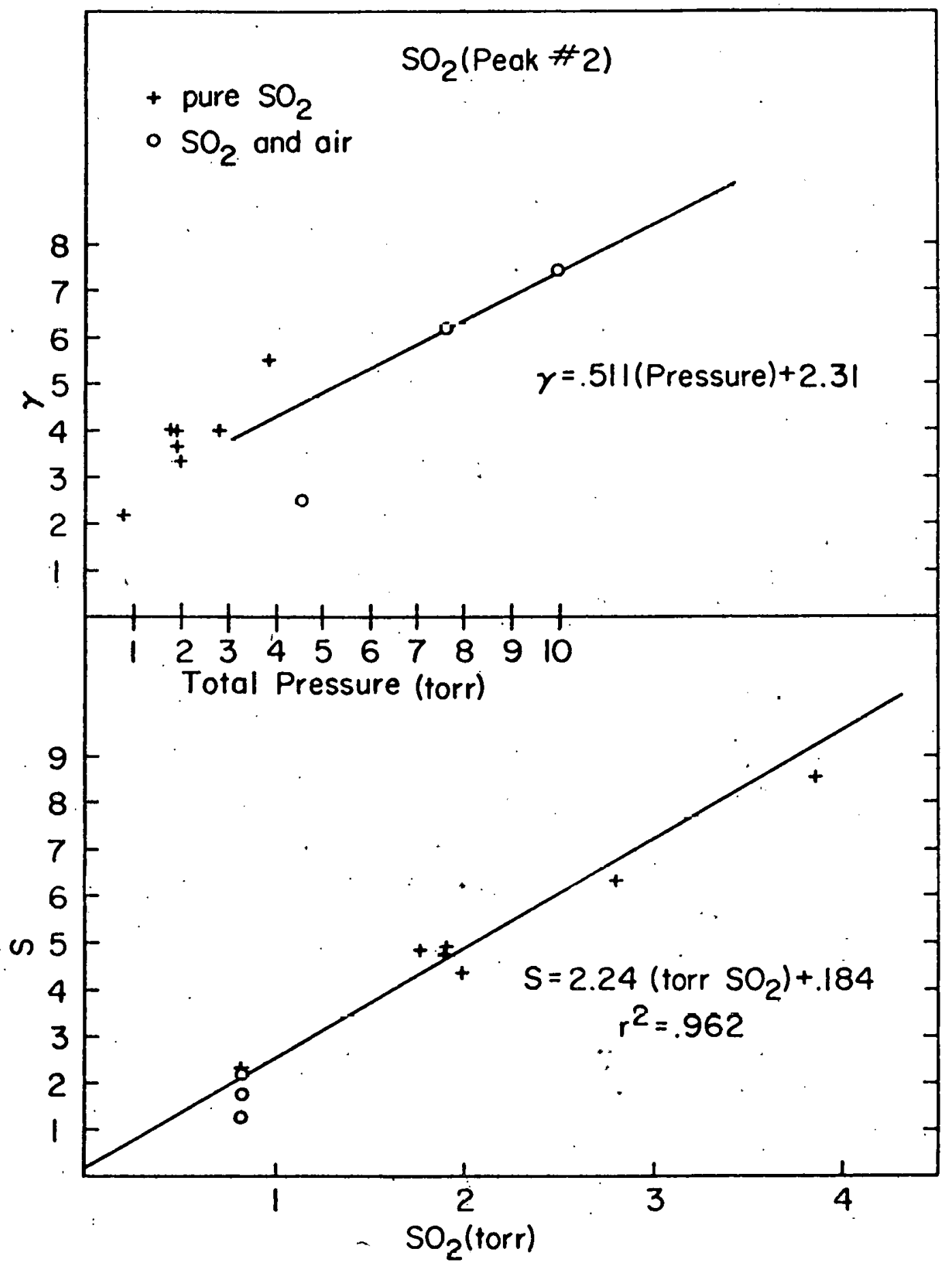


Figure 33. Graphs of intensity $(\mathrm{S})$ versus $\mathrm{SO}_{2}$ concentration in torr and $\mathrm{HWHM}(\gamma)$ versus total pressure ( $\mathrm{SO}_{2}$ and air) for $\mathrm{SO}_{2}$ peak 3 . Only the six air broadened points through which the straight line passes are used to determine the line in the $\operatorname{HWHM}(\gamma)$ versus total pressure graph. 


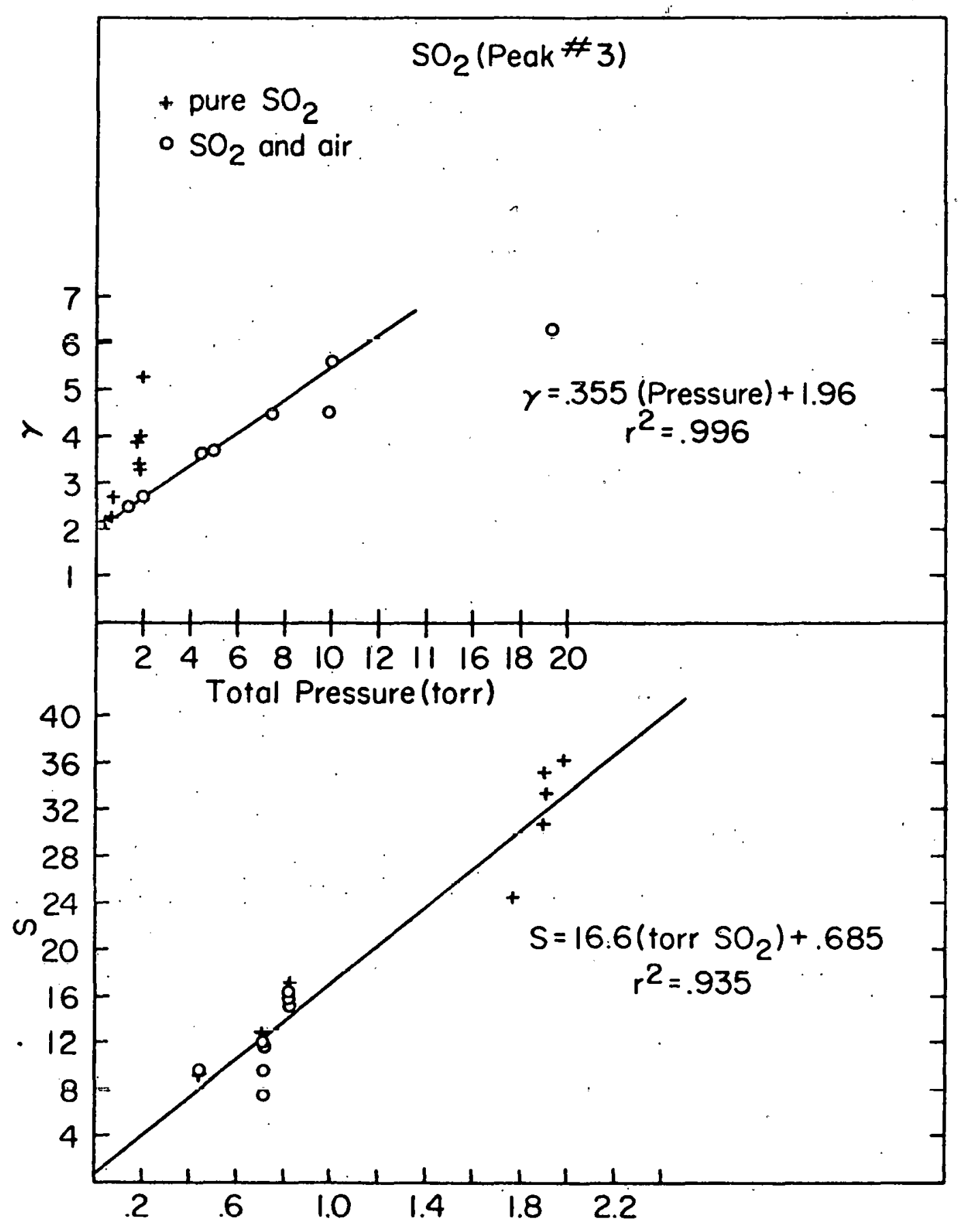


Figure 34. Graphs of intensity (S) versus $\mathrm{SO}_{2}$ concentration in torr and $\mathrm{HWHM}(\gamma)$ versus total pressure $\left(\mathrm{SO}_{2}\right.$ and air) for $\mathrm{SO}_{2}$ peak 5 . 


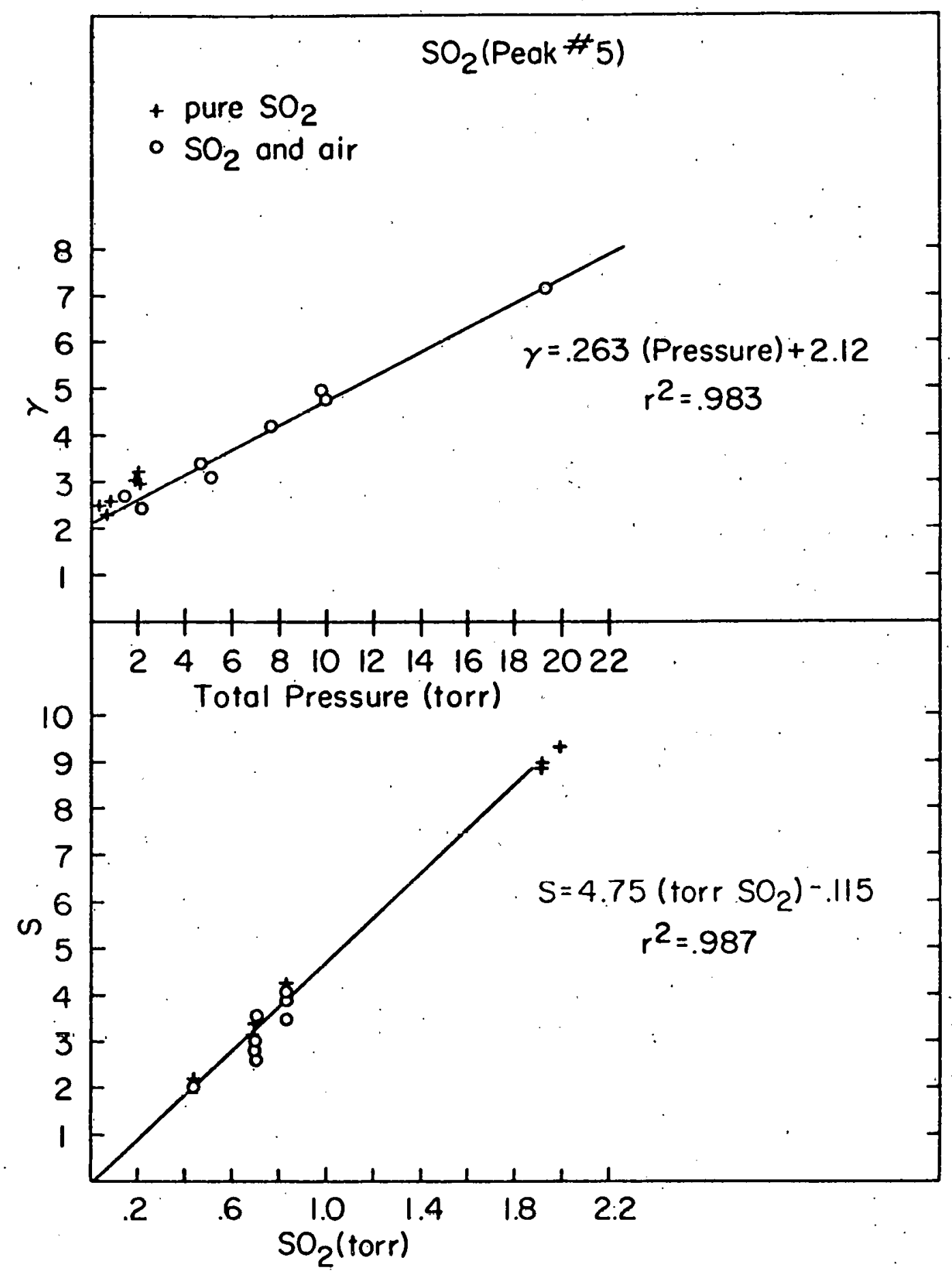


Figure 35. Graphs of intensity (S) versus $\mathrm{SO}_{2}$ concentration in torr and $\operatorname{HWHM}(\gamma)$ versus total pressure $\left(\mathrm{SO}_{2}\right.$ and air) for $\mathrm{SO}_{2}$ peak 6 . Only the three air broadened points through which the straight line passes are used to determine the line in the HWHM( $\gamma)$ versus total pressure graph. 


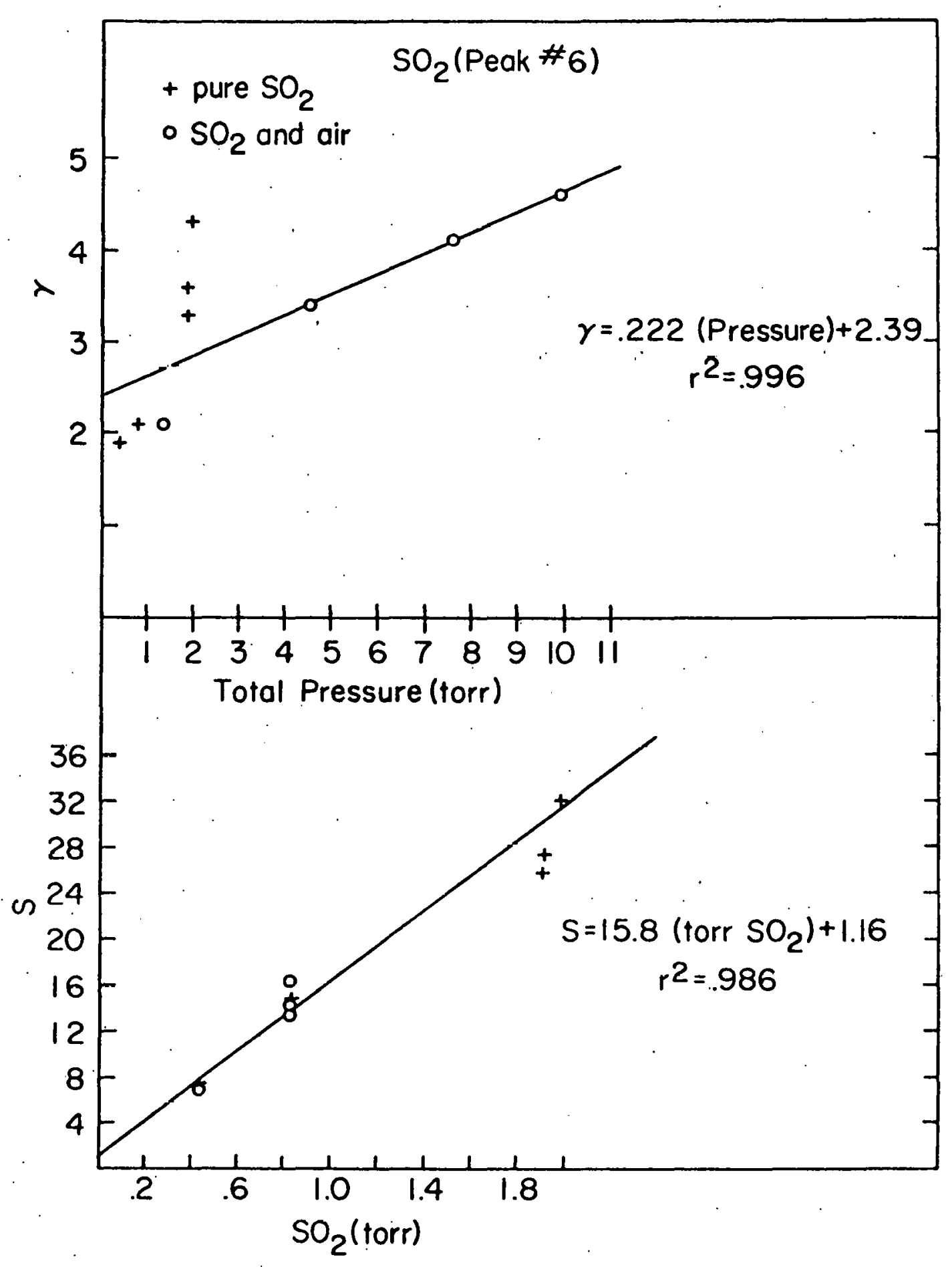


peak was very weak and the results obtained were poor. Peaks 7 and 8 were so close that in only one experiment where the pressure of $\mathrm{SO}_{2}$ was .44 torr were the lines resolved. From this one reading for each peak an intensity/torr was calculated to be 16.0 computer-units/torr for peak 7 and 26.1 computer-units/torr for peak 8. Only two values each for peaks 9 and 10 were obtained, and the average intensity/torr was calculated to be 2.77 computer-units/torr for peak 9 and 6.01 computer-units/torr for peak 10 .

Because the $\mathrm{N}_{2} \mathrm{O}$ lines are in the same spectrum as the $\mathrm{SO}_{2}$ peaks, slopes 1,2 , and 3 can be used to determine the intensities and half widths of the $\mathrm{SO}_{2}$ peaks, and the locations of the $\mathrm{SO}_{2}$ peaks relative to the $\mathrm{N}_{2} \mathrm{O}$ peaks can be determined.

For example, in Figure 30 the $1180.052 \mathrm{~cm}^{-1} \mathrm{~N}_{2} \mathrm{O}$ line has a computerunit value of 182 and the $\mathrm{SO}_{2}$ line 3 has a value of 124 . This is a difference of 58 , and this value times slope 1 gives $.020 \mathrm{~cm}^{-1}$. Therefore, the $\mathrm{SO}_{2}$ line 3 is $.020 \mathrm{~cm}^{-1}$ less than the $\mathrm{N}_{2} \mathrm{O}$ line or $1180.032 \mathrm{~cm}^{-1} . \mathrm{SO}_{2}$ peak 5 is 58 computer-units above the $\mathrm{N}_{2} \mathrm{O}$ line for a value of $.011 \mathrm{~cm}^{-1}$ greater than the $\mathrm{N}_{2} \mathrm{O}$ line or $1180.063 \mathrm{~cm}^{-1}$. Recall from the $\mathrm{N}_{2} \mathrm{O}$ slope determinations that the change from slope 1 to slope 2 occurred at 400 and that the change from slope 2 to slope 3 occurred at 543 . The $\mathrm{N}_{2} \mathrm{O}$ $1180.052 \mathrm{~cm}^{-1}$ line was at 252 in that spectrum and it is at 182 in the spectrum with the $\mathrm{SO}_{2}$ Tines. The necessary coordinate conversion puts the slope 1 to slope 2 change at 330 and the slope 2 to slope 3 change at 473. Using slope 1 the wavenumber value at 330 is $1180.103 \mathrm{~cm}^{-3}$. For $\mathrm{SO}_{2}$ peaks between 330 and $473,1180.103 \mathrm{~cm}^{-1}$ and slope 2 are used. For $\mathrm{SO}_{2}$ peaks above $473,1180.166 \mathrm{~cm}^{-1}$ and slope 3 are used. Thus all $\mathrm{SO}_{2}$ 
lines were assigned a line position, and intensities and half widths were determined as was done for the $\mathrm{N}_{2} \mathrm{O}$ lines. The results of these calculations are shown in Table 4.

Table 4. $\mathrm{SO}_{2}$ intensities and atmospheric linewidths

\begin{tabular}{cccc}
\hline $\begin{array}{c}\text { Line } \\
\text { number }\end{array}$ & $\mathrm{cm}^{-1}$ & $\begin{array}{c}\text { Intensity }\left(\mathrm{cm}^{-1} /\right. \\
\left.\text { molecule } \mathrm{cm}^{-2}\right)\end{array}$ & HMWM $\left(\mathrm{cm}^{-1} / \mathrm{atmos}\right)$ \\
\hline 1 & 1179.982 & $5.64 \times 10^{-22}$ & $5.87 \times 10^{-2}$ \\
2 & 1179.996 & $1.58 \times 10^{-22}$ & $13.4 \times 10^{-2}$ \\
3 & 1180.031 & $1.17 \times 10^{-21}$ & $9.31 \times 10^{-2}$ \\
4 & 1180.050 & - & - \\
5 & 1180.063 & $3.35 \times 10^{-22}$ & $6.90 \times 10^{-2}$ \\
6 & 1180.093 & $1.11 \times 10^{-21}$ & $5.82 \times 10^{-2}$ \\
7 & 1180.154 & $1.13 \times 10^{-21}$ & - \\
8 & 1180.162 & $1.84 \times 10^{-21}$ & - \\
9 & 1180.188 & $1.92 \times 10^{-22}$ & - \\
10 & 1180.223 & $4.23 \times 10^{-22}$ & - \\
\hline
\end{tabular}




\section{SUMMARY}

The results of this study have shown that a semiconductor laser has the properties which make its use in atmospheric pollution monitoring attractive.

First, the power output of the laser at one amp was greater than 200 $\mu \mathrm{W}$ as measured using a thermopile with a sensitivity of $4 \mu \mathrm{V} / \mu \mathrm{W}$. This output was easily detected after several passes through the Wilks' multiple pass gas pas cell. The energy loss after 4 passes through the cell was about $80 \%$ due to poor alignment of the gas cell's internal mirrors. Using commercially available optics, losses after shining the laser light over several hundred meters should amount to no more than $50 \%$.

Second, the output of each mode of the laser was concentrated in a very narrow bandwidth. This was determined by observing Doppler limited linewidths (confirmed by observing no decrease in the linewidth below a pressure of about 1 torr).

Third, the laser has an extended lifetime. The laser has now been used for a period of about a year and a half with no observed decrease in the power output. Nor has there been any change in the threshold current necessary to initiate lasing.

Fourth, once the experimental setup has been optically aligned and an operating procedure established, the only requirement before lasing can take placc is that the laser be cooled to near liquid helium temperatures. There are no routine maintenance problems required to keep the laser operating. 
Lastly, the stability of the laser and the reproducibility of the laser are important in considering its use as a continuous monitoring source. On a daily basis, the laser was used continuously for a period of about eight hours. The laser was continuously scanned for most of that period and all scans were reproducible, except when the cryostat was running low on liquid-helium resulting in a change in temperature of the laser. When the cryostat was refilled with liquid-helium, the laser output was again reproducible. The problem with temperature changes due to the cryostat could be eliminated by using a closed liquid-helium recycling system.

After the laser was recycled to room temperature and back to liquid helium temperatures, there was some small change in the position of the tuning region, but the tuning rate was always about the same and absorption lines could always be returned into coincidence with the laser output. The only exception was when a power fajlure in the lab resulted in a drop in the lowest energy mode in which the laser had light output. This may have been caused by a film of diffusion pump oil forming on the laser.

The analytical parameters obtained here for $\mathrm{N}_{2} \mathrm{O}$ and $\mathrm{SO}_{2}$ are an improvement over previous determinations of analytical parameters for these gases, and their use in long path atmospheric pollution monitoring should result in improved measurements of the concentrations of these gases. The improvement over previous determinations results because this method does not require deconvolving the resulting absorption line to obtain the true lineshape, as do methods using conventional infrared spectrometers. 


\section{COMMENTS}

From one run to the next run and from day to day the relative locations of the $\mathrm{SO}_{2}$ peaks in the computerized spectra never changed by more than 3 or 4 computer-units in a region greater than 100 computer-units. This implies a stability of the semiconductor laser which is better than $96 \%$. The inaccuracy of the $\mathrm{SO}_{2}$ results is therefore due mostly to the assumption of the straight line slopes which were used in the $\mathrm{SO}_{2}$ determinations.

Assuming a worst case, let us suppose that a peak existed at the point where slope 1 changed to slope 2 . The slope at that point would have been half-way between slopes 1 and 2 and therefore have a value of $3.95 \times 10^{-4} \mathrm{~cm}^{-1} /$ unit. The percent difference between this value and slope 1 is

$$
\frac{\left(3.95 \times 10^{-4}-3.45 \times 10^{-4}\right)}{3.95 \times 10^{-4}} \times 100 \% \simeq 12 \%
$$

The unit value at the $\mathrm{N}_{2} \mathrm{O}$ line $\left(1180.052 \mathrm{~cm}^{-1}\right)$ is 182 and the unit value at the transition point from slope 1 to slope 2 is 330 . Taking the difference (18) and multiplying by slope 1 gives $.050 \mathrm{~cm}^{-1}$. Multiplying the difference by $3.95 \times 10^{-4} \mathrm{~cm}^{-1} /$ unit gives $.058 \mathrm{~cm}^{-1}$. The difference of the values is $.008 \mathrm{~cm}^{-1}$.

Thus, the stated values of the $\mathrm{SO}_{2}$ positions are $\pm .008 \mathrm{~cm}^{-1}$ and the intensity and halfwidth values are $\pm 12 \%$. This assumes of course that the $\mathrm{N}_{2} \mathrm{O}$ lines are accurate. Although the $\mathrm{N}_{2} \mathrm{O}$ line at $1180.052 \mathrm{~cm}^{-1}$ has been observed and identified using typical high resolution spectroscopy, the other less intense lines have been assigned using experimental parameters 
obtained from experiments done in different energy regions $(18,48)$. The results of the comparison of the $\mathrm{N}_{2} \mathrm{O}$ lines with the etalon in Figure 23 indicate that more work needs to be done to either verify or change the identification of the less intense $\mathrm{N}_{2} \mathrm{O}$ lines.

The major source of noise in these experiments appeared to be the detector. The detector is cooled to liquid $\mathrm{N}_{2}$ temperatures and the detector is therefore mounted in a dewar. Although the detector could be used for several experiments before reevacuation of the dewar was necessary, noise appeared to increase from one experiment to the next and then decrease substantially when the dewar was reevacuated.

The maximum pressure that was used in the experimental studies was about 40 torr. The reason for this limit is that as the pressure becomes large ( $\approx 40$ torr) the wings (edges) of the abscrption lines become very broad. It is then difficult to determine which points should be used in the $100 \%$ transmission curve and which points are still part of an absorption peak. If the peaks are clnse enough together, the wings of each peak overlap and no points can be used for a 100\% transmission curve.

To do higher pressure studies, a double beam experimental setup will have to be used. The lab now has a second lock-in amplifier and a beam splitter which make a double beam experiment practical. Because atmospheric monitoring studies are done at ambient pressure, a double beam experimental setup will be needed to do the monitoring studies.

A Lorentzian line shape equation was used to describe the absorption peaks, and for pressures greater than 10 torr, the fit to experimental points was quite good. At pressure of about a torr, the fit of the 
Lorentzian equation was not good in the wings. This is understandable because at low pressure the linewidths are limited by the Doppler effect. These Doppler widths are better described using a Gaussian lineshape. Future experimental studies can be improved by using a line shape which incorporates both the Lorentzian and Gaussian equations, particularly at pressures less than 10 torr.

The detection limit for monitoring $\mathrm{N}_{2} \mathrm{O}$ gas in the atmosphere using. the laser which was used in the previous experiments is calculated below. The laser would be centered at $\nu_{0}$ of the $1180.052 \mathrm{~cm}^{-1} \mathrm{~N}_{2} \mathrm{O}$ line. The absorbance at $\nu_{0}$ is calculated in the following equation.

$$
\begin{aligned}
\mathrm{K}\left(\nu_{0}\right) & =4.66 \times 10^{-21}\left(\mathrm{~cm}^{-1} / \text { molecule } \mathrm{cm}^{-2}\right) /\left(\pi \times 5.00 \times 10^{-2} \mathrm{~cm}^{-1}\right) \\
& =2.97 \times 10^{-20} /\left(\text { molecule } \mathrm{cm}^{-2}\right)
\end{aligned}
$$

Converting from molecules $\mathrm{cm}^{-2}$ to $\mathrm{cm}$ atmosphere gives

$$
\begin{aligned}
\mathrm{K}\left(\nu_{0}\right)= & 2.97 \times 10^{-20} /\left(\text { molecule } \mathrm{cm}^{-2}\right) \times 2.69 \times 10^{19}\left(\text { molecules } \mathrm{cm}^{-2}\right) / \\
& (\mathrm{cm} \text { atmosphere })=.80 /(\mathrm{cm} \text { atmosphere }) .
\end{aligned}
$$

A path length of about $1 \mathrm{~km}$ has been proven practical in atmospheric. pollution monitoring (16).

$.80 /(\mathrm{cm}$ atmosphere $) \times 10000 \mathrm{~cm}=8.0 \times 10^{3} /$ atmosphere

A practical transmission detection limit is $0.10 \%$ for an absorbance change of .0010 . Dividing the absorbance detection limit by the absorbance per atmosphere, one obtains the concentration detection limit in atmospheres.

$.0010 / 8.0 \times 10^{3} /$ atmosphere $=1.25 \times 10^{-7}$ atmosphere

This is about $.125 \mathrm{ppm}$. As the average concentration of $\mathrm{N}_{2} \mathrm{O}$ in air is from $0.12 \mathrm{ppm}$ to $1.25 \mathrm{ppm}$, this laser could be used to obtain information on $\mathrm{N}_{2} \mathrm{O}$ in the air (49). Because the normal concentration of $\mathrm{N}_{2} \mathrm{O}$ is near 
the instrument detection limit, other more intense $\mathrm{N}_{2} \mathrm{O}$ lines would be preferred. 


\section{BIBLIOGRAPHY}

1. International Symposium on Environmental Measurements (Beckman Instruments, Geneva, Switzerland, 1973).

2. P. J.W. Saunders, The Estimation of Pollution Damage (Manchester University Press, Manchester, 1976).

3. S. F. Singer, ed., The Changing Global Environment (D. Reidel Publishing Company, Boston, 1975).

4. C. R. Thompson, G. Kats, E. L. Pippen, and W. H. Isom, Environ. Sci. Technol. 10, 1237 (1976).

5. C. R. Thompson, G. Kats, and J. W. Cameron, J. Environ. Qual. $\underline{5}$, 410 (1976).

6. F.. S. Rowland and M. J. Molina, Rev. Geophys. Space Phys. 13, 1 (1975).

7. G. B. Lubkin, Physics Today $\underline{34}$ (0ct. 1975).

8. J. H. Douglas, Science News 112, 68 (1977).

9. F. L. Cross, Jr., Handbook on Environmental Monitoring (Technomic Publishing Co., Inc., Westport, 1974).

10. W. Gallay, H. Egan, J. L. Monkman, R. Truhart, P. W. West, and G. Widmark, eds., Environmental Pollutants - Selected Analytical Methods (Scope 6) (Butterworths, London, 1975).

11. H. Bal1, Z. Anal. Chem. 282, 301 (1976).

12. R. K. Stevens and A. E. O'Keeffe, Anal. Chem. 42, 143A (1970).

13. P. Chovin, Z. Anal. Chem. 282, 281 (1976).

14. R. Goody, J. Opt. Soc. of Am. $\underline{58}, 900$ (1968).

15. J. E. Lowder, K. G. P. Sulzmann, and S. S. Penner, J. Quant. Spectrosc. Radiat. Transfer 11, 1877 (1971).

16. R. T. Ku, E. D. Hinkley, and J. 0. Sample, Appl. Optics 14, 854 (1975).

17. B. M. Golden, M.S. Thesis, Iowa State University, 1976 (unpublished). 
18. R. A. McClatchey, W. S. Benedict, S. A. Clough, D. E. Burch, R. F. Calfee, K. Fox, L. S. Rothman, and J. S. Garing, Environmental Research Paper No. 434, AFCRL-TR-73-0096, 1973.

19. T. C. Harmon, in The Physics of Semimetals and Narrow-Gap Semiconductors, edited by D. L. Carter and R. T. Bate (Pergamon, oxford, 1971), p. 363.

20. A. R. Calawa, J. Lumin. 7, 477 (1973).

21. E. D. Hinkley, K. W. Nill, and F. A. Blum, in Laser Spectroscopy of Atoms and Molecules, edited by $H$. Walther (Springer-Verlag, Heidelberg, 1976), p. 125.

22. E. D. Hinkley, Appl. Phys. Lett. 16, 351 (1970).

23. E. D. Hinkley and P. L. Kelley, Science 171, 635 (1971).

24. E. D. Hinkley and C. Freed, Phys. Rev. Lett. 23, 277 (1969).

25. G. A. Antcliffe and S. G. Parker, J. Appl. Phys. 44, 4145 (1973).

26. W. H. Weber, P. D. Maker, K. F. Yeung, and C. W. Peters, App1. Optics 13, 1431 (1974).

27. W. H. Weber and P. D. Maker, J. Chem. Phys: 64, 2149 (1976).

28. F. A. Blum, K. W. Nill, P. L. Kelley, A. R. Calawa, and T. C. Harman, Science 177, 694 (1972).

29. K. W. Nill, F. A. Blum, A. R. Calawa, and T. C. Harman, App1. Phys. Lett. 19, 79 (1971).

30. K. W. Nill, F. A. Blum, A. R. Calawa, and T. C. Harman, Appl. Phys. Lett. 21, 132 (1972).

31. G. A. Antcliffe, S. 'G. Parker, and R. T. Bate, Appl. Phys. Lett. 21, 505 (1972).

32. G. A. Antcliffe and J. S. Wrobel, Appl. Optics 11, 1548 (1972).

33. E. D. Hinkley, A. R. Calawa, and P. L. Kelley, J. Appl. Phys. 43, $3222(1972)$.

34. F. Allario, C. H. Bair, and J. F. Butler, IEEE J. Quantum Electron. QE-11, 205 (1975). 
35. E. D. Hinkley, R. T. Ku, K. W. Nill, and J. F. Butler, Appl. Optics 15, $1653(1976)$.

36. M. Dubs and H. H. Günthard, Chem. Phys. Lett. 47, 421 (1977).

37. R. K. Hanson, Appl. Optics 16, 1479 (1977).

38. J. F. Butler and T. C. Harman, Appl. Phys. Lett. 12, 347 (1968).

39. J. F. Butler, A. R. Calawa, and T. C. Harman, Appl. Phys. Lett. $\underline{9}$, 427 (1966).

40. L. H. DeVaux and H. Kimura, Hughes Research Laboratories Technical Report for Contract No. DAAK 02-72-C-0348, 1973.

41. E. L. Wheeler, Scientific Glassblowing (Interscience Publishers, Inc., New York, 1958), p. 191.

42. D. R. Stul1, Ind. Eng. Chem. 39, 517 (1947).

43. Berlingmair, David, Ames Laboratory experimental engineer, private communication.

44. K. R. Efferson, Rev. Sci. Instrum. 38, 1776 (1967).

45. Norton Supercon Division (Natick, Mass.), Basic Solenoid Construction Bulletin, 1969.

46. D. B. Montgomery and J. Terre11, National Magnet Laboratory Report AFOSR-1525, 1961.

47. R. A. Smith, F. E. Jones, and R. P. Chasmar, Detection and Measurement of Infra-red Radiation, 2nd ed. (Clarendon Press, 0xford, 1968), p. 236 .

48. 1. Pliva, J. Mo1. Spectrose: 27, 461 (1968).

49. A. Goldman, D. G. Murcray, F. H. Murcray, W. J. Williams, T. G. Kyle, and J. N. Brooks, J. Opt. Soc. Am. 60, 1466 (1970). 


\section{ACKNOWLEDGMENTS}

I would like to thank all of the friends I have made since I have been here in Ames for providing a stimulating environment in an otherwise dissatisfying area.

I want to thank Ed Yeung for his guidance and knowledge in directing my education since I have been here.

And my most indebted thanks to my wife for her comfort and encouragement and especially her understanding when I was less than enjoyable to be around. 
IX. APPENDIX A: PROGRAM FOR READING NUMBERS OFF PAPER TAPE

The program READING PAPER TAPE converts the numbers which have been placed on paper tape in the experimental setup and places the numbers on computer cards. The $A / D$ converter is a twelve bit binary converter and the paper tape reader at the Iowa State University Computation Center is designed to read in seven bit ASCII code. Because three of the seven bits must be set in a particular fashion to signify that the other four bits are information bits, the twelve binary bits are divided into three groups of four bits when punched on the paper tape. Each group of three units of information are separated by an ASCII 215 which is a return character. The control cards at the end of the program signify that a 215 is the end of a "card image." Each group of iour bits represents sixteen different possible units of information although only ten such units represent the numbers zero through nine. For this reason, the program reads the tape in A format and converts the alphanumeric information to an equivalent number zero through fifteen. The first value read is from the four most significant bits and is therefore multiplied by $16^{2}$, the second value is from the next four significant bits and is multiplied by 16, and the third value, which is from the least significant bits, is taken as is and all three are then added together. Eight values at a time generated in this manner are then punched on computer cards. The program is always checking for the letter " $M$ " in the alphanumeric values read. This "I" marks the end of a particular run and the program prints the number of values which have been generated since the previous run on a separate card. Next, eighty "+'s" are printed on a card to facilitate manual separation of the entire deck 
into separate runs. An ASCII "control D" indicates the end of information on the paper tape. Four runs at a time are then placed on a simplotter generated graph (Figure 23) to help determine base lines, beginnings and endings of peaks, etc. for the next program which determines experimental parameters. The paper tape reading program follows.

C THIS PROGRAM TAKES A/D BITS OFF PAPER TAPE, CONVERTS THEM TO .

C NUMBERS AND PUTS THE NUMBERS ON PUNCH CARDS AND CREATES SIM-

C PLOTTER OUTPUTS OF THE NUMBERS

DIMENS ION $X(2000), Y(2000)$

CHARACTER $*] \mathrm{A}(6), \mathrm{B}(80) / 80 * \cdot 1+1 /$

INTEGER*2 IX(3),J(255)/255*0/, INUM(8)

EQUIVALENCE (IX,A)

$\operatorname{IX}(1)=0$

$\operatorname{IX}(2)=0$

$\operatorname{IX}(3)=0$

111 FORMAT (3A1)

222 FORMAT ( $8 \mathrm{I} 10)$

333 FORMAT ( $80 A 1)$

C NUMBER EQUIVALENT OF ASCII CODE PUNCHED DN TAPE

$J(240)=0$

$J(241)=1$

$J(242)=2$

$J(243)=3$

$J(244)=4$

$J(245)=5$

$J(246)=6$

$J(247)=7$

$J(248)=8$

$J(249)=9$

$J(122)=10$

$\mathrm{J}(94)=11$

$J(76)=12$

$J(126)=13$

$J(110)=14$

$\mathrm{J}(111)=15$

KNT4=0

KNT $3=0$

$7 \mathrm{KNT} 3=\mathrm{KNT} 3+1$

KNT $=0$

D01 I $I=1,2000$

$X($ II $)=I I$

$\mathrm{KNT} 2=\mathrm{II}-1$

$\operatorname{READ}(5,111, \operatorname{END}=3) A(2), A(4), A(6)$

$\operatorname{IF}(A(2) . E Q$. 'M'.OR.A(4).EQ. ' $M$ ') GO TO 15 


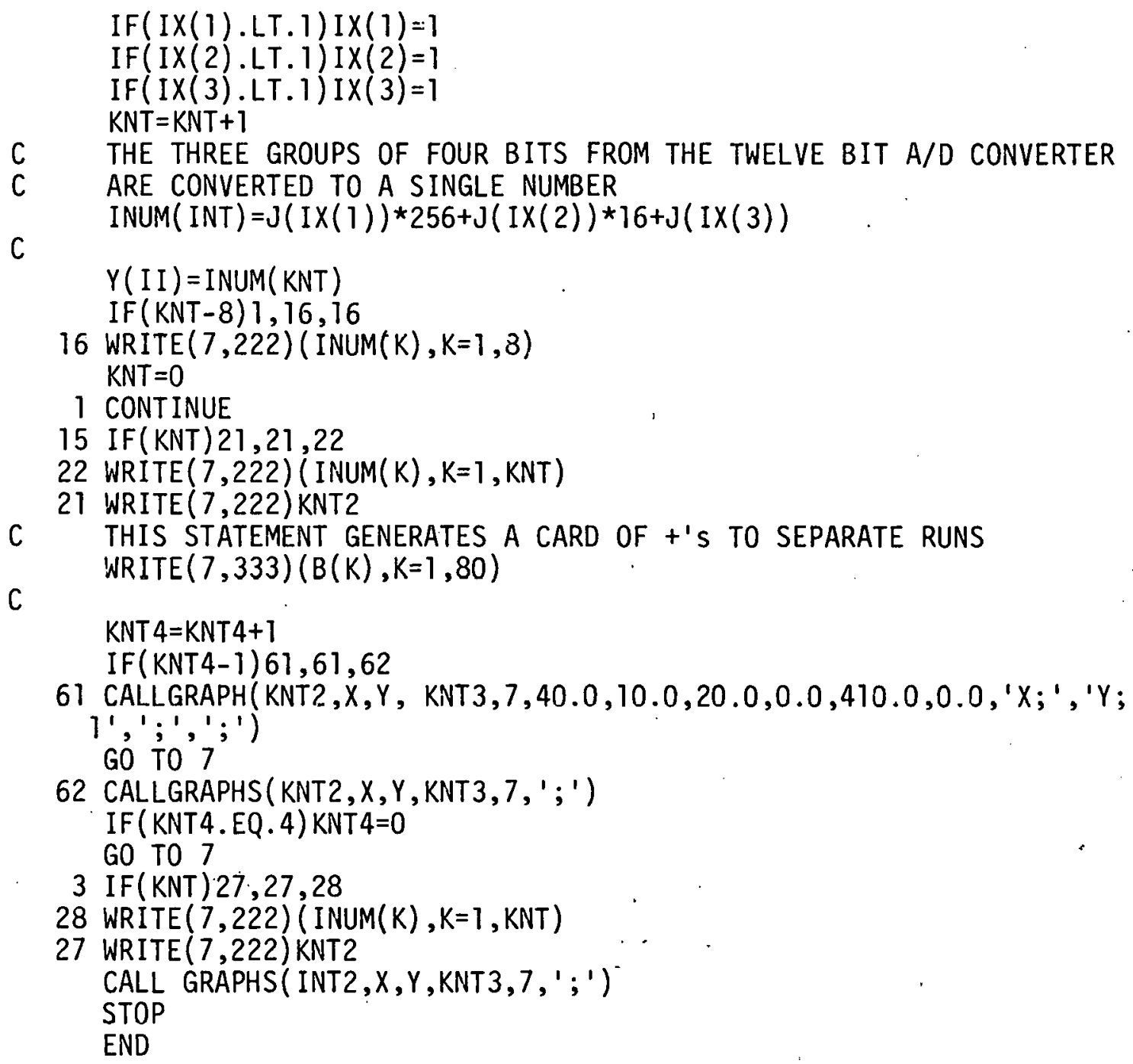




\section{$X$. APPENDiX B: the ANALYTICAL PARAMETER DETERMining PROGRAM}

This program reads into memory all of the experimental points, one run at a time, from the cards generated from the paper tape by the paper tape reading program. An average baseline for dark current is determined, and the points chosen by the programmer minus the points in the transmission peaks are fitted to a fourth degree polynomial to determine the $100 \%$ transmission value at each point in the transmission peak. I (transmission) at each point in the transmission peak is then determined. The transmission at each point in the peak is then converted to an absorption value. Using programmer provided data for the analytical parameters, a theoretical absorption value is obtained at each point in the peak, and the difference between this value and ine experimental value is squared and the squares are summed over all points in the peak. This procedure is followed for a range of values determined by the programmer for each analytical parameter, and the set of parameters which gives the smallest sum of the squares value is recorded.

For each run a graph is produced upon the incremental plotter (Figure 24). The graph includes the experimental points, a continuous line representing the fourth degree polynomial for the $100 \%$ transmission curve, and a continuous line representing the theoretical transmission of each peak obtained from the theoretical absorption values which were obtained from the best fitting analytical parameters.

The program was optimized by the Fortran $H$ compiler and an object deck was created. Because the program is run quite often, using an object deck saves having to have the program compiled everytime it is run. 
The information below concerns the exact data and formats which must go into the program.

Step

1. Card 1. This card states the number of runs which are to be read by the program in 110 Format.

2. Card 2. In 7I10 Format, this card contains first the number of points in the first run, the beginning point in the baseline determination, the ending point in the baseline determination, the number of peaks in this run, the beginning point for $I(100 \%)$ determination, the ending point for $I(100 \%)$ determination, and the number of times each variable is incremented in the least squares comparison to experimental data.

3. Card 3. In 2I10 Format, the beginning point of the first peak and the ending point of the first peak.

4. Card 4. In 3F10.0 Format, a guess for the line center, a guess for the half-width at half maximum, and an adjustment factor for the integrated area which is done iteratively by the program.

5. Card 5. Increments for integrated area, half width at half maximum, and line center in 3F10.0 Format.

6. Card 6. Identical information for the second peak as is in card 3 for the first peak if a second peak exists.

7. Card 7. Identical information for the second peak as is in card 4 for the first peak if a second peak exists.

8. Card 8. Identical information for the second peak as is in card 5 for the first peak if a second peak exists.

9.

The same procedure continues for all peaks in this run.

10. Experimental data for the first run comes next.

11. Cards for the second run follow with the same information in the same format as for the first run on the cards beginning with card 2 .

12. Data for the second run comes next.

13. The same procedure is continued for all runs. 
The graphs which were produced by the paper tape reading program aid in choosing points for the baseline determination, beginning and ending points for the $100 \%$ transmission curve determining equation, beginning and ending points for each peak, and starting values for line centers and half-widths at half maximum. The program follows.

DIMENSION AX(1500), AY (1500), Y(1500), IPKMIN (6), IPKMAX (6),W(1500) DIMENSION TRANSY (75), SERROR $(20,20,20), \operatorname{CNTR}(6), \operatorname{HALFW}(6)$ DIMENSION AADJ (6), DLTA(6), DLTW(6), DLTF(6) DOUBLEPRECISION Q(5)

$\operatorname{READ}(5,111)$ IDTSTS

D01951 IHAUCH $=1$, IDTSTS

C ITOT=TOTAL NO OF POINTS, IBMIN = STARTING POINT FOR BASE, IBMAX

$C=$ END POINT OF BASE, NUMPKS = NUMBER OF PEAKS, LOW = STARTING

c POINT FOR POLYNOMIAL FIT, IHIGH = ENDING POINT OF FIT, LOOPN =

C NUMBER OF DO LOOPS IN BEST FIT DETERMINATION OF THE ABSORPTION

C EQUATION

READ $(5,111)$ ITOT, IBMIN , IBMAX, NUMPKS , LOW, IHIGH , LOOPN DOI I $=1$, NUMPKS

C IPKMIN(I) = STARTING POINT OF PEAK I, IPKMAX(I) = ENDING POINT

C OF I $\operatorname{READ}(5,111)$ IPKMIN( I) , IPKMAX (I)

C CNTR(I) = VISUAL GUESS FOR ABS CENTER OF PEAK I, HALFW(I) =

C VISUAL GUESS OF HALFWIDTH AT HALF MAX OF PEAK I, AADJ = THE

C AREA ADJUSTMENT VALUE $\operatorname{READ}(5,222)$ CNTR (I), HALFW(I), AADJ (I)

C DLTA = INCREMENTS OF AREA IN THE BEST FIT OF ABS EQ, DLTW =

C INCREMENTS OF HALFWIDTH IN BEST FIT OF EQ, DLTF = INCREMENTS

C OF POSITION CHANGE OF PEAK CENTER

$1 \operatorname{READ}(5,222) \operatorname{DLTA}(\mathrm{I}), \operatorname{DLTW}(\mathrm{I}), \operatorname{DLTF}(\mathrm{I})$ $\operatorname{READ}(5,222)(Y(I), I=1, I T O T)$ DO77I=1, ITOT

$77 \operatorname{AX}(I)=I$

CALL GRAPH(ITOT, AX,Y $, 3,7,35.0,10.0,20.0,0.0,410.0,0.0$, ' $^{\prime} ;^{\prime}$ ',

1 'Y; $\left.{ }^{\prime}, 1^{\prime}, 1^{\prime} ;{ }^{\prime}\right)$

WRITE $(6,777)$

C BASE AVERAGING

AKNT $1=0$

TOT $1=0$

D02 I = IBMIN , IBMAX

AKNT $1=A K N T 1+1$.

2 TOT $1=T O T 1+Y(I)$

BASE $=$ TOT I/AKNTI

C

$(X, Y)$ POINTS FROM BEGINNING TO START OF FIRST PEAK KNT2 $=0$ 


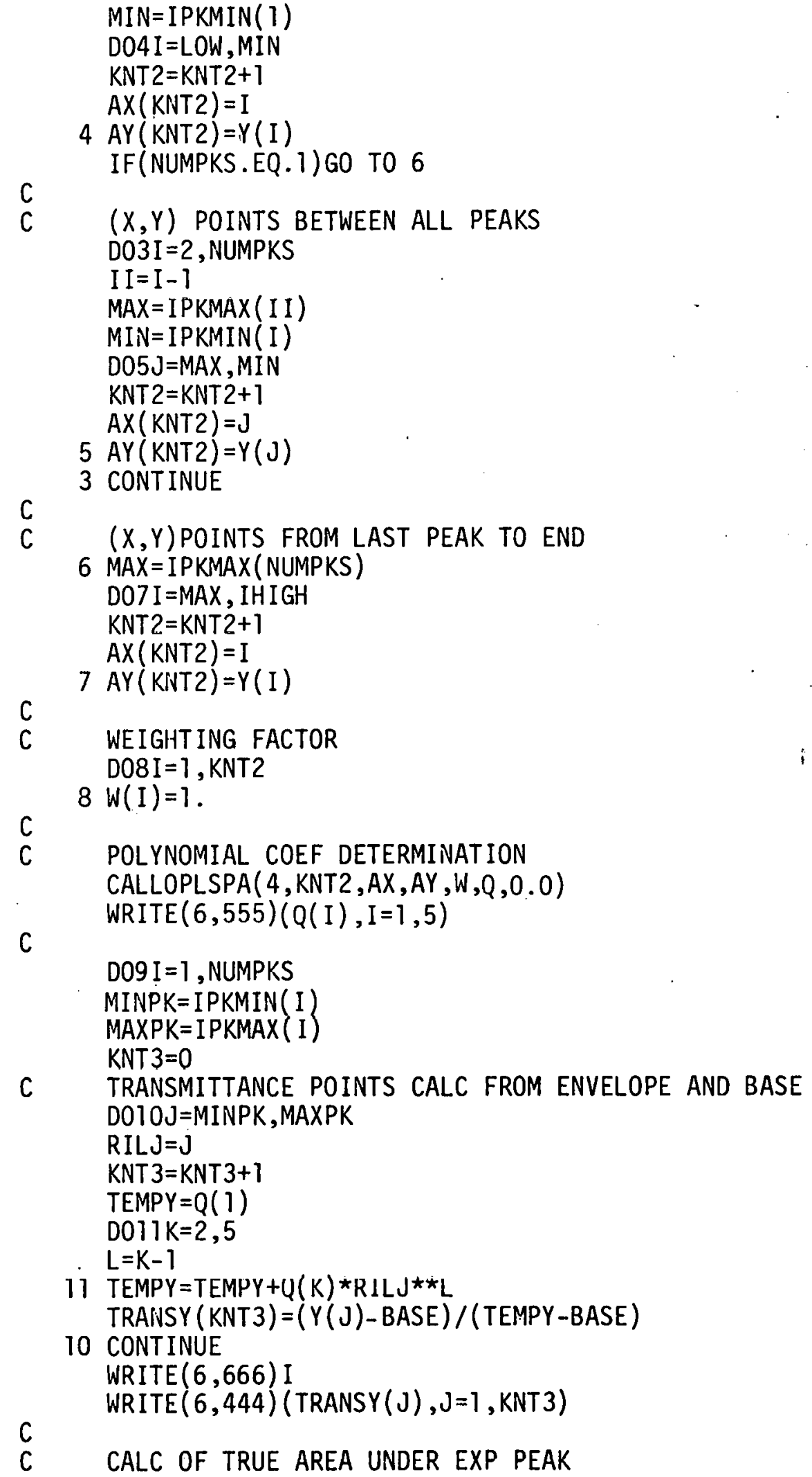




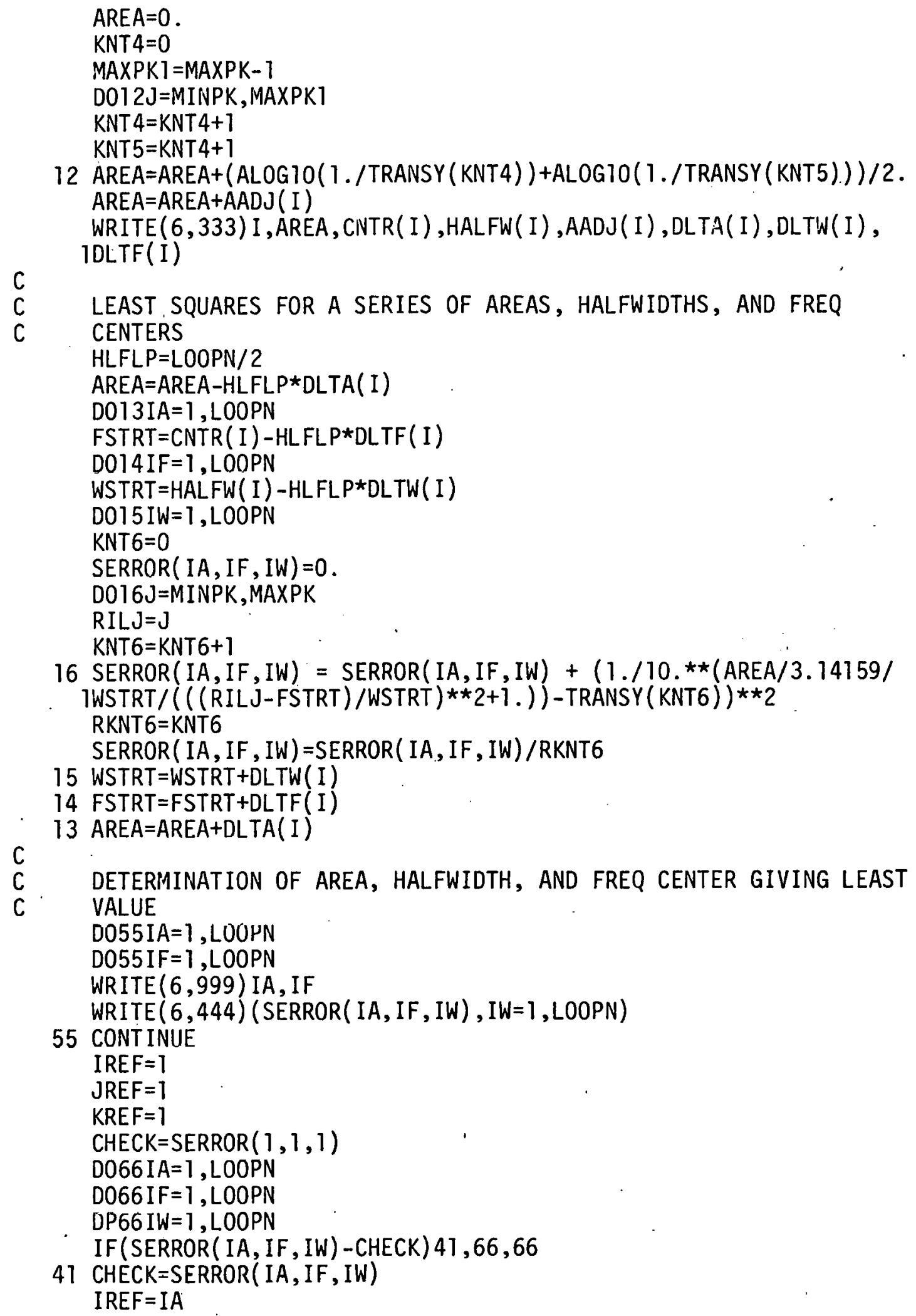

$12 \operatorname{AREA}=\operatorname{AREA}+(\operatorname{ALOGT0}(1 . / \operatorname{TRANSY}(\operatorname{KNT} 4))+\operatorname{ALOG10}(1 . / \operatorname{TRANSY}(\operatorname{KNT5}))) /$.2 . AREA $=A R E A+A A D J(I)$ WRITE $(6,333)$ I, AREA, CNTR(I), HALFW(I), AADJ(I), DLTA(I), DLTW(I), $\operatorname{IDLTF}(\mathrm{I})$

C

C LEAST SQUARES FOR A SERIES OF AREAS, HALFWIDTHS, AND FREQ 


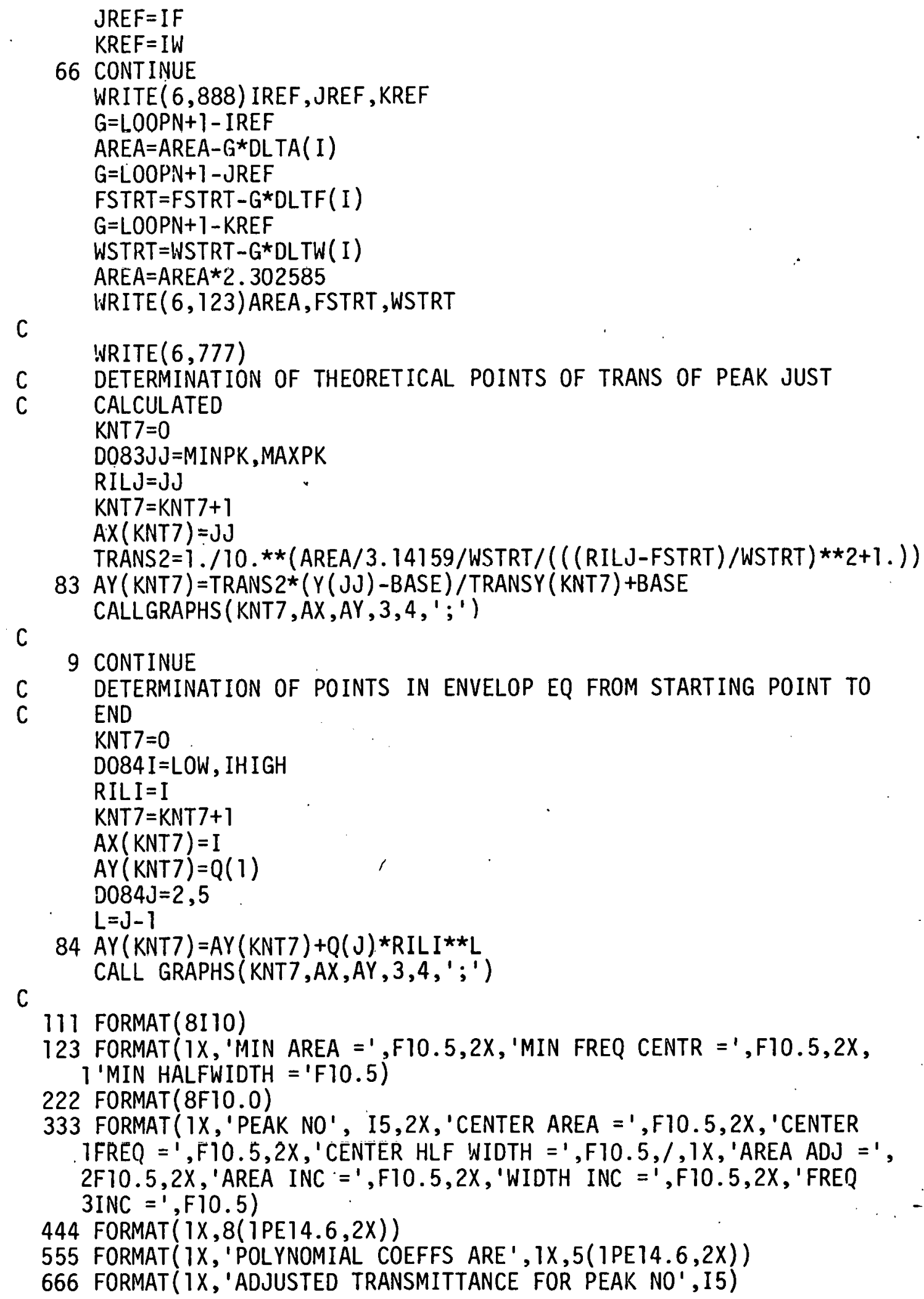

111 FORMAT (8I10)

123 FORMAT ( $1 X$, 'MIN AREA $=', F 10.5,2 X$, 'MIN FREQ CENTR =',F10.5,2X, 1 'MIN HALFWIDTH $=$ 'F10.5)

222 FORMAT (8F10.0)

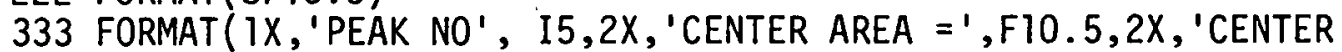
1FREQ $=1, \bar{F} 10.5,2 X,{ }^{\prime}$ CENTER HLF $W I D T H=', F 10.5, /, 1 X,{ }^{\prime}$ AREA ADJ $='$, $2 F 10.5,2 X,{ }^{\prime}$ AREA INC $={ }^{\prime}, F 10.5,2 X,{ }^{\prime}$ WIDTH INC $=1, F 10.5,2 X,{ }^{\prime}$ FREQ 3INC $=1, F 10.5)$

444 FORMAT $(1 X, 8(1$ PE $14.6,2 X))$

555 FORMAT ( $1 X$, 'POLYNOMIAL COEFFS ARE', $1 X, 5(1 P E 14.6,2 X)$ )

666 FORMAT ( $1 X,{ }^{\prime}$ 'ADJUSTED TRANSMITTANCE FOR PEAK NO', I5) 
777 FORMAT( ' 1 ')

888 FORMAT (' 0 ', 3I3)

999 FORMAT ( IX, 'AREA RUN = ', I5, 3X, 'FREQ RUN = ', I5)

1951 CONTINUE

STOP

END

The subroutines GRAPH, GRAPHS, and OPLSPA are in the Fortran library at the I.S.U. Computation Center. GRAPH plots the points which are given it with a variety of possible marks along with scaling the axes and labeling the axes. GRAPHS adds additional $(X, Y)$ points to the graph generated by the most recent GRAPH subroutine. OPLSPA fits a polynomial equation of specified degree to the $(X, Y)$ point set transferred to it and passes back the coefficients of the polynomial. 
XI. APPENDIX C: OPERATIONAL PROCEDURES FOR EXPERIMENTAL APPARATUS

I. Cooling the liquid He chamber to near liquid $\mathrm{N}_{2}$ temperatures. (A]though this cooling step is not absolutely necessary, the extra liquid He required to cool the liquid He chamber from room temperature is considerable and liquid He is expensive. This portion of the procedure should be done about twelve hours prior to the liquid He transfer operation.)

Step 1. Make sure that the cryostat is being pumped by the trapped oil diffusion pump.

Step 2. Fill the liquid $N_{2}$ chamber with liquid $N_{2}$. Stopper the inlet tube of the liquid $\mathrm{H}_{2}$ chamber.

Step 3. Run a tube from the liquid $\mathrm{N}_{2}$ chamber exit tube to the entrance tube of the 1 iquid He chamber.

Step 4. Place a bunsen valve on the liquid He chamber exit hole.

Step 5. Place a bunsen valve on the He gas boil-off tube.

II. Semiconductor laser operation procedure.

Step 1. Turn on the lock-in amplifier for warm-up.

Step 2. Turn on the $X-Y$ recorder for warm-up.

Step 3. Shut off the vacuum valve at the cryostat.

Step 4. Attach vacuum line hose to the He gas boil-off tube.

Step 5. Place the shorter end of the liquid He transfer tube into the liquid He chamber. Place a bunsen valve on the liquid $\mathrm{N}_{2}$ exit tube.

Step 6. Attach tubing from the He gas cylinder to the other end of the transfer tube.

Step 7. Partially evacuate the He chamber being careful not to collapse the bunsen valve and letting air into the chamber.

Step 8. Fill the chamber with He gas. He gas will rush out the bunscn valve when the chamber is full of gas.

Step 9. Repeat steps 7 and 8 two more times.

Step 10. Remove the bunsen valve and the vacuum 7 ine hose, attach the He return lines, and open the He return valve. 
Step 11. Turn on the He gas cylinder momentarily and verify that He is passing through the He return line by observing the ping-pong ball movement in the check valve.

Step 12. Remove the rubber hose attached to the He cylinder from the bottom of the transfer tube and place the hose over the pressurizing tube on the side of the transfer tube.

Step 13. Place the long end of the He transfer tube into the liquid He dewar, being careful that the bottom of the transfer tube rests about an inch off the bottom and being careful not to freeze the rubber connecting tube before the transfer tube is in place.

Step 14. Pressurize the He dewar to about six pounds to drive the liquid He through the transfer tube into the cryostat.

Step 15. Fill the cryostat. When liquid He first enters the cryostat, all of the He will boil off until the cryostat becomes cold enough to retain liquid $H$. This change is marked by a large rush of He gas in the return line that gradually decreases. When the liquid He level nears the top of the cryostat, the rush of He gas will again rise and this change can be used to ascertain when the cryostat is full.

Step 16. Quickly remove the transfer tube from both the cryostat and the dewar simultaneously and stopper the He chamber entrance tube.

Step 17. Measure and record the liquid He level in the dewar.

Step 18. Fill the detector with liquid $\mathrm{N}_{2}$ and turn on the detector.

Step 19. Turn on the power to the tuning fork light chopper.

Step 20. Open the spectrometer slits to about $90,000 \mu$ and set the monochromator reading to the region where the laser is expected to output.

Step 21. Remove the plastic covers from the $\mathrm{NaCl}$ focusing lenses and windows in the optical path.

Step 22. Without connecting the laser contacts, turn on the current supply, voltage offset, and voltage ramp. Turn the short switch to the short position, and verify that current is flowing through the short switch by observing the voltmeter attached to the current monitor terminal. (1 volt is equivalent to 1 amp of current.) 
Step 23. With the short switch still in the short position and the internal-external switch in the internal position, attach the laser contacts to the power supply.

Step 24. Operate the short switch to open, operate the internalexternal switch to external and adjust the d.c. offset knob until about 1 amp is flowing through the laser.

Step 25. Fine tune the optics, the monochromator setting, and the gas cell to maximize the signal as it is seen on the lockin amplifier panel meter. Some signal can usualiy be seen and fine tuning is all that is necessary unless something in the optical path has been moved. In this case, it may be necessary to realign the system according to the al ignment procedure.

Step 26. Decrease slit size to a value whigh will keep different modes from coming through the spectrometer at the same time $(900 u)$. As the slits are changed further fine tuning may be necessary.

Step 27. Adjust the voltage ramp to produce the range desired for current scanning the laser.

Step 28. Adjust the $X-Y$ plotter to have its minima and maxima correspond to the minimun and maximum of the voltage ramp and the minimum and maximum of the lock-in amplifier output for no signal and maximum signal from the laser.

Step 29. Turn on the A/D converter and the paper tape punch.

Step 30. Operate the rear switches on the $A / D$ converter to 215 and operate the reset switch to ON. Al low about three feet of paper tape to be punched with the ASCII 215 for leader tape and then operate the reset switch to reset.

Step 31. Operate the rear switches to data.

Step 32. One is now ready to make an experimental run. Introduce the gas sample of interest into the gas cell, start the voltage ramp on the laser power supply, and operate the reset switch on the $A / D$ converter to $O N$. 
Step 33. At the end of an experimental run, block the light to generate a base line, operate the reset switch to reset to halt paper tape punching, operate the rear switches to 215 , start the paper tape punch (reset switch to ON), generate 4 to $5215 \mathrm{~s}$, press the $M$ button and allow 4 to 5 Ms to be generated, and release the M button and allow 4 to 5 more $215 \mathrm{~s}$ to be generated. Halt the paper tape punch and operate the rear switches to data.

Step 34. One is now ready for the next experimental run.

III. Shut down procedure.

Step 1. When the liquid He is gone or when no more runs are to be made, operate the internal-external switch on the power supply to internal and the short switch to short.

Step 2. Disconnect the laser connections from the power supply.

Step 3. With the paper tape punch off, switch the rear switch on the $A / D$ converter to 215 , turn the paper tape punch $0 N$, generate 4 or $5215 \mathrm{~s}$, press the "Control D" button to generate 4 or 5 "Control Ds," release the Control D button and allow about three feet of trailer tape to be generated.

Step 4. Turn all devices to OFF (order is not important) and cover the $\mathrm{NaCl}$ optics.

Step 5. Rewind the paper tape on the takeup reel so that the trailer tape is on the inside and the leader tape on the outside. 